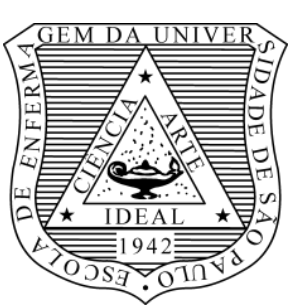

UNIVERSIDADE DE SÃO PAULO

ESCOLA DE ENFERMAGEM

SUÉLLEN MARIANE RIOS VICENTE

SÍNTESE DE EVIDÊNCIAS PARA POLÍTICAS DE SAÚDE:

PARTICIPAÇÃO SOCIAL COMO RESPOSTA A NECESSIDADES DE SAÚDE

SÃO PAULO

2019 


\title{
SÍNTESE DE EVIDÊNCIAS PARA POLÍTICAS DE SAÚDE: PARTICIPAÇÃO SOCIAL COMO RESPOSTA A NECESSIDADES DE SAÚDE
}

\author{
Versão corrigida da Dissertação apresentada ao \\ Programa de Pós-Graduação Mestrado \\ Profissional em Enfermagem na Atenção \\ Primária em Saúde no SUS (Sistema Único de \\ Saúde) - MPAPS da Escola de Enfermagem da \\ Universidade de São Paulo - USP como \\ obtenção do Título de Mestre em Ciências da \\ Saúde. \\ Área de Concentração: Cuidado em Atenção \\ Primária em Saúde \\ Orientadora: Prof. ${ }^{a}$ Dr. ${ }^{a}$ Maria Rita Bertolozzi
}

\section{VERSÃO CORRIGIDA}

A versão original encontra-se disponível na Biblioteca da Escola de Enfermagem da Universidade de São Paulo e na Biblioteca Digital de Teses e Dissertações da Universidade de São Paulo.

\section{SÃO PAULO}


AUTORIZO A REPRODUÇÃO E DIVULGAÇÃO TOTAL OU PARCIAL DESTE TRABALHO, POR QUALQUER MEIO CONVENCIONAL OU ELETRÔNICO, PARA FINS DE ESTUDO E PESQUISA, DESDE QUE CITADA A FONTE.

Assinatura: Data:

Catalogação na Publicação (CIP)

Biblioteca "Wanda de Aguiar Horta"

Escola de Enfermagem da Universidade de São Paulo

Vicente, Suéllen Mariane Rios

Síntese de evidências para políticas de saúde: participação social como resposta a necessidades de saúde / Suéllen Mariane Rios Vicente. São Paulo, 2019.

$107 \mathrm{p}$.

Dissertação (Mestrado) - Escola de Enfermagem da Universidade de São Paulo.

Orientadora: Prof. ${ }^{\text {a }}$ Dr. ${ }^{\text {a }}$ Maria Rita Bertolozzi

Área de concentração: Cuidados em Atenção Primária em Saúde

1. Atenção primária à saúde. 2. Participação comunitária. 3. Política de saúde. 4. Enfermagem baseada em evidências. I. Título.

Ficha catalográfica elaborada por Fabiana Gulin Longhi Palacio (CRB-8: 7257) 
Nome: Suéllen Mariane Rios Vicente

Título: Síntese de evidências para políticas de saúde: participação social como resposta a necessidades de saúde.

Dissertação apresentada ao Programa de Pós-Graduação Mestrado Profissional em Enfermagem na Atenção Primária em Saúde no SUS (Sistema Único de Saúde) - MPAPS da Escola de Enfermagem da Universidade de São Paulo - USP como obtenção do Título de Mestre em Ciências da Saúde.

Aprovado:

\section{Banca Examinadora}

Orientadora: Prof. ${ }^{a}$ Dr. ${ }^{a}$ Maria Rita Bertolozzi

Instituição: EEUSP

Assinatura:

Prof. ${ }^{(a)}$ Dr. ${ }^{(a)}$ Instituição:

Julgamento: Assinatura:

Prof. ${ }^{(a)}$ Dr. ${ }^{(a)}$ Instituição:

Julgamento: Assinatura:

Prof. ${ }^{(a)}$ Dr. ${ }^{(a)}$ Instituição:

Julgamento: Assinatura: 


\section{DEDICATÓRIA}

À minha mãe Eládia que nunca poupou esforços, sempre com muita calma, paciência e zelo estimulou a continuidade dos meus estudos.

Às minhas filhas Vitória e Alice, pela sensibilidade, carinho e compreensão demostrados no decorrer deste trabalho.

Amo vocês! 


\section{AGRADECIMENTOS}

Primeiramente a Deus pela oportunidade, por me fazer acreditar que seria capaz, por conhecer os desejos do meu coração, por me dar resiliência e saúde para superar os desafios e obstáculos em todos os campos da minha vida e por ter me acompanhando ao longo desses anos.

À Nossa Senhora Aparecida e Santa Catarina de Alexandria pela intercessão nos estudos, e, assim como minha mãe me protegeu e acalentou.

Ao Departamento de Enfermagem em Saúde Coletiva da Escola de Enfermagem da Universidade de São Paulo pela oportunidade de crescimento profissionale desenvolvimento das habilidades em pesquisa.

O apoio financeiro ao Projeto "Tecnologias para a Sistematização da Assistência de Enfermagem a Famílias na Atenção Básica", contemplado com recursos do Edital $n^{\circ} 27$ - Acordo CAPES/COFEN, que acreditou no sucesso deste importante programa, fruto desta parceria. A vida é feita de escolhas, desafios e obstáculos, ao longo deste percurso precisamos superar todas as dificuldades! Para isso precisamos de parceiros que acreditem nos desafios e na capacidade de sairmos vitoriosos, no desejo de trazermos mudanças e reconhecimento da nossa profissão. Confiante que as contribuições e aprendizados adquiridos nesta parceria serão de grande valia para efetivação das pesquisas desenvolvidas. Espero que esta parceria possa ser duradoura e satisfatória a nossa profissão, beneficiando outros profissionais, estabelecendo novos desafios.

À minha querida e admirável orientadora, Profa. Dra. Maria Rita Bertolozzi, sem dúvidas um presente, fonte de inspiração que contribuiu de maneira 
Grifhante na construção de conhecimentos, ideias, raciocínios e textos. Sua dedicação, orientação, parceria, com acolhimento e sensibilidade foi fundamental nessa trajetória, a quem agradeço imensamente.

Às queridas professoras do Departamento de Enfermagem em Saúde Coletiva da Escola de Enfermagem da Vniversidade de São Paulo, Dra. Cássia Baldini Soares e Dra. Célia Maria Sivalli Campos, cujas contribuições me permitiram mudar a visão de mundo, e acreditar que é possível associar pesquisa acadêmica e trajetória profissional em busca do que está evidente e oculto nas políticas públicas de saúde.

À Dra. Maritsa Carla de Bortoli e Dra. Tereza Setsuko Toma, membros do Instituto de Saúde - SP, por compartilharem seus projetos, ensinamentos e sugestões. $\mathcal{N}$ ossas reuniões foram momentos de grande aprendizado.

Aos meus queridos amigos Valdir Correia de Toledo e Fermanda Mota Rocha pelo incentivo e apoio.

À minha querida amiga, irmã e comadre Marlene Aparecida Miguel pelas lindas palavras de apoio e fé nos momentos de aflição.

Aos meus colegas do Programa da Pós-graduação Mestrado Profissional em Enfermagem na Atenção Primária em Saúde no SUS - MPPAPS, Alessandra Cristina

Ferreira Martins, Aline Marion Moreira Kolle, Ana Paula Turin Rouiller, Edyra Damasceno da Costa e Silva, Milene Aparecida Aguiar Vilas Boas, Natalia Rodrigues Mosca e Rodrigo Fontana (mesmo desistindo do programa foi um grande parceiro). E a Doutoranda da EEUSP Emiliana Maria Grando Gaiotto. Meu agradecimento a todos pela parceria, troca de experiências, angústias e alegrias ao longo destes anos. A Instituição que atuo como profissional pela oportunidade na liberação para me dedicar aos estudos, propiciando aprimoramento pessoal e profissional. A minha família sempre! 
“A vida sem luta é um mar morto no centro do organismo universal". Machado de Assis 
Vicente SMR. Síntese de evidências para políticas de saúde: participação social como resposta a necessidades de saúde [dissertação]. São Paulo: Escola de Enfermagem, Universidade de São Paulo; 2019.

\section{RESUMO}

Introdução: A participação social tem o potencial de informar as políticas de saúde e tem fundamental importância para o controle social, sendo a participação um determinante fundamental da democracia, permitindo que um coletivo decida sobre assuntos de interesse geral. Assim, as diferentes realidades da população podem ser contempladas na construção de políticas de saúde. Objetivo: Elaborar uma síntese de evidências para informar políticas de saúde a respeito da participação social para melhorar a atenção à saúde e como resposta a necessidades de saúde. Método: Utilizou-se da ferramenta SUPPORT (Supporting Policy Relevant Reviews and Trials), principal referencial metodológico da EVIPNet (EvidenceInformed Policy Network) Brasil. Foram etapas do estudo: definição do problema para informar políticas de saúde; busca das evidências e seleção dos estudos, nas bases de dados: Biblioteca Virtual em Saúde, Health Systems Evidence e ProQuest; Extração dos dados e avaliação metodológica por meio do AMSTAR; definição das opções para informar políticas de saúde; descrição das considerações sobre a implementação das opções; descrição das considerações de equidade para as opções; elaboração da síntese de evidência. Resultados: Foram obtidos 1.530 artigos. Após análise dos artigos duplicados e com base nos critérios de exclusão, restaram 06 artigos para compor as duas opções para informar políticas de saúde. Duas revisões sistemáticas foram utilizadas para compor a opção 1: Participação social para melhorar a atenção à saúde, por meio de comitês e abordagens participativas, quatro revisões sistemáticas para compor a opção 2: Participação para o aprimoramento de indicadores de saúde. Conclusão: As formas de participação social encontradas nos estudos: por meio de comitês, e através de abordagens participativas contribuem para melhorar a atenção à saúde e o aprimoramento de indicadores de saúde, no âmbito da Atenção Primária em Saúde. De fato, o que se verificou nessas revisões, são abordagens que possibilitam a participação de usuários de serviços ou de grupos populacionais, com ações e intervenções operacionalizadas, sobretudo, em âmbito institucional.

Palavras-chave: Atenção primária em saúde. Participação comunitária. Participação social. Evidências. Enfermagem. 
Vicente SMR. Evidence synthesis for health policies: social participation as a response to health needs. [dissertation]. São Paulo: School of Nursing, University of São Paulo; 2019.

\begin{abstract}
Introduction: The social participation has the potential to inform health care policies and also has the fundamental importance of social control. As an essential component in democracy, it allows a group to decide on subjective of general interest. Thus, the different realities of the population can be contemplated at the construction of health care policies. Objective: Elaborate a synthesis of evidences to inform health care policies regarding social participation to improve the attention on health care and as an answer to health care needs. Method: The SUPPORT (Supporting Policy Relevant Review sand Trials) tool was used, main methodological framework of EVIPNet (Evidence-Informed Policy Network) Brazil. The research stages were: definition of the problem to inform health care policies; the search for evidences and selection of studies, in the databases: Virtual Health Library, Health Systems Evidence and ProQuest; data extraction and methodological evaluation by AMSTAR; definition of the options to inform health care policies; description of the considerations about the implementation of the options; description of the equity considerations to the options; elaboration of the evidence synthesis. Results: 1.530 articles were obtained. After the analysis of the duplicated articles and based on the exclusion criteria, there were 06 articles left to compose the two options for informing health care policies. Two systematic reviews were used to compose the $1^{\text {st }}$ option: Social participation as a way to improve the attention on health care, through committees and participative approaches, four systematic reviews to compose the $2^{\text {nd }}$ option: participation to improve the indicators of health care. Conclusion: The ways of social participation that can be found on this study: through the committees and participative approaches, it is possible to improve both attentions on health care and social health care indicators within the Primary Health Care. Indeed, what were verified in those reviews are approaches that allow the participation of service users or population groups with operational actions and interventions, especially on institutional framework.
\end{abstract}

Keywords: Primary health care. Community participation. Social participation. Evidences. Nursing. 


\section{LISTA DE ILUSTRAÇÕES}

Figura 1 - Categorias empíricas das dimensões que compõem as relações sociais para o reconhecimento de necessidades ampliadas de saúde em indivíduos, famílias, grupos/classes sociais, segundo Campos (2009).

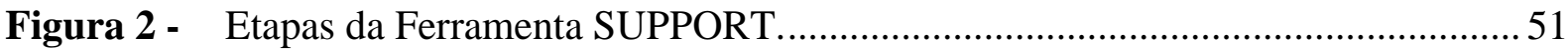

Figura 3 - Diagrama de Fluxo da Seleção dos Estudos, segundo o PRISMA. São Paulo, 2019. 


\section{LISTA DE QUADROS}

Quadro 1 - Mecanismo de busca junto à Health Systems Evidence - HSE 59

Quadro 2 - Mecanismo de busca na Biblioteca Virtual de Saúde - BVS 59

Quadro 3 - Mecanismo de busca na ProQuest 60

Quadro 4 - Descrição da síntese das evidências relevantes para a Opção 1. 67

Quadro 5 - Descrição da síntese das evidências relevantes para a Opção 2

Quadro 6 - Implementação da opção 1 e implicações em relação aos usuários, trabalhadores de saúde e para a organização dos serviços e sistemas de saúde.

Quadro 7 - Implementação da opção 2 e implicações em relação aos usuários, trabalhadores de saúde e para a organização dos serviços e sistemas de saúde.

Quadro 8 - AMSTAR (A measurement tool to assess the methodological quality of systematic reviews) ferramenta para a avaliação e classificação da qualidade da revisão sistemática

Quadro 9 - Revisões sistemáticas sobre a opção 1. Participação social para melhorar a atenção à saúde (comitês e abordagens participativas).

Quadro 10 - Revisões sistemáticas sobre a opção 2. Participação social para o aprimoramento de indicadores de saúde.

Quadro 11 - Estudos excluídos após leitura completa. 


\section{LISTA DE ABREVIATURAS}

\begin{tabular}{ll} 
abr. & abril \\
cap. & capítulo \\
dez. & dezembro \\
dra. & doutora \\
ed. & edição \\
enferm. & enfermagem \\
esc. & escola \\
jan. & janeiro \\
jul. & julho \\
jul. & julho \\
mai. & maio \\
mar. & março \\
n. & número \\
org. & organizadores \\
out. & outubro \\
p. & página \\
profa. & professora \\
rev. & revista \\
v. & volume \\
\hline
\end{tabular}




\section{LISTA DE SIGLAS}

Abrasco Associação Brasileira de Pós-graduação em Saúde Coletiva

AMSTAR A MeaSurement Tool to Assess Reviews

APS Atenção Primária em Saúde

ASSIA Applied Social Sciences Index and Abstracts

Bireme Centro Latino-Americano e do Caribe de Informação em Ciências as Saúde

BVS Biblioteca Virtual de Saúde

CGGC Coordenação Geral de Gestão do Conhecimento

CICT Comissão Intersetorial de Ciência e Tecnologia

CNS Conselho Nacional de Saúde

Conasems Conselho Nacional de Secretarias Municipais de Saúde

Conass Conselho Nacional de Secretários de Saúde

Decit Departamento de Ciência e Tecnologia da Secretaria de Ciência

EEUSP Escola de Enfermagem da Universidade de São Paulo

ERIC Educational Resources Information Center

EVIPNet Evidence-Informed Policy Network

Fiocruz Fundação Oswaldo Cruz

HFC Health Facility Committees

HI High Income

HIV Human Immunodeficiency Virus

HSE Health Systems Evidence HSE

INAMPS Instituto Nacional de Assistência Médica e Previdência Social

IS Instituto de Saúde 
LI Low Income Countries

LMI Low Middle Income

MPAPS Mestrado Profissional na Atenção Primária em Saúde

MST Movimento dos Trabalhadores Rurais Sem Terra

MS Ministério da Saúde

NHS National Health Service

ONG Organização Não-Governamental

ONGs Organizações Não-Governamentais

OMS Organização Mundial da Saúde

OPAS Organização Panamericana da Saúde

SCTIE Tecnologia e Insumos Estratégicos

SP São Paulo

SUDS Sistema Unificado e Descentralizado de Saúde

SUPPORT Supporting Policy Relevant Reviews and Trials

SUS Sistema Único de Saúde

UMI Upper Middle Income

US\$ United States Dólar

USP Universidade de São Paulo

WHO World Health Organization 


\section{SUMÁRIO}

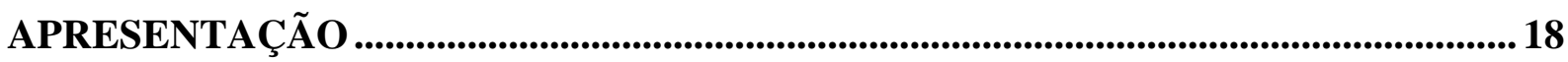

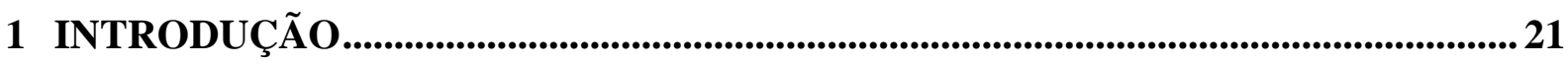

1.1 A PARTICIPAÇÃO NAS POLÍTICAS DE SAÚDE DO BRASIL .............................2 21

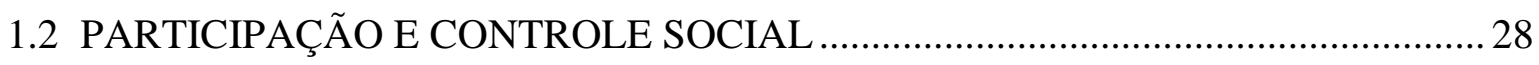

1.2.1 Conselhos de Saúde e Conferências de Saúde ................................................. 31

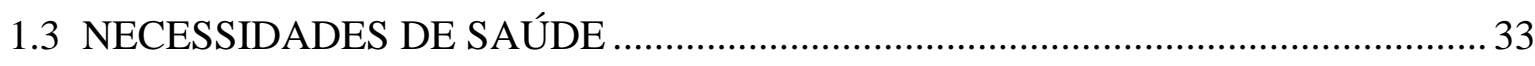

2 OBJETIVOS.............................................................................................................................38

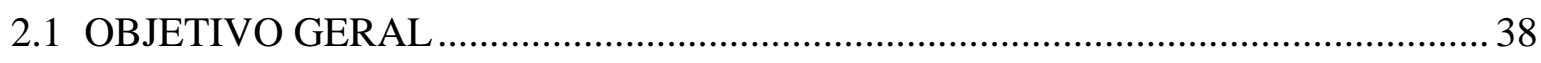

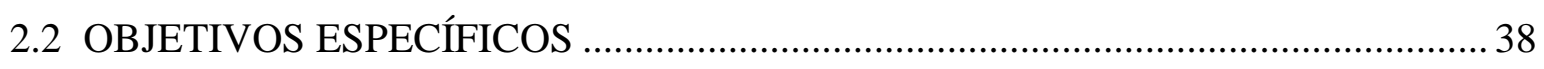

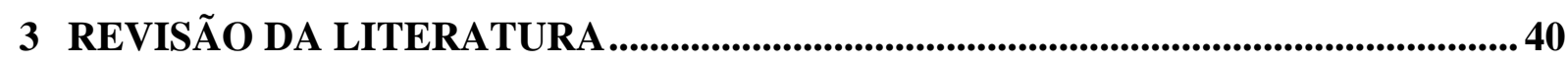

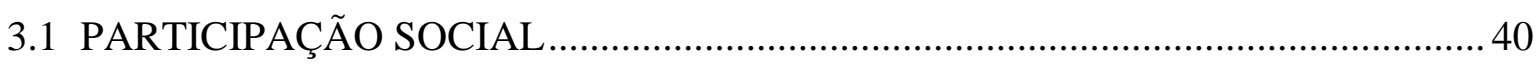

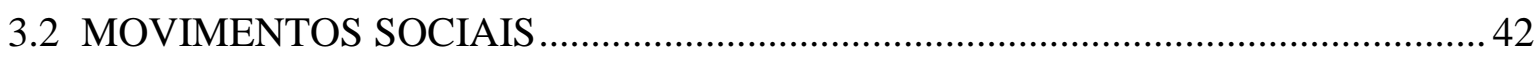

3.3 POLÍTICAS DE SAÚDE INFORMADAS POR EVIDÊNCIAS .................................. 46

3.3.1 EVIPNet (Evidence-Informed Policy Network) - Rede para Políticas Informadas por Evidências ............................................................................ 48

3.3.2 Ferramentas Supporting Policy Relevant Reviews and Trials (Ferramentas

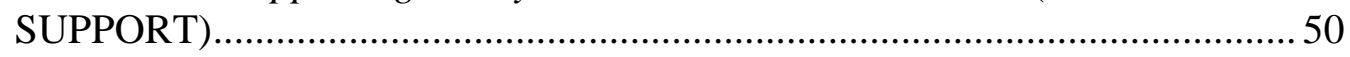

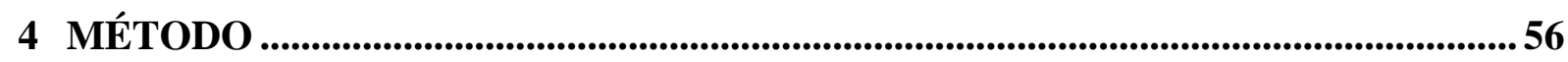

4.1 Etapa 1: As prioridades na definição dos programas/políticas.......................................57

4.2 Etapa 2: Busca das evidências e seleção dos estudos ................................................... 57

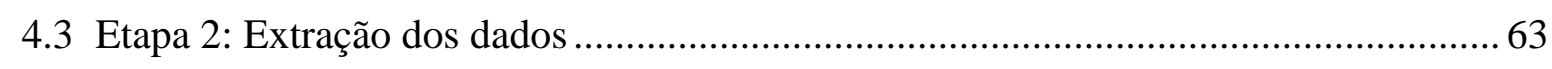

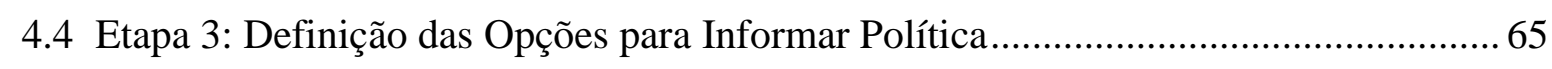

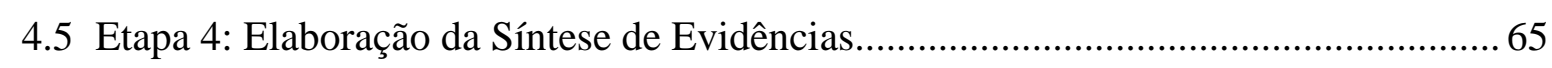

5 RESULTADOS ........................................................................................................................6

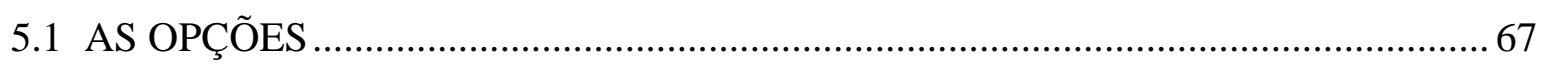

5.1.1 Opção 1 - Participação social para melhorar a atenção à saúde (por meio de

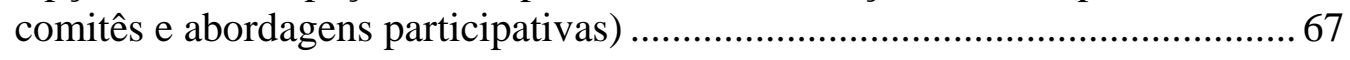

5.1.2 Opção 2 - Participação social para o aprimoramento de indicadores de saúde 69

5.2 CONSIDERAÇÕES SOBRE EQUIDADE NAS OPÇÕES …………………….......73

5.2.1 Opção 1 - Participação social para melhorar a atenção à saúde (comitês e abordagens participativas) 
5.2.2 Opção 2 - Participação social para o aprimoramento de indicadores de saúde 75 5.3 CONSIDERAÇÕES SOBRE A IMPLEMENTAÇÃO DAS OPÇÕES ..................... 77

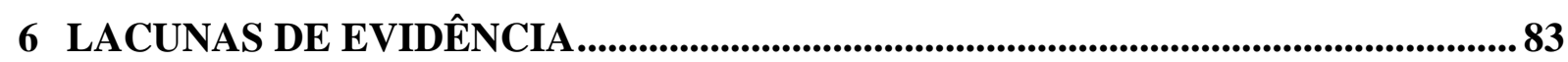

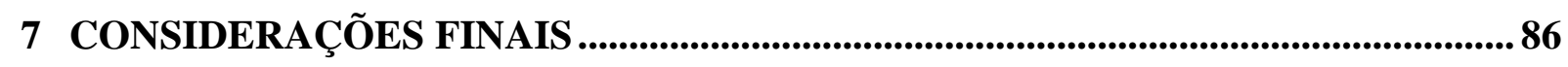

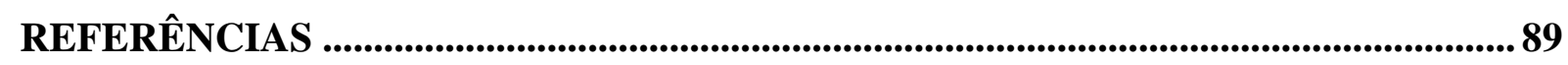

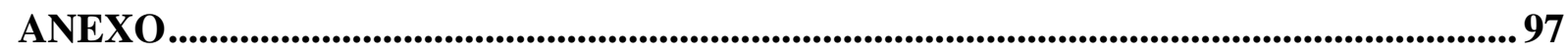

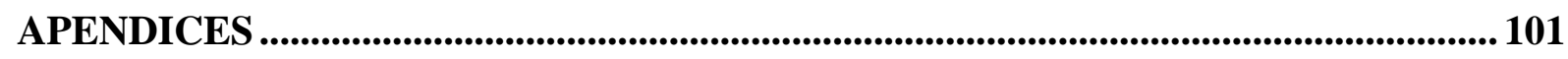

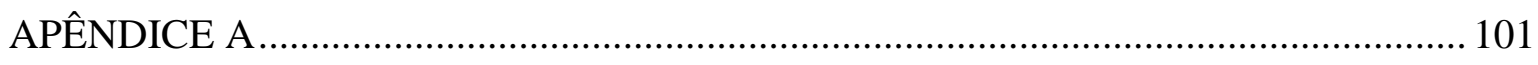

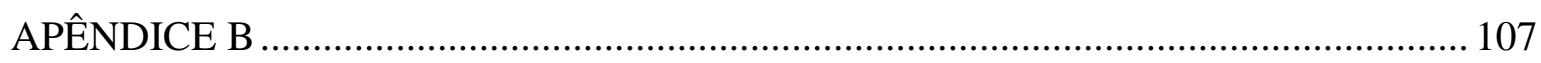


APRESENTACÃO 


\section{APRESENTAÇÃo}

“Caminhando e cantando e seguindo a canção

Somos todos iguais braços dados ou não Nas escolas, nas ruas, campos, construções [...] [...] Pelos campos há fome em grandes plantações

Pelas ruas marchando indecisos cordões

Ainda fazem da flor seu mais forte refrão E acreditam nas flores vencendo o canhão [...] [...] Os amores na mente, as flores no chão A certeza na frente, a história na mão [...] [...] Aprendendo e ensinando uma nova lição Vem, vamos embora, que esperar não é saber Quem sabe faz à hora não espera acontecer".

Geraldo Vandré

Os trechos da música "Pra não dizer que não falei das flores, de Geraldo Vandré", retratam um momento histórico brasileiro, marcado por grandes manifestações, protestos e lutas pela liberdade, pelo fim da censura e conquista de um País democrático. Mesmo após 40 anos, a música parece tão atual, fazendo repensar quão importante é a luta pelos nossos direitos, objetivos, ideais, desejos, sonhos e esperança, mas principalmente, sobre como o conhecimento dos nossos direitos e deveres nos impulsionam para que se construa uma sociedade justa e democrática, assegurando e garantindo os direitos Constitucionais.

O Sistema Único de Saúde (SUS) representa uma das nossas maiores conquistas e, atualmente, nos deparamos com seu desmonte. Essa é a base a partir da qual emergiu o desejo de ingressar no Mestrado Profissional, pois este possibilita a busca pela melhoria contínua na qualidade e prestação dos serviços de saúde. 
A escolha do termo "Participação social" e "Necessidades de saúde", se deu através de discussões junto às orientadoras e representantes do Instituto de Saúde - SP, que lançaram o desafio de trabalhar com o método da Síntese de Evidências para Políticas Públicas de Saúde, através da ferramenta SUPPORT, constituindo o principal referencial metodológico da EVIPNet Brasil. Ao me aprofundar do tema Participação Social pude perceber o quanto estava alheia a ele, enquanto diretriz do SUS, profissional da saúde e usuária do Sistema. Em todas as fases do estudo percebi as dificuldades e desafios que o SUS impõe para se consolidar enquanto política do Estado, reiterando o direito Constitucional à saúde por meio de respostas efetivas às necessidades de saúde da população. Por fim, não poderia deixar de mencionar a relevância da participação social no processo de identificação das necessidades e da consolidação de uma estrutura de participação nas políticas públicas de saúde que pressupõe a existência de organizações da sociedade civil fortalecida e que tenha autonomia. Cabe ressaltar que não podemos deixar de considerar a magnitude da exclusão social no Brasil, responsável pelo aumento significativo das desigualdades sociais.

Sendo de suma importância a organização e a mobilização da população para a conquista do direito à saúde, acredito que somente assim podemos mudar não somente a realidade do local em que atuo como Supervisora de Enfermagem, mas também, de apoiar as mudanças das condições de vida das pessoas com base no reconhecimento das necessidades de saúde. Essa foi a minha motivação inicial e continua sendo a motivação propulsora. Não tenho dúvidas que este trabalho foi coletivo, tem uma alta complexidade e envolve um anseio para a transformação da realidade e construção de uma sociedade com melhores e mais oportunidades de condições de vida, contribuindo para a redução das desigualdades sociais. Também anseio que o produto deste estudo (Síntese de Evidências) possa servir de orientação para os gestores, tomadores de decisão, profissionais as saúde e usuários do SUS no Brasil.

"Somos a transformação que queremos no mundo". 
1 INTRODUCÃO 


\section{INTRODUÇÃO}

\subsection{A PARTICIPAÇÃO NAS POLÍTICAS DE SAÚDE DO BRASIL}

Em primeiro lugar é necessário afirmar que a participação social tem a potencialidade de influenciar a proposição e a implementação de políticas. É nesse sentido que esta primeira Seção da Introdução se dedicará a expor alguns aspectos da participação nas políticas de saúde do Brasil.

A história das políticas de saúde no Brasil possui características marcantes, e evidencia as tendências políticas e econômicas de cada momento histórico, assim como algumas dificuldades e entraves que repercutem e persistem até os dias atuais (Aguiar, 2011). Na perspectiva de um recorte é possível destacar que os problemas de saúde da população brasileira evidenciaram-se no contexto das grandes epidemias, da excessiva pobreza e da alta mortalidade derivada das condições de vida nas cidades no final do século XIX e início do século XX (Nespoli, 2014).

No percurso histórico das políticas de saúde do Brasil destacam-se as características de um sistema que excluiu de seus serviços grande parcela da população, vinculado aos interesses privatistas e lucrativos de uma sociedade capitalista, que consolidou um modelo assistencial fragmentado, curativista e pouco resolutivo. Neste contexto, e sob o regime ditatorial dos anos 70 e 80, merece destaque o florescer dos ideais da Reforma Sanitária, que na VIII Conferência Nacional de Saúde teve seu momento áureo, consolidando o consenso quanto às estratégias para a construção de um Sistema Único de Saúde (SUS) para todos, independentemente da vinculação ao sistema previdenciário (Aguiar, 2011).

Nessa trajetória, cabe ressaltar o período da Nova República (1985-1988), inicialmente marcado por um grande movimento político em prol das eleições diretas para a Presidência. Entretanto, com a reorganização das forças políticas surgiu a Aliança Democrática, que impediu as eleições diretas, e elegeu, através da Câmara, um novo Presidente, Tancredo Neves e, como seu vice, José Ribamar Sarney (Bertolozzi e Grecco, 1996). 
Em março de 1985, com a morte precoce de Tancredo Neves, Sarney tomou posse na Presidência da República. Mantendo o compromisso assumido por Tancredo Neves, enviou ao Congresso a proposta de convocação da Assembléia Nacional Constituinte, a ser composta pelos deputados federais e senadores que seriam eleitos no pleito previsto para 1986 e pelos senadores já eleitos em 1982 (Aguiar, 2011).

O governo José Sarney, na tentativa de conter a crise inflacionária vivenciada pelo País, propôs vários planos econômicos, que pouco transformaram a realidade econômica e social da nação, ainda privilegiando os setores de maior poder econômico, em detrimento da maciça população brasileira (Bertolozzi e Grecco, 1996).

"Com o início desse governo de "transição", desencadearam-se no setor saúde, diferentes medidas que tinham o objetivo de alterar as políticas que privilegiavam a atenção privatizante em detrimento das ações do setor público” (Bertolozzi e Grecco, 1996, p.391).

Nesse cenário, diversas entidades e movimentos sociais impulsionaram a mobilização e estimulavam a participação popular, no processo de discussão de uma nova Carta Constitucional, almejando que a sua elaboração fosse fruto da atuação dos diversos segmentos sociais e não apenas centralizados nas elites econômicas e políticas, possibilitando um avanço em torno da democracia e na garantia dos direitos e deveres de cidadania (Aguiar, 2011).

Esse clima de ação participativa, de lutas por mudanças e ampliação da cidadania foi favorável para introduzir a saúde na agenda política, difundindo as propostas da Reforma Sanitária. Sendo assim, a realização da VIII Conferência Nacional de Saúde, em Brasília, no ano de 1986, criou um importante espaço para os debates dos problemas do sistema de saúde e de propostas de reorientação da assistência médica e da saúde pública (Aguiar, 2011).

O processo da Reforma Sanitária foi desencadeado por intelectuais e profissionais do Movimento Sanitário, e impulsionou a realização da VIII Conferência Nacional de Saúde, convocada pelo Ministério da Saúde (Bertolozzi e Grecco, 1996).

A VIII Conferência Nacional de Saúde contou com a participação de mais de 4.000 pessoas, entre membros da sociedade civil, representantes dos diversos movimentos sociais, movimentos populares de saúde, trabalhadores, usuários, estudantes e intelectuais da saúde, parlamentares, sindicatos, entre outros representantes, inovando as conferências de saúde que até então haviam sido convocadas para discutir questões de caráter essencialmente técnico (Aguiar, 2011). No âmbito da VIII Conferência foram debatidos os seguintes temas: Saúde 
como direito; Reformulação do Sistema Nacional de Saúde e Financiamento do setor (Brasil, 1986).

"Os debates que se travaram no decorrer da VIII Conferência colocaram à tona as políticas de saúde como questão a ser discutida pelo coletivo, marcando contundentemente a história da saúde no Brasil, uma vez que definiu um Programa para a Reforma Sanitária" (Bertolozzi e Grecco, 1996, p.392). Destaca-se, nesse debate, o conceito ampliado do termo saúde, seu reconhecimento como direito de todos e dever do Estado, a criação do SUS (incluindo a unificação dos serviços do Instituto Nacional de Assistência Médica da Previdência Social - INAMPS e do Ministério da Saúde), a descentralização e a hierarquização dos serviços, a atenção integral às necessidades de saúde da população e a participação popular (Aguiar, 2011).

Bertolozzi e Grecco (1996, p. 392) destacam que:

[...] a VIII Conferência representou um avanço técnico e um pacto político, ao propor a criação do Sistema Único de Saúde (SUS), tendo como diretrizes: a universalidade, a integralidade das ações e a participação social, [...], entretanto, cabe explicitar que o Estado se antecipou a implementação do SUS, criando por decreto o Sistema Unificado e Descentralizado de Saúde (SUDS), que incluía a redução da máquina previdenciária do nível estadual, a transferência dos serviços de saúde para os estados e municípios e o estabelecimento de um gestor único da saúde em cada esfera de governo. Além disso, a implementação do SUDS dependia do grau de compromisso dos governantes.

Para o encaminhamento das propostas oriundas da VIII Conferência à Assembleia Nacional Constituinte e sua inscrição na nova Constituição Federal, foi instituída a Comissão Nacional de Reforma Sanitária (Aguiar, 2011, p.37).

Em outubro de 1988, com a promulgação da Constituição Federal, foi aprovado o Sistema Único de Saúde (SUS), complementando o processo de retorno do País ao regime democrático, e incorporando a maioria das propostas do movimento da Reforma Sanitária, apresentadas por emenda popular, a partir da participação dos segmentos interessados (Aguiar, 2011). Nesse contexto de busca por um Estado de bem-estar social, a nova Carta Constitucional transformava a saúde em direito de cidadania e dava origem ao processo de criação de um sistema público, universal e descentralizado de saúde, transformando profundamente a organização desse setor no Brasil (Paiva e Teixeira, 2014). 
A aprovação do SUS, com os princípios e as diretrizes da Reforma Sanitária, representou uma significativa vitória para a sociedade. Foi criado em um momento no qual o País atravessava uma importante crise e instabilidade econômica, com altas taxas de inflação e decorrências da conjuntura internacional neoliberal, com impacto nos movimentos sociais. Por outro lado, também se verificavam sérias dificuldades para a regulamentação do SUS, bem como para a implantação dos princípios, diretrizes e concretização das propostas da Constituição Cidadã (Aguiar, 2011). Os trabalhadores perdiam o poder de compra e, simultaneamente ao processo de Reforma Sanitária, as empresas de saúde se reorganizavam para atender às demandas dos novos clientes, recebendo subsídios do governo e consolidando os investimentos no setor privado (Paim et al., 2011).

Cabe ressaltar que, em 1990, em meio a esta importante e crítica crise econômica, tomou posse Fernando Collor de Melo, o primeiro presidente eleito por voto popular desde a ditadura militar, mas que absolutamente não se comprometeu com a Reforma Sanitária (Paim et al., 2011). De fato, reduziu em quase metade os recursos destinados ao setor da saúde, adotou uma política neoliberal, cujos elementos básicos que a norteiam são: a desvalorização da moeda, a liberalização do comércio exterior, a redistribuição da riqueza e da receita governamental, a redução do déficit público, acompanhada da redução do emprego público, a privatização, o controle salarial, a eliminação do controle de preços, o cumprimento de parcelas da dívida externa ativa e a priorização das exportações, com consequente queda da qualidade do sistema público (Bertolozzi e Grecco, 1996). Em meio a este contexto, os governos estaduais também reduziram sua participação orçamentária para a saúde, e todas essas deliberações contrariavam a política pública do SUS, que nascia enfrentando um importante colapso nos serviços de saúde e na descrença popular em relação ao Estado (Aguiar, 2011).

"O resultado desse processo começou a se expressar através da oferta de serviços altamente discriminatória e seletiva para os diferentes cidadãos, segundo a sua inserção social e fixada na atenção médica" (Bertolozzi e Grecco, 1996). Também ampliava o interesse voltado ao lucro na saúde, evidenciando amplamente o florescimento do projeto conservador antagônico à política pública de saúde defendida pela Reforma Sanitária (Aguiar, 2011).

Mesmo assim, em 1990, com o intuito de especificar as atribuições e a organização do SUS, foi aprovada a Lei Orgânica da Saúde (Lei 8.080/90) e o projeto da Reforma Sanitária foi retomado em 1992, após o impeachment de Collor (Paim et al., 2011). 
Como decorrência da Constituição Federal, elaborou-se no período de 1989 -1990 a Lei n. 8.080, de setembro de 1990 - a chamada Lei Orgânica da Saúde, que dispõe sobre as condições para a promoção, proteção e recuperação da saúde, as Constituições Estaduais e as Leis Orgânicas Municipais (Brasil, 2011, p. 17).

É possível compreender que estava implícito o processo para impedir o desenvolvimento e a implementação do SUS e, como resultado, o Governo adiou a convocação da IX Conferência Nacional da Saúde, bem como a regulamentação da Lei Orgânica (Lei 8080), a qual teve sua aprovação após importante processo de mobilização (Bertolozzi e Grecco, 1996).

De acordo com Bertolozzi e Grecco (1996), a Lei Orgânica (Lei 8080) sofreu importantes alterações decorrentes de vetos do Presidente Collor, que foram negociados e parcialmente recuperados na Lei n. 8.142.

Ainda conforme as mesmas autoras, (1996, p. 393), no que se refere aos vetos de Fernando Collor de Melo:

Dos 9 vetos de Collor à Lei 8080, os mais importantes foram: o que instituía as conferências e os conselhos de saúde como instâncias colegiadas e representativas para formular e propor estratégias, além de exercer controle sobre a execução das políticas de saúde; a não extinção dos escritórios regionais do INAMPS; a transferência da verba direta para os Estados e Municípios; a obrigatoriedade de planos de carreiras, de cargos e salários para o SUS em cada esfera de governo e a fixação de pisos nacionais de salário (Bertolozzi e Greco, 1996: 393)

Esses vetos atingiram pontos fundamentais, como a instituição dos Conselhos e das Conferências de Saúde, no Congresso Nacional (Brasil, 2011).

Mas, como resultado de intensas pressões, a Lei 8.142 recuperou a transferência automática de recursos, a participação e o controle social, mas não alterou a questão da carreira, mantendo o SUS com vários vínculos empregatícios diferentes nos serviços de saúde (Bertolozzi e Grecco 1996).

A Lei 8.142 , de dezembro de 1990 , em seu artigo $1^{\circ}$, regula a participação da comunidade no SUS, instituindo os Conselhos de Saúde e as Conferências de Saúde (Brasil, 2011). Conforme Documento Oficial (Brasil, 2011, p. 17):

No seu Parágrafo $3^{\circ}$, a lei define a participação do CONASS e do Conasems no Conselho Nacional de Saúde.

A Seção de Saúde da Constituição Federal e as Leis n. 8.080 e n. 8.142, de 1990, constituem respectivamente as bases jurídicas, constitucional e infraconstitucional do SUS. 
Compreender a evolução histórica das políticas de saúde do Brasil subsidia uma atuação mais consciente, proativa e coesa na continuidade da construção e consolidação do Sistema Único de Saúde (SUS), como um sistema de saúde para todos, sustentada por movimentos e manifestações populares em prol das necessidades de saúde da população (Aguiar, 2011). O Sistema Único de Saúde (SUS) é reconhecido como uma conquista da sociedade civil contra um governo militar autoritário, centralizador e antidemocrático e a participação social versa pela democratização dos processos políticos e de gestão do sistema de saúde brasileiro (Nespoli, 2014).

O Sistema Único de Saúde (SUS) é o sistema de saúde oficial do Brasil, que surgiu como importante conquista após um longo processo de acúmulo e de lutas desde os anos 70, em decorrência de movimentos populares, da atuação de trabalhadores da saúde, de usuários, intelectuais, sindicalistas e militantes dos mais diversos movimentos sociais, constituindo o que se denomina como processo de Reforma Sanitária (Gouveia e Palma, 1999). A Reforma Sanitária refere-se ao projeto articulado, ao longo dos anos 70 e 80 no Brasil, na perspectiva de reformulação do sistema de saúde. Tal projeto preconizava a criação de um sistema único de saúde, que terminasse como o duplo comando do Ministério da Saúde e do Instituto Nacional de Assistência Médica e Previdência Social (INAMPS), os quais executavam ações de saúde em perspectivas antagônicas. Todos os atores sociais envolvidos nesse projeto (lideranças populares, trabalhadores, sindicatos, parlamentares de esquerda, intelectuais, estudantes de saúde e entidades) lutavam contra as condições precárias de vida da população, contra as iniquidades do sistema de saúde e pelo reconhecimento da saúde como direito social a ser garantido pelo Estado (Aguiar, 2011).

Uma característica fundamental da Reforma Sanitária brasileira é o fato de ter sido conduzida pela sociedade civil, e não por governos, partidos políticos ou organizações internacionais. O SUS, resultante desse processo, aumentou o acesso ao cuidado à saúde para uma considerável parcela da população brasileira, em uma época na qual o sistema vinha sendo progressivamente privatizado. Do início de sua implementação até 2016, muitos avanços podem ser apontados, como investimento em recursos humanos, ciência e tecnologia na atenção básica, além de um importante processo de descentralização, ampla participação social e maior conscientização sobre o direito à saúde (Paim et al., 2011), apesar de verificar-se uma série de limitações e de dificuldades, à exemplo da importante restrição financeira. 
De fato, embora o SUS represente um avanço na política de saúde, ainda são necessários esforços, dentre os quais a intensificação da participação social, como mecanismo de enfrentamento aos constantes desafios, com o intuito de firmá-lo como um sistema capaz de promover ações que respondam às necessidades de saúde da população (Aguiar, 2011). Para que o sistema de saúde brasileiro se torne verdadeiramente universal ainda há muito a fazer e, para isto, é muito importante que supere importantes limitações, sendo necessária maior mobilização política para reestruturar o financiamento e redefinir os papéis dos setores público e privado (Paim et al., 2011), dentre outras.

A instituição do SUS produziu resultados imediatos. Dentre estes, o mais importante foi a rupturada separação que havia no sistema público de saúde brasileiro entre as populações dos incluídos e dos não incluídos economicamente. Para os incluídos, havia a saúde previdenciária a que tinham direito os portadores de registro em carteira e que tinham acesso ao Instituto Nacional de Assistência Médica e Previdência Social (INAMPS); para os não incluídos, restava à atenção ambulatorial provida por unidades de medicina simplificada e a atenção hospitalar prestada por entidades filantrópicas aos indigentes (Brasil, 2011).

Em pouco tempo, com a Lei n. 8.689, de 27 de julho de 1993, que dispõe sobre a extinção do INAMPS, o SUS pôs fim à figura iníqua dos indigentes sanitários, promovendo a integração do INAMPS ao sistema público único de saúde (Brasil, 2011).

A Lei 8.142 dispõe sobre a participação da comunidade na gestão do SUS e sobre as transferências intergovernamentais de recursos financeiros na área da saúde. Assim, coloca-se a participação como um importante espaço público de controle social, por meio, por exemplo, das conferências e dos conselhos de saúde em todas as esferas do governo (Brasil, 1990a).

Para Costa et al. (2013):

[...] O sonho de o Brasil garantir a igualdade de acesso em saúde para todos que precisam, em qualquer lugar, a qualquer hora, só irá adiante se os fundos públicos ganharem aportes significativos, passando a financiar apenas serviços, equipamentos e redes, públicos e privados, porém absolutamente includentes e deliberadamente universais.

Resgatar o SUS como um bem comum a ser protegido requer mobilização e novos arranjos políticos capazes de confrontar a marcha triunfal do privado. À hora é de escolhas essenciais para o futuro da saúde no Brasil. Não desistiremos de seguir lutando por um sistema de saúde moderno e justo, controlado pelos usuários, trabalhadores e agentes públicos, que traga desenvolvimento ao país e tome um lugar de destaque na vida nacional. 
Após terem sido apresentadas alguns momentos relevantes da implementação do SUS, a Seção seguinte tratará da participação social, tendo-se como um dos nortes a afirmação: “[...] é preciso pensar a participação para além dos mecanismos de representação e radicalizar o processo de democratização do SUS, [...] tornando a governamentalidade porosa à ação política do povo" (Nespoli, 2014, p.85).

\subsection{PARTICIPAÇÃO E CONTROLE SOCIAL}

"O controle social foi historicamente exercido pelo Estado sobre a sociedade durante muitos anos, na época da ditadura militar" (Rolim, Cruz e Sampaio, 2013, p. 141).

Na década de 80, a sociedade brasileira, ao mesmo tempo em que vivenciou um processo de democratização política, tentando superar o regime ditatorial a partir de 1964, experimentou também uma profunda e prolongada crise econômica que se prolongou até o início dos anos 2000. A decepção vivenciada com a transição democrática decorreu principalmente do conservadorismo instaurado após 1988, acompanhado da contenção dos ganhos materiais pela massa da população (Bravo e Menezes, 2013).

A organização e a mobilização popular ganham novo corpo na década de 80, no início do século XX, em prol de um Estado democrático e garantidor do acesso universal aos direitos a saúde, colocando em evidência a possibilidade de inversão do controle social. Surge, então, a perspectiva do controle da sociedade civil sobre o Estado, o qual foi incorporado à nova Constituição Federal de 1988 (Conselho Nacional de Saúde, 2006).

Nesse período é importante ressaltar o processo constituinte e a promulgação da Constituição de 1988 que representou, no plano jurídico, não somente a promessa de afirmação e a extensão dos direitos sociais frente à grave crise, mas também as demandas de enfrentamento dos enormes índices de desigualdade social (Bravo e Menezes, 2013).

“A Constituição Federal introduziu avanços e buscou corrigir as históricas injustiças sociais acumuladas secularmente, como a incapacidade de universalizar direitos, tendo em vista a longa tradição de privatizar a coisa pública pelas classes dominantes" (Bravo e Menezes, 2013, p.50). 
É oportuno ressaltar que o controle social refere-se às ações que os cidadãos exercem para monitorar, fiscalizar, avaliar, e de interferir na gestão estatal e não o inverso. Pois, como pode ser de conhecimento geral, também se denominam controle social as ações do Estado para controlar a sociedade, por meio da legislação, do aparato institucional ou mesmo por meio do exercício da força (Rolim, Cruz e Sampaio, 2013).

De acordo com Roncalli (2003) os princípios doutrinários do SUS (a universalidade, a equidade e a integralidade da atenção); e os princípios organizativos (a descentralização, a regionalização, a hierarquização do sistema, a participação e o controle social) expressam as ideias filosóficas que permeiam a criação e a implementação do SUS e personificam o conceito ampliado de saúde e o princípio do direito à saúde.

Esses princípios e diretrizes apontam para a democratização nas ações e serviços de saúde, possibilitando o direito a todos, independente de contribuir ou não para a previdência ou outros pré-requisitos, organizando-se descentralizadamente, de modo a facilitar o acesso e a participação dos cidadãos nas decisões e nos rumos da política de saúde (Aguiar, 2011).

Com a descentralização do poder federal e a democratização das políticas públicas, foram definidos importantes dispositivos, no sentido da criação de um novo pacto federativo, sendo então o município reconhecido como um órgão autônomo da federação, transferindo-se para o âmbito local, novas competências e novos recursos públicos capazes de fortalecer o controle social e a participação da sociedade civil nas decisões políticas (Bravo e Menezes, 2013).

A participação é a garantia constitucional de que a população, por meio de suas entidades representativas, participará do processo de formulação das políticas de saúde, do controle e de sua execução, em diversos níveis, desde o local até o federal. A participação pressupõe a democratização do conhecimento do processo saúde-doença e dos serviços, estimulando-se a comunidade para o efetivo exercício do controle social na gestão do sistema (Brasil, 1990b).

De acordo com Bravo e Menezes (2013), “[...] a concepção de participação popular, tendo como referência os movimentos sociais urbanos, defende o confronto com o Estado, pois este é compreendido, em sentido restrito, como instrumento da classe dominante cuja função seria manter o status quo". 
O controle social sem dúvida representa a corporificação do processo de redemocratização brasileira nas políticas públicas, tendo sido o princípio constitucional mais combatido após a aprovação da Carta Magna, que culminou no seu veto pelo então presidente da República Fernando Collor de Mello, na Lei 8.080, que regulamentaria esse princípio (Roncalli, 2003). Com a Lei 8.142, que resultou do enfrentamento e da articulação da sociedade civil, é que a participação no SUS foi regulamentada. Ainda de acordo com essa última Lei, o SUS conta, em cada esfera de governo, sem quaisquer prejuízos das funções do Poder Legislativo, com as seguintes instâncias colegiadas: a conferência e os conselhos de saúde (Brasil, 1990a). Essa Lei consolida a garantia de um importante espaço público de controle social, mediante a participação da população, de modo a influir na gestão pública em relação à elaboração, ao controle e à fiscalização das políticas públicas (Aguiar, 2011).

Atualmente, os conselhos e conferências de saúde representam os principais espaços para o exercício da participação e do controle social na implementação das políticas de saúde em todas as esferas governamentais (Brasil, 2009a).

Para Bravo e Menezes (2013), os conselhos e conferências de saúde representam uma importante conquista na construção e na ampliação da participação plena e efetiva, idealizada pelo movimento sanitário, apesar de não garantida totalmente.

Conforme mencionado, o controle social é hoje um direito conquistado pela Constituição Federal de 1988. Mais precisamente em relação ao princípio "participação social”, são garantidas duas instâncias formais, que também são espaços de lutas: o conselho de saúde e a conferência de saúde. Destaca-se, entretanto, que estes não são os únicos espaços de ação para o exercício do controle social, embora sejam pilares fundamentais já previstos em lei federal. Os demais mecanismos que também podem ser entendidos como espaços de exercício do controle social, são: o Ministério Público, os órgãos de defesa do consumidor, os meios de comunicação oficiais e os conselhos profissionais (Bravo e Menezes, 2013).

Ainda para Bravo e Menezes (2013, p.57) é necessário:

Envolver os diversos sujeitos sociais preocupados com as políticas públicas, defendendo a ampliação dos direitos sociais e as conquistas obtidas na Constituição de 1988. Ressalta-se como fundamental nesse processo a efetiva participação social da sociedade civil e de mecanismos importantes dessa resistência, que são os conselhos e conferências concebidos como espaço de tensão entre interesses contraditórios na luta por melhores condições de vida. 


\title{
1.2.1 Conselhos de Saúde e Conferências de Saúde
}

De acordo com Guizard e Pinheiro (2006, p.799):

\begin{abstract}
Com o SUS a saúde emerge como questão de cidadania e a participação política como condição de seu exercício, perspectiva assegurada no princípio constitucional de "participação da comunidade" e na Lei Federal nº 8.142 de 28 de dezembro de 1990 que estabelecia os Conselhos e as Conferências de Saúde como espaços de representação institucional. Com eles, se pretendia que o controle social assumisse lugar estratégico na definição e execução das políticas de saúde.
\end{abstract}

Os conselhos de saúde representam instâncias de participação popular de caráter deliberativo no que tange aos rumos das políticas públicas da saúde nas três esferas do governo (municipal, estadual e federal). De acordo com a Lei 8.142, os órgãos colegiados de caráter permanente e deliberativo têm a função não somente de formular estratégias, mas controlar e fiscalizar a execução de políticas de saúde inclusive em relação aos aspectos econômicos e financeiros, devendo suas decisões ser homologadas pelo poder executivo, em cada esfera governamental (Brasil, 1990a).

Segundo Aguiar (2011), a Lei 8.142 não definiu a composição paritária do conselho de saúde. Sua composição foi proposta pela Resolução 33/1992 do Conselho Nacional de Saúde e ratificada posteriormente pela Resolução 333 de 2003 e nas recomendações da $10^{\mathrm{a}}$ e $11^{\mathrm{a}}$ Conferências Nacionais de Saúde. A paridade estabelecida quer dizer que 50\% dos conselheiros devem ser representantes do segmento dos usuários, e os outros $50 \%$ representantes dos demais segmentos, sendo $25 \%$ aos profissionais de saúde e $25 \%$ ao conjunto de prestadores de serviço e governantes (Moreira e Escorel, 2010).

São inquestionáveis os avanços alcançados com a institucionalização dos conselhos de saúde, que ocorreu de forma expressiva nos anos 90 . A conquista desses espaços de participação popular foi um fator decisivo na organização de uma institucionalidade democrática, sem a qual o direito à saúde não poderia efetivar-se como direito de cidadania. Hoje, os conselhos de saúde reúnem milhares de usuários, profissionais e gestores na definição de políticas de saúde em suas localidades. Esse "movimento de democratização das relações da sociedade e o Estado" é um acontecimento inédito na história das políticas sociais no País, colocando a saúde como pioneira na luta pela consolidação dos direitos sociais, formalizando a mais abrangente rede de instâncias participativas (Guizard e Pinheiro, 2006). Apesar dos avanços inegáveis, o funcionamento dos conselhos de saúde ainda representa um grande desafio, pela prática autoritária e clientelista 
que marca a gestão das políticas públicas no Brasil, inclusive no SUS, implicando em dificuldades e obstáculos que comprometem a sua legitimação e eficácia (Aguiar, 2011).

As conferências de saúde foram instituídas, inicialmente, pela Lei 378, de 13/01/1937, que reorganizou o Ministério da Educação e Saúde. Na ocasião, as conferências tinham o papel de promover intercâmbios de informações entre a esfera federal e as esferas estaduais, facilitando ao governo federal o conhecimento das atividades de educação e saúde realizadas em todo o País para fins de controle e regulação de fluxo dos recursos financeiros (Brasil, 2009a).

Segundo Aguiar (2011), as conferências de saúde não se realizavam com a participação popular e apresentavam periodicidades variadas. Diversas conferências ocorreram, mas somente a partir de 1986, na VIII Conferência Nacional de Saúde, passou-se a contar com a participação de representantes de trabalhadores e de organizações da sociedade civil. Também a partir desse evento é que as conferências passaram a ser precedidas por conferências preparatórias em estados e municípios, e seu caráter de espaço público se ampliou. Nas esferas estaduais e municipais, as conferências foram instituídas pela Lei $\mathrm{n}^{\circ} .8142 / 1990$, e começaram a se disseminar. Nessa ocasião, cerca de metade dos municípios brasileiros então existentes e todos os estados e o Distrito Federal realizaram suas conferências (Brasil, 2009a).

A Lei 8.142/90 ainda estabelece que as conferências nacionais de saúde devem ocorrer a cada quatro anos, com representação de vários segmentos (usuários, trabalhadores, gestores e prestadores de serviços) (Aguiar, 2011).

O objetivo das conferências é avaliar e analisar a situação de saúde, além de propor e estabelecer diretrizes, o que significa indicar caminhos para atingir objetivos definidos como fundamentais para que sejam atendidas as necessidades expressas pela população e para que seja alterada a situação de saúde identificada no momento da realização da conferência. Isso envolve debate entre os representantes dos diferentes grupos de interesse (trabalhadores, gestores e prestadores de serviços) e a construção de acordos sobre aspectos que devem ser considerados prioritários na definição das ações do sistema (Brasil, 2009a).

De acordo com Aguiar (2011, p.57), os conselhos de saúde e as conferências de saúde constituem: 
Espaços institucionais importantes para o exercício do controle social, possibilitado à população participar das decisões, propor ações e programas para a resolução dos problemas de saúde, fiscalizar a aplicação dos recursos financeiros e avaliar a qualidade da assistência oferecida pelos serviços do SUS.

Para garantir a participação da sociedade, por meio dos seus representantes legais, as instituições públicas têm o dever de fornecer informações e os conhecimentos necessários à população, de modo a possibilitar-lhe o posicionamento e a tomada de decisão nas questões referentes à política de saúde (Aguiar, 2011).

Por isso defende-se que seja realizada a identificação de necessidades de saúde, que será tratada na Seção a seguir, com o intuito de propor o seu reconhecimento de forma ampliada, considerando que as necessidades são definidas na articulação mais ampla das relações sociais e entendendo-se que a participação social é a instância que possibilita a discussão e o embate das necessidades e dos interesses das classes/grupos sociais e dos grupos organizados da sociedade civil (Campos e Soares, 2013).

\subsection{NECESSIDADES DE SAÚDE}

Na literatura podem ser encontradas diversas definições para o termo "necessidades de saúde". No presente estudo optou-se por adotar a definição proposta por Campos e Soares (2013), desenvolvida à luz da Saúde Coletiva em inflexões sobre os conceitos de necessidades de Agnes Heller e Ricardo Bruno Mendes Gonçalves.

As necessidades de saúde são geradas no contexto das relações que os seres humanos estabelecem entre si para se reproduzirem como sujeitos e como sociedade, ou seja, as necessidades originam-se nas relações de reprodução social em que os sujeitos se desenvolvem como seres sociais (Campos e Soares, 2013).

Nessa perspectiva, as necessidades de saúde são compreendidas como necessidades de reprodução das classes sociais, entendendo-se que os indivíduos ocupam diferentes posições nas relações de reprodução social. Portanto, as necessidades de saúde são distintas e se manifestam nos indivíduos com a especificidade decorrente da inserção de classe, dado que o acesso desses indivíduos ao que os satisfaz é desigual. Sendo assim, necessidades de saúde devem ser interpretadas e respondidas como necessidades sociais, subordinadas às diferenças de classe, no âmbito de instituições sociais (Campos, 2013; Campos e Soares, 2013). 
Portanto, sendo as relações de reprodução social base das necessidades de saúde dos indivíduos, estas são identificadas no:

[...] conjunto de vida social desse indivíduo (formas de produzir, de partilhar e de consumir o que é socialmente produzido - formas de trabalhar e modo de viver - do indivíduo, da família e da classe/grupo social à qual pertencem; relações que o indivíduo, a família e a classe/grupo social à qual pertencem estabelecem com outras pessoas, outros grupos e com as instituições sociais do território; características do território onde vive - ambientais, geográficas e sociais) e também devem ser identificadas nas consequiências dessas formas de trabalhar e de viver no campo biopsíquico dos indivíduos e das famílias - as doenças - nas diferentes classes/grupos sociais aos quais pertencem (Campos, 2009, p. 148).

Campos (2009) destaca categorias empíricas das dimensões que compõem as relações sociais para o reconhecimento de necessidades ampliadas de saúde em indivíduos, famílias, grupos/classes sociais, estabelecendo que essas dimensões articulam-se em circularidade (Figura 1).

Figura 1 - Categorias empíricas das dimensões que compõem as relações sociais para o reconhecimento de necessidades ampliadas de saúde em indivíduos, famílias, grupos/classes sociais, segundo Campos (2009).

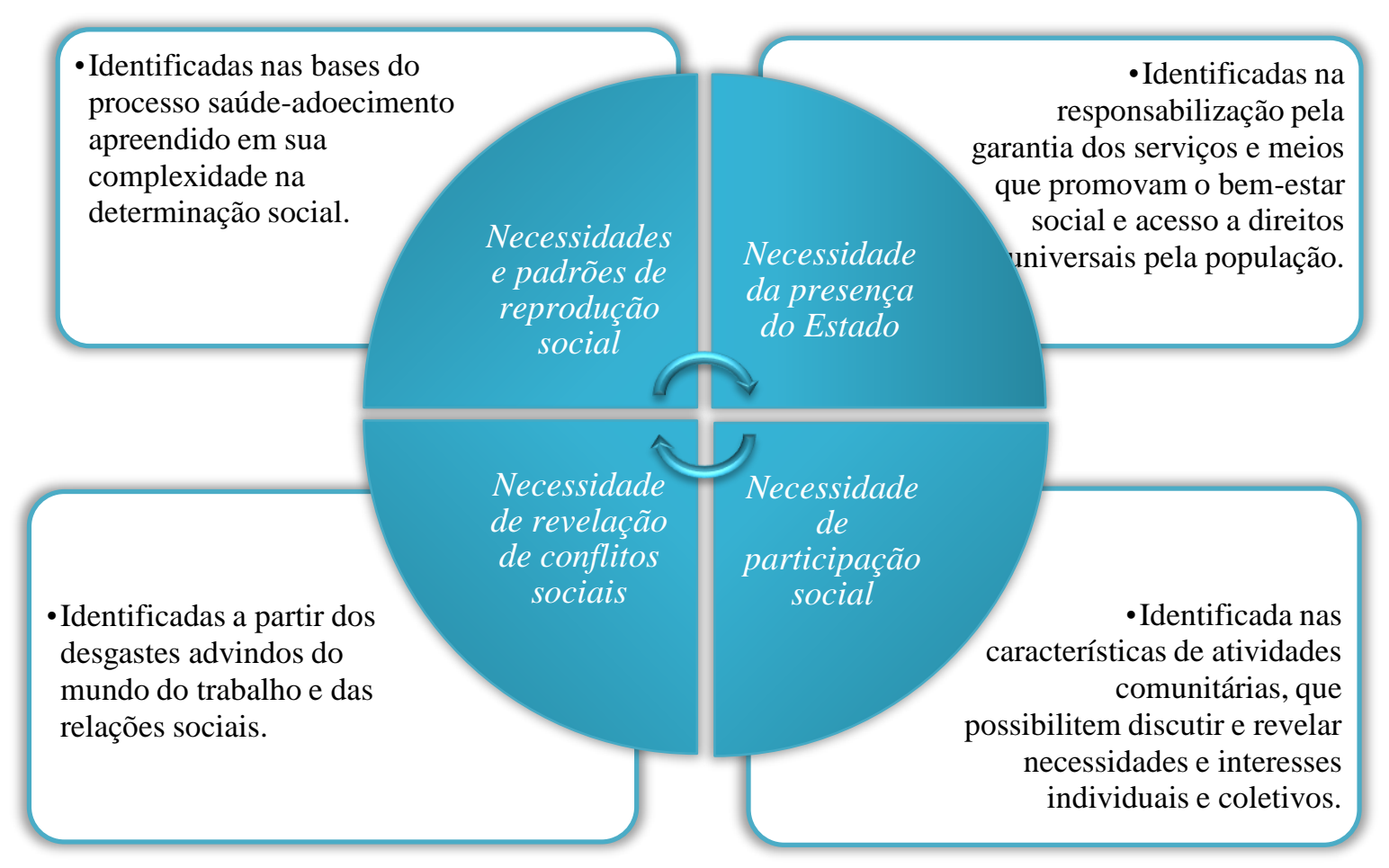

Fonte: Modificado de Campos (2009). 
Atender as necessidades de saúde significa o seu reconhecimento na perspectiva da determinação social do processo saúde-doença, por meio de processos de trabalho, que operem no âmbito dos condicionantes, e nos produtos, ou seja, no agravo/doença, e encaminhar a política pública de saúde na direção do direito universal (Campos, 2013).

O conceito de necessidades de saúde é complexo, amplo e abrangente, vai além da dimensão biológica e cultural, envolvendo, também, as dimensões econômica, ecológica e política que, no modo de produção capitalista, são, em última instância, comandadas pela dimensão econômica (Campos, 2013). As necessidades de saúde têm início no indivíduo, que pode ou não identificá-las; e se expressam no serviço de saúde, onde pode ou não ser decodificadas como necessidade (Campos, 2009).

Com o intuito de identificar as necessidades de saúde, a Saúde Coletiva vem desenvolvendo instrumentos epidemiológicos capazes de captar a reprodução social dos diferentes grupos sociais, sendo objeto da atenção os perfis epidemiológicos de indivíduos e famílias que constituem os grupos sociais. A partir da definição dos perfis de reprodução social, podem se apreendidas as necessidades de reprodução social e as necessidades de presença do Estado no território. Os perfis de saúde-doença indicam as necessidades de saúde referidas a problemas de saúde já instalados (Campos e Soares, 2013).

Na Atenção Básica, os processos de trabalho, de modo geral, têm prescindido do reconhecimento das necessidades de saúde dos usuários, sendo implementados a partir de programas propostos pelo Ministério da Saúde, ainda significativamente voltados ao atendimento e monitoramento de algumas doenças e agravos, justificados por seus resultados técnicos e apresentados como necessidades sociais (Campos, 2013).

As necessidades de saúde têm sido reconhecidas pela população como necessidades de serviços de saúde e são tomadas pelos serviços como sinônimos de problemas de saúde já instalados nos indivíduos, os quais devem ser corrigidos pelas práticas do serviço, primordialmente as fundamentadas nos instrumentos da Clínica (Campos e Bataiero, 2007).

De acordo com Campos (2013), coerente ao arcabouço teórico da Saúde Coletiva, necessidades de saúde são necessidades de reprodução social e para serem captadas e respondidas, convocam a necessidade da presença do Estado, na responsabilização pela garantia dos diversos serviços que promovem o bem-estar social da população e o acesso a direitos universais através dos serviços públicos, quanto mais estiver consciente a necessidade de 
participação política. Essa instância possibilita a discussão e o embate entre as necessidades e os interesses das classes e grupos sociais diversos e os grupos organizados da sociedade civil, revelando os conflitos sociais encobertos pelos desgastes advindos do mundo do trabalho contemporâneo. Tal confronto, se assentado na mobilização popular, possibilita a construção de um projeto emancipatório, no qual estejam postas as necessidades de todos.

Sendo assim, é preciso, além de realizar o diagnóstico do problema trazido pelo indivíduo que procura o serviço de saúde, buscar suas raízes. É necessário investigar as quais potenciais de desgaste e de fortalecimento a pessoa está exposta. Por isso, reconhecer necessidades de saúde de indivíduos requer conhecer necessidades de saúde de suas famílias e classes/grupos sociais; significa identificar as características e as consequências das necessidades relacionadas ao âmbito da reprodução social, à presença do Estado e à participação política (Campos, 2013).

Isto reflete a importância da participação/mobilização social dos indivíduos e grupos sociais. Conforme Campos (2013, p. 11):

[...] na esfera da sociedade civil, os movimentos sociais, tanto as organizações formais como os sindicatos, quanto os grupos comunitários informais, como os comitês, e os movimentos sociais de larga escala, [...] estão associados a modificações positivas na esfera social, política e econômica, que impactam positivamente o aprimoramento das condições de saúde individual e de toda a população.

O pressuposto do presente estudo é que a participação e a mobilização social podem responder de maneira mais ampliada às necessidades de saúde, melhorando a atenção à saúde, na implementação de políticas públicas de saúde, para reduzir a desigualdade social, proporcionando e garantindo o acesso a serviços públicos de saúde de qualidade, concretizando o exercício dos direitos universais. Com essa compreensão, questionou-se:

$\checkmark$ Quais as estratégias de participação social para melhorar a atenção à saúde? 
2 OBJETIVOS 


\section{OBJETIVOS}

\subsection{OBJETIVO GERAL}

$\checkmark$ Elaborar uma síntese de evidências para informar políticas de saúde a respeito da participação social para melhorar a atenção à saúde e como resposta a necessidades de saúde.

\subsection{OBJETIVOS ESPECÍFICOS}

$\checkmark$ Identificar evidências científicas em revisões sistemáticas sobre ações de participação social;

$\checkmark$ Descrever estratégias de participação para melhorar a saúde;

$\checkmark$ Identificar possíveis barreiras para a implementação dessas estratégias. 
3 REVISÃO DA LITERATURA 


\section{REVISÃO DA LITERATURA}

\subsection{PARTICIPAÇÃO SOCIAL}

Para Souza e Krüger (2010), a palavra participação, conforme a época e a conjuntura histórica, pode se apresentar associada a outros termos, como: representação, organização, conscientização, cidadania, direitos sociais, solidariedade e exclusão.

Para Carvalho (1995, p. 24), a "participação tem o sentido de resistir à exclusão social, significa integrar múltiplas formas de ação coletiva voltada para obtenção/ampliação do acesso a bens e serviços de consumo coletivo".

"Esse sentido de participação foi construído no processo de redemocratização e resultou no reconhecimento dos direitos sociais na Carta Constitucional de 1988" (Souza e Krüger, 2010).

No Brasil, desde a Constituição de 1988, a participação é um elemento central nos processos de reforma democrática do Estado, processo que estimulou a participação social na tomada de decisões sobre as políticas públicas (Milani, 2008).

A ideia de participação social na esfera púbica, debatendo, deliberando acerca das questões coletivas que dizem respeito às vidas da coletividade, sempre foi um dos elementos essenciais da democracia e da política (Cocinello, 2008).

A população brasileira viveu um longo período sob um Estado ditatorial, com a centralização das decisões, o tecnicismo e o autoritarismo. Entretanto, durante a década de 1980 ocorreu uma abertura democrática que possibilitou reconhecer a necessidade de revisão do modelo de saúde vigente na época, com propostas no sentido de ampliar a participação social nas decisões e descentralizar a gestão pública em saúde, com vistas a aproximar as decisões do Estado ao cotidiano dos cidadãos brasileiros (Rolim, Cruz e Sampaio, 2013).

No caso do SUS, a participação social deveria significar relações democráticas, em que as decisões políticas fossem divididas e socializadas (Souza e Krüger, 2010). 
A participação social, dentre os princípios do SUS, destaca-se pela relevância social e política, pois se constitui na garantia de que a população participará do processo de formulação e controle das políticas de saúde (Rolim, Cruz e Sampaio, 2013).

O SUS foi a primeira política pública no Brasil a adotar, constitucionalmente, a participação social como um dos seus princípios, reiterando não somente o exercício do controle social nas práticas de saúde, mas também a possibilidade de seu exercício (Rolim, Cruz e Sampaio, 2013).

Para Rolim, Cruz e Sampaio (2013, p. 145):

[...] devemos instituir e proporcionar condições para que a democracia participativa se efetive na prática e que a sociedade civil se torne protagonista nesse processo de controle social em políticas públicas de saúde, pleiteando constituir um Brasil, como referência mundial, em boas práticas na área de fiscalização e controle social em saúde.

De acordo com Cocinello (2008), a participação social no Brasil produziu vários resultados, especialmente voltados para o alargamento, ao menos no plano formal, dos direitos sociais da população brasileira. Algumas conquistas obtidas, por meio da contribuição da sociedade, através da sua atuação e mobilização, são: o acesso gratuito a todos os serviços de saúde, a universalização desse direito social básico, por meio do SUS; benefícios, por meio de um conjunto de programas e ações voltadas para diferentes grupos; o direito de todo trabalhador (a)/rural a uma aposentadoria mínima, mesmo que não tenha contribuído para a previdência social; programas e recursos destinados à agricultura familiar; a inclusão, na agenda política nacional, de temas transversais, essenciais para o combate às desigualdades sociais, tais como, gênero, raça/etnia, juventude, idosos, pessoas com deficiência, entre outros.

A mobilização da sociedade possibilitou por em marcha, de forma inédita, um conjunto de medidas e de instituições governamentais voltadas para a implementação de políticas públicas destinadas a enfrentar as questões decorrentes dos temas transversais supracitados (Cocinello, 2008).

Nesse sentido, será abordado no capítulo a seguir, a compreensão, importância e impacto da mobilização da sociedade por meio dos movimentos sociais, apontando-se a necessidade de que a sociedade civil se torne protagonista e fortaleça o controle social no âmbito do SUS. Cabe salientar que o envolvimento da população na tomada de decisão possibilita avançar na democracia e participação, na medida em que os indivíduos se tornam capazes de compreender 
a realidade vivida, e apontar os problemas e as possíveis soluções relativas às suas necessidades de saúde (Martins et al., 2011).

Embora a capacidade do Estado brasileiro, em implementar políticas públicas e efetivar os direitos previstos no ordenamento jurídico, esteja cada vez mais reduzida, aliado a um País ainda comandado por uma elite política e econômica que se estrutura em torno de privilégios, em que, em grande parte, as leis e os direitos (mesmo garantidos em legislação) são cumpridos parcialmente, excluindo os pobres e indivíduos vulneráveis; a participação social permite romper com esse processo, possibilitando a construção de um arcabouço legal extremamente progressista. "Entretanto, a permanência de relações de poder desiguais e a fragilidade do Estado brasileiro não permitam a sua efetivação. Esse é um novo desafio da participação social: consolidar uma institucionalidade de exigibilidade dos direitos" (Cocinello, 2008).

\subsection{MOVIMENTOS SOCIAIS}

Ao longo da história, os movimentos sociais foram e continuam a ser as alavancas da mudança social, geralmente permeados por crise nas condições de vida que tornam insustentáveis a existência cotidiana para a maioria das pessoas. Em geral, são induzidos por uma profunda desconfiança nas instituições políticas que administram a sociedade (Tostes e Silva, 2015).

Recentemente, estudos sociológicos reconhecem os movimentos sociais como uma forma de luta política organizada que se afirma por mobilizar um grupo ou uma coletividade, construindo discursos, identidade e intervindo para que haja uma mudança social. Dentre alguns movimentos sociais organizados no século XX, destaca-se um importante movimento de mulheres, conforme pode se verificar a seguir (Paula, 2016).

Durante o regime militar na Argentina (1976-1983) emergiu o Movimento das Mães da Praça de Maio, constituído por grupos de mulheres que lutam contra as violações de direitos humanos praticados pelos órgãos de repressão. O movimento, embora surgido de um contexto de cerceamento de liberdade e de autoritarismo, elaborou uma identidade que orientou a atuação para a defesa dos direitos humanos e para a luta contra a ditadura (Paula, 2016).

O aumento de desaparecidos, após a instalação da ditadura militar em 1976, intensificou a peregrinação de mães e familiares ao Ministério do Interior, à polícia e aos organismos de direitos humanos. A falta de respostas satisfatórias das autoridades e de sintonia com os movimentos de denúncia, motivou Azucena Villaflor de De Vicenti a propor a um grupo de 
mães, um encontro na Praça de Maio, em Buenos Aires, no dia 30 de abril de 1977. Elas elaboraram um abaixo-assinado em que pediam "a verdade", como a única maneira de "saber se os seus filhos estão vivos ou mortos e onde estão?” (Paula, 2016).

Essas mulheres em sua maioria, eram mães cujos filhos foram presos e desaparecidos por órgãos da repressão. Azucena Villaflor de De Vicenti, Maria Adela Gard de Antokoletz, María Ponce de Bianco, Beatriz Aicardi de Neuhaus e María Del Rosario Carballe da Cerruti compunham o grupo de 14 mulheres que elegeram o dia 30 de abril para concentrar informações sobre os filhos desaparecidos, na Praça de Maio. A partir dessa data, seguida por mudança do dia dos encontros, para as quintas-feiras, mais mulheres aderiram ao grupo. Dentre elas, estavam mães que se tornariam fundamentais para a constituição e a consolidação do Movimento, como Hebe Pastor de Bonafini, Nora de Cortiñas, María Esther de Careaga, Juana Meller de Pargament e Angélica Sosa Mignone.

Outro exemplo de movimento social pode ser constatado na Espanha. Após mais de 40 anos de ditadura franquista, em 1980, esse país atravessava um processo profundo de reformulação político-econômica. O reestabelecimento e a consolidação das instituições democráticas se deram com forte impulso de partidos políticos que foram se alternando no poder, entre conservadores e socialistas. Na ocasião, mais precisamente em 1986, o país se tornou membro da União Europeia. Nesse cenário, no âmbito econômico, ocorre o chamado "milagre" espanhol, quando se verifica modernização, diversificação e crescimento da economia espanhola. Em parte, isso ocorreu em função dos fundos de coesão da União Europeia. Até os anos 2000, a economia espanhola continuou crescendo e funcionando como estabilizador social para o País, momento em que esse modelo começa a dar os primeiros sinais de esgotamento, através do aumento dos índices de desemprego e endividamento público e privado. Em um contexto caótico, o choque externo, provocado pela crise de 2008, iniciada nos Estados Unidos da América, chega à Europa em 2009. A Espanha aparece dentre os países que mais sofreram o impacto da crise na região: em 2011, o índice de desemprego chegou a $22 \%$ da população, tendo afetado $47 \%$ dos jovens. Como em outras crises, há corrosão social e aumento de um sentimento generalizado de insatisfação em relação às políticas nacionais, bem como falta de confiança em políticos e nas instituições. É nesse plano de crises que surge o Movimento $15 M$, também chamado de Movimento dos Indignados, de forma descentralizada, em diferentes bairros e cidades, com intensa presença de sindicalistas. O Movimento tinha por objetivo explicitar suas críticas à democracia representativa e propor uma nova forma de se fazer 
política, procurando construir meios de participação de acesso aberto. Os Indignados ficaram marcados pelo slogan "Democracia real ya", e o Movimento buscava organizar-se em assembleias e deliberar em espaços públicos, satisfazendo a carência de participação. Não havia lideranças unificadas e as decisões mais importantes eram tomadas através da busca de consenso (Tostes e Silva, 2015).

Ainda mencionado por Tostes e Silva (2015, p. 259), embora a governabilidade não ficasse garantida, na Espanha:

[...] houve condições para o surgimento de uma nova ideologia partidária desde o movimento dos Indignados. Assim, além das vitórias de candidatos de esquerda nas eleições gerais, emergentes dos movimentos sociais obtiveram sucesso na candidatura das principais prefeituras do país nas eleições de 2015 (Barcelona, Madri e Valencia). A institucionalização das demandas dos Indignados incorporadas no novo partido revela uma certa continuidade e sucesso das ruas espanholas.

Outros importantes movimentos sociais, relatados por Navarro (2007), foram os Panteras Negras, constituído por jovens negros que ocuparam partes dos bairros negros em Baltimore (uma cidade com uma população que é 75\% afro-americana), na década de 1960 e início de 1970. Tal Movimento mobilizou jovens negros desempregados, e um dos resultados foi a diminuição drástica da tóxico dependência nesse grupo, estendendo-se à população negra do leste de Baltimore. Outro movimento social que o autor discorre trata do que ocorreu entre mineiros de carvão em Appalachia (Virgínia Ocidental), na década de 1970, quando se mobilizaram e entraram em greve para protestar contra condições insalubres de trabalho, paralisando as operações de minas por vários meses. Isso criou um impasse em que os proprietários das minas e empregadores quase perderam o controle da situação, solicitando ao Exército assumi-las. Nessa mobilização, cada mineiro lutou não apenas individualmente em relação à sua própria saúde, mas coletivamente para melhorar a saúde de todos os mineiros, incluindo outros grupos sociais que compõem a população. O primeiro caso mostra a luta de indivíduos por melhores condições de saúde e, o segundo, além deste motivo, inclui a luta por melhores condições de trabalho.

Para Navarro (2007), empoderaras populações vulneráveis é um componente essencial de um sistema nacional de saúde pública. Conscientizar as pessoas para agir não apenas individualmente, mas também coletivamente para resolver problemas de saúde do coletivo é uma dimensão importante da política nacional de saúde. O autor aponta a necessidade de que 
as intervenções em saúde pública estejam orientadas tanto para os indivíduos, mas também para a coletividade.

Em um dos seus artigos “A Critique of Social Capital”, Navarro (2002) menciona a necessidade de mudança da prática da participação social de modo que se oriente não somente ao âmbito privado, mas que inclua a vida pública, o local de trabalho, a moradia, os encontros que reunem a comunidade, em vários contextos, incluindo o religioso, o cultural ou o político. O objetivo desta chamada para maior participação é recuperar e restabelecer um senso de comunidade.

No Brasil, um dos movimentos sociais de importante impacto é o Movimento dos Trabalhadores Rurais Sem Terra, também conhecido como Movimento dos Sem Terra ou MST, que surgiu da reunião de vários movimentos populares de luta pela terra, os quais promoveram ocupações de terra nos Estados do Rio Grande do Sul, Santa Catarina, Paraná, São Paulo e Mato Grosso do Sul, na primeira metade da década de 80. Oficialmente, o MST foi fundado em janeiro de 1984, na cidade de Cascavel, no Estado do Paraná, por ocasião do Primeiro Encontro Nacional do Movimento dos Trabalhadores Rurais Sem Terra, com 80 representantes de 13 Estados (Comparato, 2001).

Para Caldart (2001), “o MST vem ajudando a recolocar na agenda política brasileira a questão da Reforma Agrária: fazendo a luta pela terra e afirmando, em suas iniciativas, a possibilidade de novas relações sociais, e de um novo projeto de desenvolvimento para o campo, e para o país". Nesta luta coletiva, muitas pessoas perderam suas vidas, seja no dia a dia da violência do latifúndio, seja em massacres mundialmente divulgados, como no caso de Eldorado dos Carajás, no Pará, em 1996.

O MST tem chamado a atenção dos diversos segmentos da sociedade, por apresentar determinadas características que o distinguem, em sua trajetória de movimento social de trabalhadores e trabalhadoras do campo. Cabe ressaltar algumas características deste importante Movimento social: A radicalidade do seu jeito de fazer a luta e os sujeitos que envolve; a multiplicidade de dimensões em que atua; a combinação de formatos organizativos diversos; a capacidade que vem construindo de universalizar, ou de tornar a sociedade como um todo, uma bandeira de luta que nasce de um grupo social específico e de seus interesses sociais imediatos (Caldart, 2001).

Cardart (2001, p. 215) afirma que: 
[...] uma luta social produz e reproduz um movimento sócio cultural, maior do que ela mesma, significa dizer que sua dinâmica encarna, exige e projeta dimensões relacionadas ao modo de vida das pessoas em uma sociedade: mexe com valores, posturas, visão de mundo, tradições, costumes [...], enfim, provoca a reflexão da sociedade sobre si mesma. Por isto as ações de seus sujeitos acabam tendo um sentido histórico e uma influência política que extrapola o seu conteúdo específico, os interesses sociais imediatos e a consciência política que produziu não somente as ações, mas seus próprios sujeitos.

Para Comparato (2001), o MST conquistou um importante espaço político no quadro público atual, contrariando toda uma suposta tradição de passividade e anomia do povo brasileiro, ao conseguir se organizar, ter força política e desafiar os poderes constituídos.

Quanto à participação social na saúde, de acordo com Nespoli (2014, p. 88):

[...] para darmos continuidade à Reforma Sanitária, devemos produzir mais vontade de criação e menos vontade de verdade (ou de poder), para reativar, assim, a participação política, não como um instrumento de governo, mas como uma forma de governo e de afirmação da vida, e o espaço público como uma via de acesso e construção de outros mundos [...] só assim podemos afirmar a saúde como nossa capacidade de luta.

Dando seguimento, a próxima Seção irá tratar das políticas de saúde informadas por evidências.

\subsection{POLÍTICAS DE SAÚDE INFORMADAS POR EVIDÊNCIAS}

Com a implantação do Sistema Único de Saúde (SUS), a situação de saúde no Brasil apresentou significativos avanços, embora ainda persistam desigualdades entre as diversas regiões do País, desigualdades estas que são percebidas até mesmo no interior dos próprios municípios, entre uma área de abrangência e outra.

Destaca-se que o golpe midiático, jurídico e parlamentar, ocorrido em 2016, ocasionou uma ruptura nos princípios e diretrizes no SUS, evidenciando um retrocesso em relação a várias conquistas.

A necessidade premente de superação desse processo, que vem trazendo uma série de consequências, que podem ser inclusive irreparáveis em termos de solução em curto prazo, coloca em pauta o desafio paralelo relacionado à utilização de informações científicas na gestão do SUS (Brasil, 2009b). 
Nesse contexto, é imprescindível a necessidade de aperfeiçoar a capacidade nacional de produção e uso do conhecimento científico para auxiliar os gestores na tomada de decisão e nortear a formulação de políticas públicas em saúde (Brasil, 2009b).

Segundo Oliver et al. (2014), “a lacuna entre pesquisa e prática ou política é frequentemente descrita como um problema".

A tomada de decisão, independente da área, incluindo a área da saúde, é determinada por diversos fatores que influenciam o contexto em que se encontram os tomadores de decisão. A própria ótica dos tomadores de decisão representa uma importante etapa do processo. Mais do que nunca, se reconhece a importância da pesquisa científica, e muitos esforços vêm sendo empreendidos para promover a tomada de decisão informada por evidências (Oliver et al., 2014).

Com o intuito de auxiliar os gestores na melhor tomada de decisão, e nortear a formulação de políticas públicas, a Secretaria de Ciência, Tecnologia e Insumos Estratégicos do Ministério da Saúde, por meio do Departamento de Ciência e Tecnologia (Decit), apresentou projeto à Organização Panamericana da Saúde (OPAS) para a adesão do Brasil à EVIPNet (Evidence-Informed Policy Network). O País compôs, assim, uma rede colaborativa para a elaboração e a implementação de políticas baseadas em evidências científicas (Brasil, 2009a).

A EVIPNet surge, então, em resposta à recomendação originada da reunião de ministros sobre pesquisa em saúde, realizada no México, em novembro de 2004, e referendada na $58^{\mathrm{a}}$ Assembleia Mundial da Saúde em Genebra, em maio de 2005 (Brasil, 2009a). Nessa Assembleia foi discutida a lacuna entre a produção dos resultados de pesquisas e a utilização desse conhecimento nas práticas e na formulação de políticas de saúde. E, como bem apontado no relatório da 58 assembleia Mundial da Saúde, é necessário criar pontes entre o conhecimento e a utilização prática de evidências (Bortoli et al., 2017).

Portanto, o presente estudo se baseia na necessidade de estabelecer mecanismos para melhorar a utilização de resultados de pesquisa no desenvolvimento de sistemas e políticas de saúde pública (Brasil, 2009a). 


\subsubsection{EVIPNet (Evidence-Informed Policy Network) - Rede para Políticas Informadas por Evidências}

A EVIPNet tem como objetivo desenvolver políticas baseadas em evidências científicas; promover o uso sistemático de evidências de pesquisa no processo de elaboração e definição de políticas de saúde, por meio de parcerias entre gestores, representantes do controle social e pesquisadores; difundir o uso compartilhado de conhecimentos científicos, bem como sua aplicação, com formato e linguagem adequados aos gestores de saúde, tanto para a prática clínica, como para a gestão dos sistemas de saúde, a formulação de políticas públicas e a cooperação técnica entre os países participantes (Brasil, 2009b).

Outro importante objetivo da EVIPNet é contribuir para a adoção de métodos e estratégias inovadoras em saúde, atuando, dessa forma, como um espaço de troca de informações e experiências, maximizando a probabilidade de que a evidência obtida na investigação seja usada para configurar novas estratégias para políticas públicas exitosas (Brasil, 2009b).

Há inúmeros desafios associados à redução da lacuna entre o conhecimento e a ação. É importante considerar que os processos de tomada de decisão são complexos e o conhecimento, ou a evidência, são apenas um dos fatores que podem influenciar o processo no qual as políticas são elaboradas. A evidência de pesquisa deve ser articulada com crenças, intuição, hábitos, superstições, tradições, experiências vividas, cultura, interesses pessoais e considerações sobre o cenário político (Bortoli et al., 2017).

Outro aspecto relevante e que se refere à formulação das políticas de saúde, é a tradução do conhecimento para responder e superar muitos problemas levantados pelo descompasso ainda existente entre a teoria e a prática (Chapman, 2016).

A OMS definiu a tradução do conhecimento (knowledge translation) por uma síntese, intercâmbio e aplicação ética do conhecimento científico, como mecanismo de fortalecimento dos sistemas de saúde para melhorar a saúde das pessoas. A tradução do conhecimento tem o objetivo de reduzir a lacuna entre a evidência gerada e a tomada de decisão (tradução do conhecimento para a ação). Inclui uma gama de estratégias capaz de abordar as barreiras para as tomadas de decisões baseadas em evidências (Wichmann et al., 2016). 
A Coordenação da EVIPNet no Brasil é realizada por uma Secretaria Executiva, sediada na Coordenação Geral de Gestão do Conhecimento do Departamento de Ciências e Tecnologia da Secretaria de Ciências, Tecnologia e Insumos Estratégicos do Ministério da Saúde (CGGC/Decit/SCTIE/MS). A EVIPNet pode ser compreendida como uma plataforma de tradução do conhecimento, como mecanismo facilitador da incorporação dos resultados de produção científica para a formulação de políticas de saúde mais efetivas (Wichmann et al., 2016).

No Brasil, ela foi reconhecida, no âmbito do Ministério da Saúde, pela Portaria $\mathrm{n}^{\circ}$ 2.636/GM/MS, de 7 de outubro de 2009 (Ministério da Saúde, 2009), que instituiu e definiu as atribuições de seu conselho consultivo, como uma resposta concreta à convocatória mundial da OMS (Wichmann et al., 2016). Em 12 de setembro de 2013, a composição desse conselho foi atualizada pela Portaria n 2.001/GM/MS (Ministério da Saúde, 2013). Para incluir todas as secretarias do Ministério da Saúde são parceiros: o Ministério da Saúde, a OPAS/Organização Mundial da Saúde (OMS), o Centro Latino Americano e do Caribe de Informação em Ciências da Saúde (Bireme), a Fundação Oswaldo Cruz (Fiocruz), a Associação Brasileira de Saúde Coletiva (Abrasco), a Comissão Intersetorial de Ciência e Tecnologia do Conselho Nacional de Saúde (CICT/CNS), o Conselho Nacional de Secretários de Saúde (Conass) e o Conselho Nacional de Secretarias Municipais de Saúde (Conasems), com possibilidade de integrar outros parceiros (Brasil, 2009b).

Desde a sua criação, em 2007, a EVIPNet Brasil vem contribuindo, no âmbito regional, com a EVIPNet Américas, bem como com a EVIPNet Global, através de diferentes ações, em especial para a disseminação e o intercâmbio das lições aprendidas e estratégias desenvolvidas, por meio da participação em congressos, em reuniões de eventos internacionais, e na organização de oficinas de capacitação (Wichmann et al., 2016).

Nos diálogos deliberativos de políticas, a EVIPNet vem contribuindo para apoiar as Políticas Informadas por Evidências, assim como na promoção do uso da evidência científica nos processos de formulação e implementação de políticas de saúde, na produção de sínteses de evidências e de diálogos de políticas e na articulação nacional das instituições-membros que compõem a rede e instituições parceiras (Wichmann et al., 2016). 
Para capacitar, produzir síntese de evidências para políticas e organizar os diálogos deliberativos utilizam-se as Ferramentas Supporting Policy Relevant Reviews and Trials (Ferramentas SUPPORT) (Wichmann et al., 2016).

Desde 2014, o Instituto de Saúde (IS) vem atuando, no Estado de São Paulo, na difusão das Ferramentas SUPPORT, buscando envolver os gestores na utilização das tomadas de decisões e incentivar o desenvolvimento de Síntese de Evidências por profissionais das diversas instâncias da gestão e da atenção à saúde do Sistema Único de Saúde (SUS) (Gaiotto e Isoyama, 2016).

\subsubsection{Ferramentas Supporting Policy Relevant Reviews and Trials (Ferramentas SUPPORT)}

As ferramentas SUPPORT são endereçadas principalmente aos tomadores de decisão, formuladores de políticas e público que os apoiam. São elaboradas para a utilização em diferentes cenários, abrangendo países de alta a baixa renda. Tais ferramentas compõem o arcabouço e constituem o principal referencial metodológico da EVIPNet (Barreto e Toma, 2016).

Elas são fundamentais aos que queiram o máximo de rigor metodológico em suas sínteses de evidências, e em relação aos produtos de tradução do conhecimento sobre um determinado problema a ser pesquisado. Os documentos que compõem as ferramentas SUPPORT são conhecidos como síntese de evidências para políticas de saúde ou Evidence Brief for Health Policy, em inglês (Barreto e Toma, 2016).

As ferramentas SUPPORT são constituídas por seis etapas, sendo quatro etapas de transferência do conhecimento, EVIPNet: definição das prioridades das políticas de saúde/programas; busca das evidências para elaborar as opções para o enfrentamento do problema; síntese de evidências para políticas de saúde; o diálogo deliberativo e a finalização da síntese de evidências para políticas de saúde. Duas outras etapas de considerações futuras são: a implementação; e o monitoramento e avaliação (Gaiotto, 2016).

As etapas de considerações futuras não serão contempladas no presente projeto. As etapas das ferramentas SUPPORT serão apresentadas a seguir (Figura 2) e constituem as etapas percorridas neste estudo: 
Figura 2 - Etapas da Ferramenta SUPPORT.

\section{Ferramenta SUPPORT}

1. Definir prioridades para Políticas de Saúde

6. Monitoramento e Avaliacão

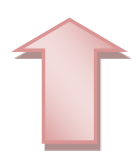

5. Implementação

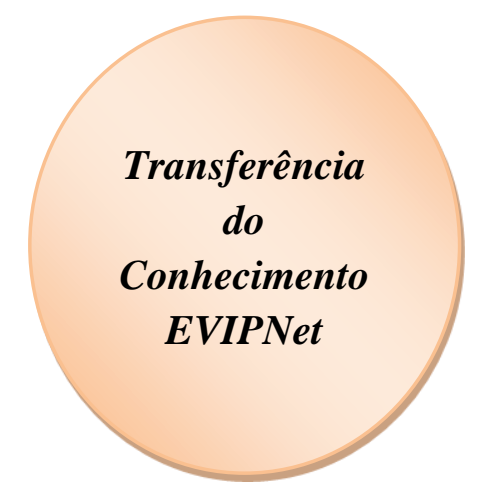

2. Buscar evidências para elaborar opções

3. Síntese de Evidências para Políticas de Saúde

4. Diálogo deliberativo e finalização da Síntese de Evidências para Políticas de Saúde

Fonte: Adaptado de Barreto e Toma, 2016.

\subsubsection{Etapa 1: Definir prioridades para a elaboração dos Programas/Políticas de Saúde}

A definição de prioridades, na elaboração dos programas/políticas de saúde, tem o objetivo de apoiar a formulação de políticas com base em evidências científicas, através de uma abordagem que defina claramente os prazos estabelecidos. As questões de alta prioridade devem ser tratadas de diferentes formas, utilizando-se de abordagem com critérios explícitos para o estabelecimento de prioridades e de abordagem que incorpora uma estratégia de comunicação e um plano de acompanhamento e avaliação (Lavis et al., 2009a). 


\subsubsection{Etapa 2: Busca das Evidências, seleção dos estudos e extração dos dados}

Nesta etapa realiza-se a busca das evidências científicas nas bases de dados selecionadas. Verifica-se a qualidade dos estudos, e, se enquadram na proposta elencada. Para esclarecer as necessidades das evidências é importante identificar revisões sistemáticas, esclarecer problemas e, para definir as opções para o enfrentamento do problema, é relevante descrever os benefícios, prejuízos, custo/relação e custo-benefício de cada opção (Lavis et al., 2009b).

Após localizar as revisões sistemáticas que são utilizadas para a formulação das opções para o enfrentamento do problema é imprescindível avaliar a confiabilidade das evidências para que os formuladores de políticas e demais pessoas possam julgar e considerar a confiança nas mesmas. Diversas ferramentas foram concebidas para avaliar a qualidade das revisões sistemáticas, incluindo a AMSTAR (A MeaSurement Tool to Assess Reviews = Uma Ferramenta de Mensuração para Avaliar Revisões), que indica o grau de confiabilidade das revisões. Em geral, uma alta classificação do AMSTAR sugere que os resultados das revisões são mais confiáveis, no entanto, uma revisão sistemática de boa qualidade não corrige vieses dos estudos primários incluídos. Por outro lado, uma baixa classificação indica que os resultados das revisões são menos confiáveis e que as revisões devem ser cuidadosamente examinadas para que suas principais limitações sejam identificadas (Lewin et al., 2009).

\subsubsection{Etapa 3: Diálogo deliberativo}

Um dos aspectos de maior relevância para a elaboração das políticas/programas de saúde é o diálogo deliberativo, e a orientação e o direcionamento de estratégias para informar e envolver a participação popular no desenvolvimento e na implementação das políticas. A importância de envolver pacientes e cidadãos, em todos os níveis dos sistemas de saúde é amplamente reconhecida (Oxman et al., 2009):

\footnotetext{
Eles são os destinatários finais dos impactos desejáveis e indesejáveis de políticas públicas, e muitos governos e organizações reconheceram o valor de envolvê-los no desenvolvimento de políticas baseadas em evidências. Os benefícios potenciais disso incluem o estabelecimento de políticas que incluam suas ideias e abordem suas preocupações, a melhor implementação de políticas, melhores serviços de saúde e melhor saúde. O envolvimento público pode também ser visto como uma meta por meio do encorajamento da democracia participativa, responsabilidade pública e transparência.
} 
De acordo com os mesmos autores, a Declaração de Alma-Ata da Organização Mundial da Saúde, por exemplo, declara que "[...] as pessoas têm o direito e o dever de participar individualmente e coletivamente no planejamento e na implementação de seu sistema de saúde" (WHO, 1978).

Oxman et al. (2009) sugerem três perguntas que podem ser consideradas com relação às estratégias da participação popular:

1. Quais estratégias podem ser usadas quando se trabalha com a mídia para informar a coletividade sobre o desenvolvimento e a implementação de políticas?

2. Quais estratégias podem ser usadas quando se trabalha com grupos da sociedade civil para informá-los e envolvê-los no desenvolvimento e na implementação de políticas?

3. Quais métodos podem ser usados para envolver as pessoas no desenvolvimento e na implementação de políticas?

\subsubsection{Etapa 4: Elaboração da Síntese de Evidências para Políticas de Saúde}

A elaboração da síntese de evidências busca descrever o problema de política estabelecido como prioritário e apresentar a melhor evidência disponível para definir seu tamanho, natureza e magnitude. As opções para o enfrentamento do problema visam identificar melhores alternativas para enfrentá-lo, através de um número mínimo de opções (no caso do presente estudo, duas opções). É fundamental considerar as potenciais barreiras para a implementação das opções e as estratégias apropriadas ao enfrentamento do problema, bem como a melhor forma de avaliação e monitoramento (Giaiotto, 2016).

Segundo Oxman et al.(2009), “Os efeitos do recurso financeiro (as economias ou custos de uma política ou programa comparado ao status quo ou outra alternativa) precisam ser considerados junto com a saúde e outros impactos quando são feitas avaliações sobre o equilíbrio dos prós e contra de uma política ou programa de saúde”.

\subsubsection{Etapa 5: Considerações para a Implementação}

No que se refere à implementação de evidências, é primordial trabalhar as barreiras e estratégias para o seu enfrentamento, sendo de responsabilidade do Núcleo de Evidências em Saúde, após o diálogo deliberativo, escolher o melhor mecanismo para implementá-las e acrescentar outras barreiras que não foram definidas (Fretheim et al., 2009). 
De acordo com Fretheim et al.(2009), para a definição das barreiras de implementação de cada opção, alguns pontos precisam ser observados: as barreiras potenciais à implementação bem-sucedida de uma nova política; as estratégias que devem ser consideradas ao se planejar a implementação de uma nova política para permitir que ocorram as mudanças comportamentais necessárias entre os usuários do serviço de saúde, cidadãos e profissionais de saúde; e as estratégias que devem ser consideradas ao se planejar a implementação de uma nova política para permitir que ocorram as mudanças organizacionais necessárias e as mudanças necessárias nos sistemas.

É relevante elucidar que alguns fatores podem ser considerados de forma independente ou em combinação, como critérios para definir prioridades na implementação de políticas/programas de saúde: a magnitude do problema, o número de pessoas afetadas, os benefícios, os efeitos adversos, o uso de recursos vinculados aos custos e os impactos sobre a equidade (Fretheim et al., 2009).

\subsubsection{Etapa 6: Monitoramento e Avaliação}

Ambos os termos não são usados consistentemente e podem significar aspectos diferentes para diferentes pessoas. De acordo com Fretheim et al. (2009), o termo monitoramento se refere à descrição do processo sistemático de coleta de dados para fornecer respostas a determinadas perguntas, podendo ser utilizado como monitoramento de desempenho quando o principal foco de uma avaliação é a comparação. Já o termo avaliação é utilizado indistintamente com o termo monitoramento. Entretanto, este último, em geral, sugere um foco mais forte em relação ao alcance dos resultados. O termo avaliação do impacto é frequentemente usado quando um esforço/tentativa é feito para avaliar se as alterações observadas nos resultados podem ser atribuídas a uma determinada política ou programa.

Conforme sugerido por Fretheim et al. (2009), há quatro perguntas que podem ser utilizadas para subsidiar o monitoramento e a avaliação de uma política/programa:

1. É necessário o monitoramento?

2. O que deve ser medido?

3. A avaliação de impacto deve ser feita?

4. Como a avaliação de impacto deve ser feita? 


\title{
4 MÉTODO
}

Conforme apontado na Seção específica, o presente estudo tem por objetivo elaborar uma síntese de evidências para informar políticas de saúde, por meio de resultados de revisões sistemáticas.

As revisões sistemáticas devem ser abrangentes e não tendenciosas na sua preparação. Os critérios adotados devem ser divulgados de modo que outros pesquisadores possam repetir o procedimento. Revisões sistemáticas de boa qualidade são consideradas o melhor nível de evidência para as tomadas de decisão (Galvão e Pereira, 2014).

\begin{abstract}
As revisões sistemáticas são consideradas estudos secundários, que têm nos estudos primários sua fonte de dados. Entende-se por estudos primários os artigos científicos que relatam os resultados de pesquisa em primeira mão. São mais frequentes as revisões sistemáticas de ensaios clínicos randomizados. No entanto, há número crescente de revisões preparadas com base em investigações observacionais, como as de coorte, de caso-controle, transversal, série e relato de casos. Outros delineamentos utilizados são os estudos de avaliação econômica e os qualitativos. Quando se verifica que os estudos primários incluídos em revisão sistemática seguem procedimentos homogêneos, os seus resultados são combinados, utilizando-se técnicas de metanálise (Galvão e Pereira, 2014, p. 183).
\end{abstract}

As revisões sistemáticas surgiram como um novo delineamento de pesquisa, pois se trata de um tipo de investigação focada em questão bem definida, que visa identificar, selecionar, avaliar e sintetizar as evidências relevantes disponíveis, sendo praticada na área da saúde há tempo (Galvão e Pereira, 2014).

As revisões consideradas sistemáticas começaram a surgir na década de 1950. No entanto, o desenvolvimento metodológico dessas pesquisas, na área da saúde, só se consolidou no final da década de 1980. Foram marcos nesse processo, a publicação do livro Effective care during pregnancy and childbirth, na década seguinte, e a criação da Colaboração Cochrane, em Oxford, Reino Unido (Galvão e Pereira, 2014).

As revisões sistemáticas são, cada vez mais, as principais fontes de informação para a formulação de políticas, especialmente no que se refere à descrição dos impactos das opções, podendo ser empreendidas para expor os problemas em uma perspectiva de comparação. Ademais inclui a descrição de possíveis aspectos negativos de uma opção, bem como compreende os significados que os indivíduos ou grupos atribuem a um dado problema, de que 
maneira as opções funcionam, além dos pontos de vista e as experiências das partes interessadas com relação às opções específicas (Lavis, 2009a).

O método proposto para elaborar a presente síntese de evidências científicas foi realizado por meio da ferramenta SUPPORT (Supporting Policy Relevant Reviews and Trials), que constitui o principal referencial metodológico da EVIPNet Brasil, utilizando elementos que subsidiam e promovem a elaboração de políticas públicas de saúde informadas por evidências, com o intuito de proporcionar melhorias nos resultados de saúde.

\subsection{Etapa 1: As prioridades na definição dos programas/políticas}

No início dos trabalhos reuniram-se professoras e discentes do Programa de PósGraduação Mestrado Profissional em Enfermagem na Atenção Primária em Saúde no SUS (Sistema Único de Saúde) MPAPS da Escola de Enfermagem da Universidade de São Paulo USP, e representantes do Instituto de Saúde da Secretaria de Estado da Saúde de São Paulo SP, para a formação de um grupo de evidências no município de São Paulo, com um total de 08 participantes. Como resultado das discussões, um dos temas eleito como prioridade foi Participação Social, entendendo-se que há baixa participação social como resposta às necessidades de saúde.

Subsequentemente, foram realizadas aproximadamente 25 reuniões, algumas destas com cronograma pré-estabelecido e outras em caráter excepcional, de acordo com as demandas do grupo de pesquisadoras.

\subsection{Etapa 2: Busca das evidências e seleção dos estudos}

A busca das evidências foi realizada por dois revisores, de maneira independente, em datas distintas. Nessa fase, ambos identificaram os mesmos estudos. As bases de dados são apresentadas a seguir, a fim de identificar revisões sistemáticas acerca do tema.

A busca teve início com base na pergunta: "Como a participação pode responder às necessidades de saúde". Foi realizada nas seguintes bases:

$\checkmark$ Biblioteca Virtual em Saúde - BVS; 
$\checkmark$ Cochrane Library;

$\checkmark \quad$ Health Systems Evidence - HSE;

$\checkmark \quad$ JBI Data base of Systematic Reviews and Implementation Reports (Joanna Briggs);

$\checkmark$ ProQuest (Applied Social Sciences Index \& Abstracts - ASSIA, Educational Resources Information Center - ERIC, e Sociological Abstracts);

$\checkmark$ Pubmed;

$\checkmark$ Scopus.

A Participação Social revelou-se restrita à atuação individual dos sujeitos, com referência a tratamentos e cuidados de saúde, além de evidenciar-se a atuação da população por meio de ações voltadas para grupos específicos, principalmente com enfoque em enfermidades. Dada a limitação dos achados, tendo em vista um conceito amplo de Participação Social, base conceitual adotada no presente estudo, foi necessário realizar nova busca com base na pergunta: “Quais as estratégias de participação social para melhorar a atenção à saúde?” E nas seguintes bases de dados:

$\checkmark \quad$ Biblioteca Virtual em Saúde - BVS;

$\checkmark \quad$ Health Systems Evidence - HSE

$\checkmark$ ProQuest (Applied Social Sciences Index \& Abstracts - ASSIA, Educational Resources Information Center - ERIC, e Sociological Abstracts).

A segunda busca proporcionou os achados e resultados da presente síntese de evidências.

Os quadros a seguir representam os mecanismos de busca utilizados para cada base de dados, realizados a partir da leitura dos títulos e sem filtros. 
Quadro 1 - Mecanismo de busca junto à Health Systems Evidence - HSE

\begin{tabular}{|c|c|c|c|c|c|c|}
\hline $\begin{array}{c}\text { Base de } \\
\text { dados }\end{array}$ & $\begin{array}{c}\text { Total } \\
\text { artigos }\end{array}$ & Filtros & $\begin{array}{l}\text { Após } \\
\text { filtros }\end{array}$ & Seleção & $\begin{array}{c}\text { Data da } \\
\text { busca }\end{array}$ & Mecanismo \\
\hline $\begin{array}{c}\text { Health } \\
\text { Systems } \\
\text { Evidence } \\
\text { HSE }\end{array}$ & 25 & Sem filtros & - & $\begin{array}{c}01 \\
\text { (duplicado) } \\
\text { na base da } \\
\text { ProQuest }\end{array}$ & 26.09 .2018 & $\begin{array}{l}\text { primary health care AND } \\
\text { ("community participation" OR } \\
\text { "social participation" OR "political } \\
\text { activism" OR "social movement" } \\
\text { OR "social movements" OR } \\
\text { "political participation" OR } \\
\text { "interest groups" OR "social } \\
\text { advocacy" OR "political advocacy" } \\
\text { OR "human rights" OR "rights" OR } \\
\text { "collective action" OR "political } \\
\text { action") }\end{array}$ \\
\hline
\end{tabular}

Quadro 2 - Mecanismo de busca na Biblioteca Virtual de Saúde - BVS

\begin{tabular}{|c|c|c|c|c|c|c|}
\hline $\begin{array}{c}\text { Base de } \\
\text { dados }\end{array}$ & $\begin{array}{c}\text { Total } \\
\text { artigos }\end{array}$ & Filtros & $\begin{array}{l}\text { Após } \\
\text { filtros }\end{array}$ & Seleção & $\begin{array}{c}\text { Data da } \\
\text { busca }\end{array}$ & Mecanismo \\
\hline $\begin{array}{c}\text { Biblioteca } \\
\text { Virtual de } \\
\text { Saúde } \\
\text { BVS }\end{array}$ & 13 & Sem filtro & - & 0 & 27.09 .2018 & $\begin{array}{l}\text { (tw:("primary health care")) AND } \\
\text { (tw:("community participation")) OR } \\
\text { (tw:( "political activism")) OR } \\
\text { (tw:("social participation")) OR } \\
\text { (tw:("social movement")) OR } \\
\text { (tw:("political participation")) OR } \\
\text { (tw:("social movements")) OR } \\
\text { (tw:("interest groups")) OR } \\
\text { (tw:("social advocacy")) OR } \\
\text { (tw:("political advocacy")) OR } \\
\text { (tw:("collective action")) OR } \\
\text { (tw:("political action")) AND } \\
\text { (tw:("systematic review")) }\end{array}$ \\
\hline
\end{tabular}


Quadro 3 - Mecanismo de busca na ProQuest

\begin{tabular}{|c|c|c|c|c|c|c|}
\hline $\begin{array}{c}\text { Base de } \\
\text { dados }\end{array}$ & $\begin{array}{c}\text { Total } \\
\text { artigos }\end{array}$ & Filtros & $\begin{array}{l}\text { Após } \\
\text { filtros }\end{array}$ & Seleção & $\begin{array}{c}\text { Data da } \\
\text { busca }\end{array}$ & Mecanismo \\
\hline ProQuest & 1492 & Sem filtros & - & 28 & 28.09 .18 & $\begin{array}{l}\text { primary health care AND } \\
\text { ("community participation" OR } \\
\text { "social participation" OR "political } \\
\text { activism" OR "social movement" OR } \\
\text { "social movements" OR "political } \\
\text { participation" OR "interest groups" } \\
\text { OR "social advocacy" OR "political } \\
\text { advocacy" OR "human rights" OR } \\
\text { "rights" OR "collective action" OR } \\
\text { "political action") AND "systematic } \\
\text { review" }\end{array}$ \\
\hline
\end{tabular}

Esse processo resultou em um total de 1.530 estudos. A primeira seleção, com a leitura dos títulos, resultou em 28 estudos. A segunda seleção, realizada com a leitura dos resumos, resultou em um total de 10 estudos. Para a leitura completa restaram 10 estudos.

Foi elaborada uma planilha no Excel contendo os 1.530 estudos identificados após busca nas bases de dados. Após exclusão das duplicidades, restaram 1.422 estudos. Seguiu-se a leitura dos títulos por dois pesquisadores, sendo excluídos 1.394 estudos, restando 28 estudos. Os pesquisadores de maneira independente realizaram a leitura dos 28 resumos dos estudos, sendo identificados por cor:

$\checkmark \quad$ Vermelho: excluídos, pois não recortavam o objeto de estudo, apresentavam foco em outras intervenções ou não eram revisões sistemáticas;

$\checkmark$ Amarelo: Dúvida quanto ao estudo, elencado para discussão entre os pesquisadores;

$\checkmark$ Verde: revisão sistemática elegível para compor a síntese de evidência.

Nos casos de dúvidas, um terceiro pesquisador foi consultado para a avaliação dos estudos. Nessa fase foram excluídos 18 estudos, restando 10 revisões sistemáticas para a leitura completa. A partir desta, foram excluídas 04 revisões sistemáticas, sob justificativa que se encontra explicitadas no Apêndice B. Assim, foram elencadas para a extração de dados 06 revisões sistemáticas. 
Os critérios de inclusão dos estudos foram:

1. Revisões sistemáticas;

2. Revisões sistemáticas com resultados conclusivos;

3. Revisões sistemáticas em inglês, espanhol e português;

4. Revisões sistemáticas que recortavam o objeto da síntese.

Os critérios de exclusão utilizados foram:

$\checkmark$ Estudos duplicados;

$\checkmark$ Estudos que abordavam intervenções muito específicas (a exemplo de intervenções específicas a certas enfermidades, sobre o autocuidado, estilos de vida, entre outras);

$\checkmark$ Estudos com focos diversos, que não recortavam o objeto da síntese.

$\mathrm{Na}$ etapa seguinte do estudo foi realizada a leitura completa dos estudos, que resultaram na base para a definição das opções (Figura 3).

Para a utilização das revisões sistemáticas, com o objetivo de fundamentar a tomada de decisão, os formuladores de políticas precisam julgar a confiabilidade das evidências científicas. $\mathrm{O}$ uso de processos sistemáticos e transparentes pode contribuir para uma melhor acurácia, evitando a inclusão de erros e vieses em seus julgamentos. Em relação a esse aspecto cabe ressaltar que um processo sistemático e transparente também possibilita que outras partes interessadas, incluindo a população, compreendam e avaliem os julgamentos (Lewin, 2009).

Segundo Lavis (2009a), de acordo com a Ferramenta SUPPORT, avaliar a qualidade das evidências requer um minucioso e rigoroso julgamento sobre a certeza de que uma estimativa de efeito é correta. Sendo assim, cada revisão sistemática utilizada na elaboração da síntese de evidências foi avaliada utilizando o instrumento AMSTAR, que avalia a qualidade em uma escala de 0 a 11 pontos, de tal forma que os escores de 0 a 3 pontos correspondem a uma baixa qualidade, de 4 a 7 pontos correspondem a revisões de moderada qualidade e de 8 a 11 pontos, as revisões de alta qualidade (Beverley, 2007). “A ferramenta é composta por 11 itens e possui boa validade de face e conteúdo para mensurar a qualidade metodológica das revisões sistemáticas" (Beverley, 2007, p. 1). Os 11 itens do AMSTAR são apresentados sob a forma de questionamentos, contemplando as seguintes respostas: "Sim" (descrição completa do item), "Não" (não descrito, ou parcialmente descrito), "Não é possível responder" (não há 
informações suficientes para responder o questionamento) ou "Não se aplica". A pontuação total é calculada somando um ponto para cada "sim” atribuído (Shea et al., 2007).

Assim, a qualidade das revisões sistemáticas foi realizada através do instrumento AMSTAR (Assessing the Methodological Quality of Systematic Reviews) (Anexo I), não sendo utilizada pontuação limite para a exclusão dos estudos. O instrumento foi aplicado de maneira independente por duas pesquisadoras. Após sua aplicação, as pesquisadoras entraram num consenso quanto às pontuações atribuídas nos critérios em que houve divergências.

Figura 3 - Diagrama de Fluxo da Seleção dos Estudos, segundo o PRISMA. São Paulo, 2019.

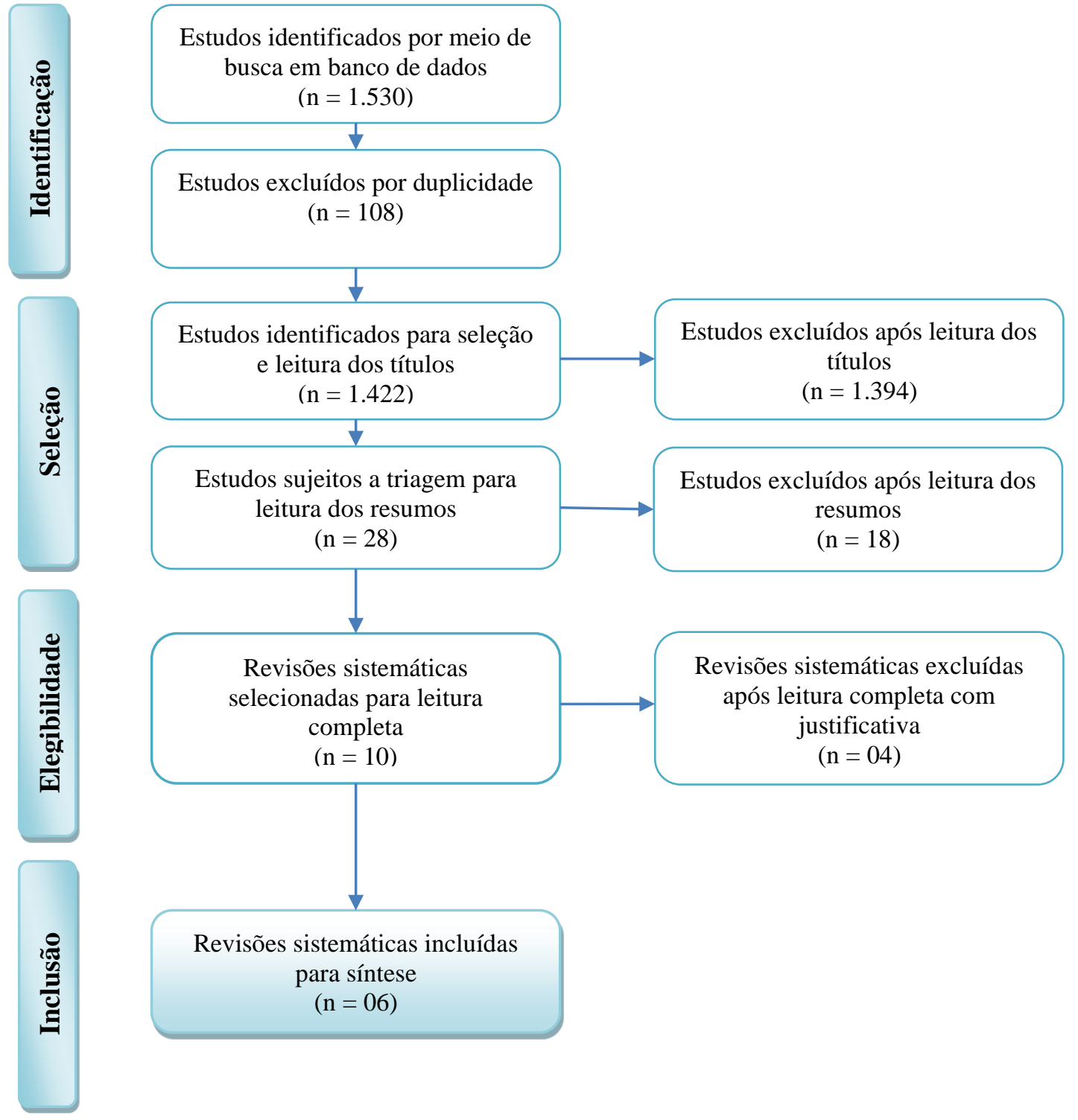

Fonte: Adaptado de Moher et al., (2009). 


\subsection{Etapa 2: Extração dos dados}

Para a extração dos dados foi elaborado um quadro (Anexo II), apresentado em seu formato original com 09 colunas. Para melhor estratificação optou-se pela inserção de mais 14 colunas, contemplando ao todo 24 colunas com os principais achados de cada revisão sistemática. As colunas referem-se especificamente à:

$1^{\mathrm{a}}$ : autores de cada revisão;

$2^{\mathrm{a}}$ : título das revisões;

$3^{\mathrm{a}}$ : ano de publicação das revisões;

$4^{\mathrm{a}}$ : objetivos das revisões;

$5^{\text {a. }}$ principais elementos das pesquisas com base no resumo das revisões;

$6^{\mathrm{a}}$ : focos primários de cada revisão

$7^{\text {a: }}$ focos secundários de cada revisão;

$8^{\mathrm{a}}$ a $12^{\mathrm{a}}$ : principais dados das revisões (o que é, para que, para quem, quem entrega e quem desenvolve);

$13^{\mathrm{a}}$ : principais elementos das revisões (características das revisões sistemáticas: quantos estudos, tipos de estudo, tipo de intervenção, características da população, número de participantes);

$14^{\mathrm{a}}$ : contexto da revisão (resultados primários e secundários, conclusão, benefícios, danos potenciais, custo efetividade, incertezas - viés, implementação ou teste em algum lugar);

$15^{\mathrm{a}}$ : considerações sobre a implementação;

$16^{\mathrm{a}}$ : considerações sobre equidade;

$17^{\mathrm{a}}$ : lacunas do conhecimento;

$18^{\mathrm{a}}$ : caracterização da qualidade metodológica das revisões, com base no escore, após aplicação do instrumento AMSTAR;

$19^{\mathrm{a}}$ : proporção de estudos que incluíram a população-alvo; 
$20^{\mathrm{a}}$ : proporção de estudos realizados em países de baixa renda (Low Income Countries LI), média baixa renda (Low Middle Income - LMI), média alta renda, que inclui o Brasil (Upper Middle Income - UMI) e alta renda (High Income - HI);

$21^{\mathrm{a}}$ : proporção das revisões com foco no problema estabelecido como prioritário da síntese de evidências científicas;

$22^{\mathrm{a}}$ : observações, espaço opcional para descrever dúvidas ou considerações sobre o artigo, finalizando o processo;

$23^{\mathrm{a}}$ : aceite para inserção do estudo para o desenvolvimento da opção;

24ㄹ último ano de busca das revisões sistemáticas incluídas na síntese para a formação das opções.

Esse quadro (Anexo II) foi base para a construção das opções. Em decorrência, foi elaborado outro Quadro 9 e 10 (contendo as opções) no qual são apresentados os seguintes conteúdos: principais evidências quanto aos benefícios da intervenção, quaisquer danos ou riscos da intervenção, quando disponíveis; incertezas em relação aos benefícios, potenciais danos e riscos, com o intuito de que o monitoramento e avaliação sejam garantidos caso ocorra a escolha da opção; avaliação da implementação da intervenção em locais diferentes; e avaliação dos sujeitos sociais envolvidos na opção em relação à sua efetividade.

Também foram observadas as potenciais barreiras na implementação das opções (relacionadas ao paciente/indivíduo, trabalhadores da saúde e organização do sistema de saúde). Esse processo foi descrito e sistematizado de maneira transparente no transcorrer do estudo.

Comentários adicionais sobre a equidade foram arrolados com a finalidade de elucidar possíveis implicações da adoção das diferentes opções sugeridas (Gaiotto, 2016).

Caso ocorra a escolha de uma opção pelos gestores e/ou tomadores de decisão é necessário que o monitoramento e a avaliação sejam assegurados, bem como a avaliação da implementação da intervenção em outros locais, assim como a avaliação dos sujeitos sociais envolvidos na opção em relação à efetividade. 


\subsection{Etapa 3: Definição das Opções para Informar Política}

A definição das opções para informar políticas foi realizada por meio dos dados extraídos das revisões sistemáticas selecionadas, com o agrupamento de intervenções semelhantes implementadas em outros países. Esse processo está descrito e sistematizado de forma transparente, possibilitando a compreensão e o acesso aos que se interessarem pelo presente estudo.

As discussões para a definição das opções foram centradas em torno da participação social, necessidades de saúde e as estratégias de participação social para melhorar a atenção à saúde. Para a escolha das opções, foram avaliadas as 06 revisões sistemáticas selecionadas após leitura completa. As revisões foram classificadas, segundo: Participação Social por meio de comitês e abordagens participativas; e Participação Social como estratégia para melhorar o cuidado e indicadores de saúde.

\subsection{Etapa 4: Elaboração da Síntese de Evidências}

A síntese de evidências buscou descrever o problema de política estabelecido como prioridade, disponibilizando a melhor evidência disponível, as opções identificadas para enfrentar o problema, a descrição de como as evidências relevantes tem impactos potenciais para os grupos ou cenários desfavorecidos ou estratégias que reduzam a desigualdade nas opções, a descrição sobre as possíveis barreiras, as estratégias de implementações e sugestões de monitoramento e avaliação para as opções identificadas nos quatro níveis do sistema de saúde: usuários do sistema de saúde, trabalhadores de saúde, organização dos serviços e sistema de saúde.

Os resultados dessa síntese de evidências são apresentados a seguir. 


\section{RESULTADOS}

\subsection{AS OPÇÕES}

\subsubsection{Opção 1 - Participação social para melhorar a atenção à saúde (por meio de comitês e abordagens participativas)}

Para a descrição da Opção 1 foram utilizadas duas revisões sistemáticas, sendo uma de alta qualidade e a outra de moderada qualidade metodológica. A estratégia dessa Opção referese ao estabelecimento de comitês e formas de abordagens participativas. A Opção retrata evidências de que os comitês podem ser eficazes para a melhoria da qualidade e da cobertura da atenção à saúde, bem como produzir impacto nos resultados de saúde. Os comitês são apontados pelos autores como uma solução simples para os problemas de serviços de saúde precários. As abordagens participativas representam um impacto notável sobre a saúde e os resultados sociais.

O Quadro 4 apresenta um resumo das evidências para a Opção 1, quanto aos benefícios, danos potenciais, custos e/ou custo-efetividade, incertezas em relação aos benefícios/danos, principais elementos da opção; necessidades de adaptações e percepções e experiências das partes interessadas (grupos de interesse).

Quadro 4 - Descrição da síntese das evidências relevantes para a Opção 1.

continua

\begin{tabular}{|c|l|}
\hline \multicolumn{1}{|c|}{ Categorias } & \multicolumn{1}{c|}{ Síntese das evidências relevantes } \\
\hline Benefícios & $\begin{array}{l}\text { McCoy, Hall e Ridge (2011) conduziram uma revisão sistemática sobre a eficácia de } \\
\text { Cômites de Unidades de Saúde (Health Facility Committees - HFCs) em que há } \\
\text { representação comunitária, em países de baixa e média renda. Os HFCs constituem } \\
\text { estratégia para o fortalecimento dos sistemas de saúde e para a obtenção de resultados } \\
\text { de saúde. Nessa revisão são apresentados os resultados de quatro estudos que fornecem } \\
\text { fortes evidências de que os HFCs podem impactar positivamente na qualidade do } \\
\text { atendimento prestado e nos resultados de saúde, desde que sejam projetados e } \\
\text { implementados com cuidado. Os HFCs podem ser muito eficazes, com evidências de } \\
\text { que a participação da comunidade pode resultar em beneficios para a saúde e maior } \\
\text { aceitação dos serviços, como aumento pela procura e utilização dos serviços de saúde } \\
\text { em casos de agravos, cuidado no pré-natal, aumento na cobertura de imunização, redução } \\
\text { dos casos de diarréia, aumento do uso de soro de reidratação oral, aumento do quadro de }\end{array}$ \\
\hline
\end{tabular}


Quadro 4 - Descrição da síntese das evidências relevantes para a Opção 1.

continuação

\begin{tabular}{|c|c|}
\hline Categorias & Síntese das evidências relevantes \\
\hline Benefícios & $\begin{array}{l}\text { pessoal, e redução de absenteísmo profissional. Os HFCs também ajudam a melhorar os } \\
\text { indicadores de saúde da comunidade (conhecimento em saúde, práticas de saúde, } \\
\text { conhecimento e uso dos serviços de saúde); estabelecendo ligaçães mais fortes entre a } \\
\text { comunidade e os trabalhadores de saúde. Esses achados corroboram relatos de que os } \\
\text { comitês ajudam a avaliar as necessidades da comunidade; contribuem para a construção } \\
\text { de abrigos para mães, tanques de água e sanitários; apóiam a mobilização de açães de } \\
\text { promoção à saúde e o acompanhamento de cuidados da comunidade; além de obter } \\
\text { recursos para a saúde da comunidade. } \\
\text { Evans, Pilkington e McEachran (2010) realizaram uma revisão sistemática que avaliou } \\
\text { o impacto de abordagens participativas sobre resultados sociais e de saúde, realizadas } \\
\text { por unidades de saúde pública do Reino Unido. Sete estudos preencheram os critérios de } \\
\text { inclusão para o desenvolvimento da pesquisa, retratando eficácia em estratégias de saúde } \\
\text { pública como: consultas; planejamento estratégico da saúde com participação da } \\
\text { comunidade; intervenção comunitária no tabagismo; fórum para troca de informações, } \\
\text { facilitando o envolvimento da população local na tomada de decisões e no } \\
\text { desenvolvimento de projetos para saúde. Há um forte e marcante compromisso político } \\
\text { do Reino Unido em relação à participação na saúde e à orientação sobre como envolver } \\
\text { as comunidades. A participação é um processo de extrema relevância para a população, } \\
\text { conforme apontam os próprios documentos de política e livros-texto, devendo ser uma } \\
\text { importante premissa refletida na literatura de pesquisa em saúde pública. }\end{array}$ \\
\hline Danos potenciais & $\begin{array}{l}\text { As revisões sistemáticas de McCoy, Hall e Ridge (2011) e Evans, Pilkington e } \\
\text { McEachran (2010) não apontam danos potenciais. }\end{array}$ \\
\hline $\begin{array}{l}\text { Custos e/ou custo- } \\
\text { efetividade em } \\
\text { relação à situação } \\
\text { atual }\end{array}$ & $\begin{array}{l}\text { McCoy, Hall e Ridge (2011) relatam que, com a instalação dos comitês, um dos estudos } \\
\text { evidenciou aumento na geração de receita. A melhoria dos sistemas financeiros reduziu } \\
\text { a fuga de fundos e a má gestão financeira, ao mesmo tempo em que as barreiras de custo } \\
\text { para os mais pobres foram reduzidas através da implementação de isenções e } \\
\text { deferimentos de taxas. Também verificou-se redução de } 35 \% \text { na probabilidade de morte } \\
\text { de uma criança menor de } 5 \text { anos. O custo de evitar a morte de uma criança menor de } 5 \\
\text { anos é de aproximadamente US } \$ 300 \text { (McCoy, Hall e Ridge,2011). } \\
\text { Na revisão sistemática de Evans, Pilkington e McEachran (2010) não foram encontrados } \\
\text { estudos específicos sobre custos e/ou custo-efetividade nas abordagens participativas } \\
\text { realizadas pelas unidades de saúde pública do Reino Unido e seu impacto nos resultados } \\
\text { sociais e de saúde. }\end{array}$ \\
\hline $\begin{array}{l}\text { Incertezas } \\
\text { relacionadas aos } \\
\text { benefícios, danos } \\
\text { potenciais, de } \\
\text { modo que o } \\
\text { monitoramento e a } \\
\text { avaliação possam } \\
\text { se concentrar em } \\
\text { áreas específicas } \\
\text { de incerteza, caso } \\
\text { a opção seja } \\
\text { implementada }\end{array}$ & $\begin{array}{l}\text { McCoy, Hall e Ridge (2011) descrevem um impacto positivo em relação à efetividade } \\
\text { dos HFCs, mas o pequeno número de estudos sugere a possibilidade de viés de análise, } \\
\text { explicada pela onipresença dos HFCs. Os autores também apontam que a participação } \\
\text { da comunidade é um processo social complexo e específico, com variações de uma } \\
\text { comunidade para outra, ou seja, o que funciona em uma comunidade pode não funcionar } \\
\text { da mesma maneira ou ter o mesmo efeito em outra comunidade. } \\
\text { Evans, Pilkington e McEachran (2010) destacam uma lacuna aparentemente extensa } \\
\text { entre a retórica e a realidade da participação e as abordagens participativas nas unidades } \\
\text { de saúde pública do Reino Unido. Para os autores, se o Serviço Nacional de Saúde } \\
\text { (National Health Service - NHS) do Reino Unido e seus parceiros de fato valorizarem a } \\
\text { prática baseada em evidências no que diz respeito ao envolvimento da comunidade para } \\
\text { melhorar a saúde, pesquisadores de saúde pública e financiadores de pesquisa necessitam } \\
\text { priorizar estudos para avaliar a qualidade e a eficácia das abordagens participativas em } \\
\text { unidades de saúde pública do NHS, na prática. }\end{array}$ \\
\hline
\end{tabular}


Quadro 4 - Descrição da síntese das evidências relevantes para a Opção 1.

continuação

\begin{tabular}{|c|c|}
\hline Categorias & Síntese das evidências relevantes \\
\hline $\begin{array}{l}\text { Principais } \\
\text { elementos da } \\
\text { opção (se já foi } \\
\text { implementada/ } \\
\text { testada em outro } \\
\text { local) }\end{array}$ & 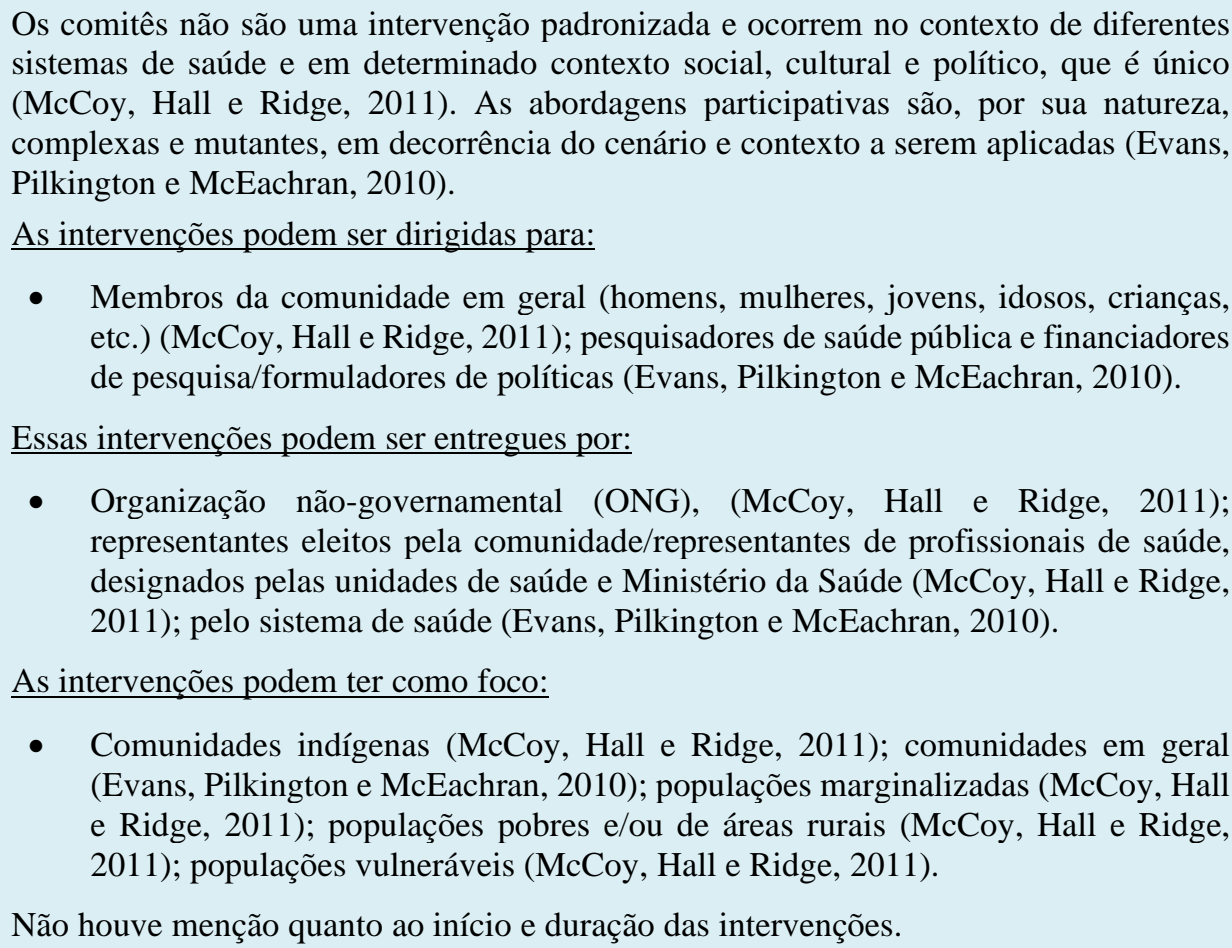 \\
\hline $\begin{array}{l}\text { Percepções e } \\
\text { experiências das } \\
\text { partes } \\
\text { interessadas } \\
\text { (grupos de } \\
\text { interesse) }\end{array}$ & $\begin{array}{l}\text { De acordo com McCoy, Hall e Ridge (2011), o estudo de Iwami e Petchey, conduzido } \\
\text { no Peru, mostra melhor satisfação do usuário e acesso para os mais pobres, em parte, em } \\
\text { decorrência de divulgação e isenção de taxas para usuários pobres e famílias. Vários } \\
\text { estudos retratam que os políticos locais ou elites reivindicam controle sobre os comitês } \\
\text { para benefício próprio. } \\
\text { Nenhum estudo utilizado na revisão sistemática de Evans, Pilkington e McEachran } \\
\text { (2010) mencionou as percepções e experiências das partes interessadas (grupos de } \\
\text { interesse). }\end{array}$ \\
\hline
\end{tabular}

conclusão

\subsubsection{Opção 2 - Participação social para o aprimoramento de indicadores de saúde}

Para o desenvolvimento da Opção 2 foram utilizadas quatro revisões sistemáticas de moderada qualidade metodológica. As possibilidades de intervenções para essa Opção referemse às estratégias de participação para aprimorar os indicadores de saúde, possibilitando iniciativas de participação social que podem contribuir para processos positivos, no âmbito social e da saúde, construindo a capacidade da comunidade, assegurando a eficácia e a sustentabilidade da intervenção na saúde comunitária. A participação social é o princípio fundamental da atenção primária à saúde, com benefícios amplamente reconhecidos, incluindo melhores resultados de saúde, gestão do cuidado, aceitabilidade, qualidade e capacidade de 
resposta. A melhoria dos indicadores de saúde pode ser ocorrer pelo fortalecimento e engajamento de individuos, familias, grupos/classes socais. A participação social é um processo onde as pessoas estão ativamente envolvidas na determinação de prioridades e na implementação de soluções, com impacto direto nos resultados e indicadores de saúde.

\section{O Quadro 5 apresenta um resumo das evidências para a Opção 2 quanto os benefícios,}

danos potenciais, custos e/ou custo-efetividade, incertezas em relação aos benefícios/danos, principais elementos da opção; necessidades de adaptações e percepções e experiências das partes interessadas (grupos de interesse).

Quadro 5 - Descrição da síntese das evidências relevantes para a Opção 2

continua

\begin{tabular}{|c|c|}
\hline Categorias & Síntese das evidências relevantes \\
\hline Benefícios & 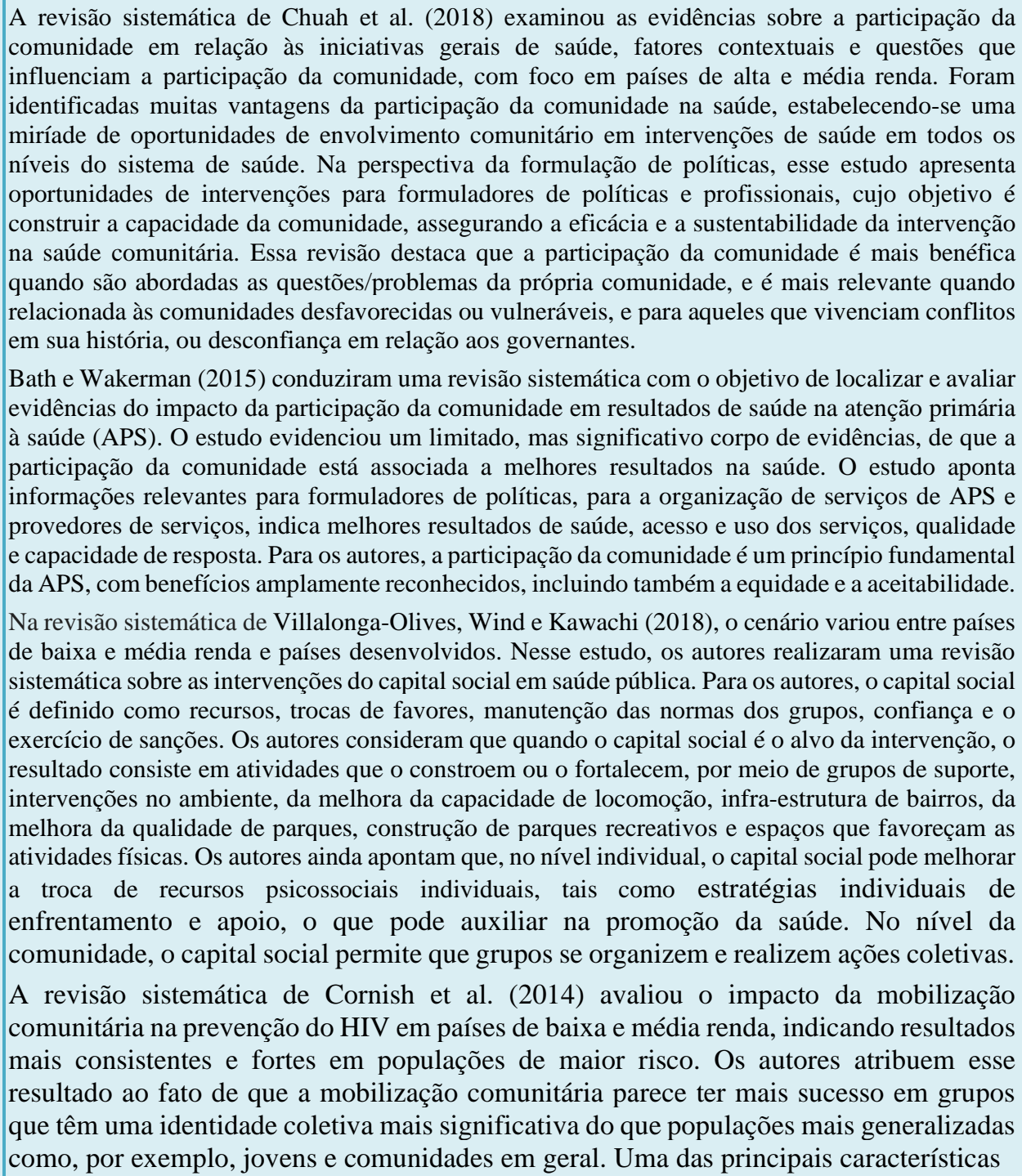 \\
\hline
\end{tabular}


Quadro 5 - Descrição da síntese das evidências relevantes para a Opção 2

continuação

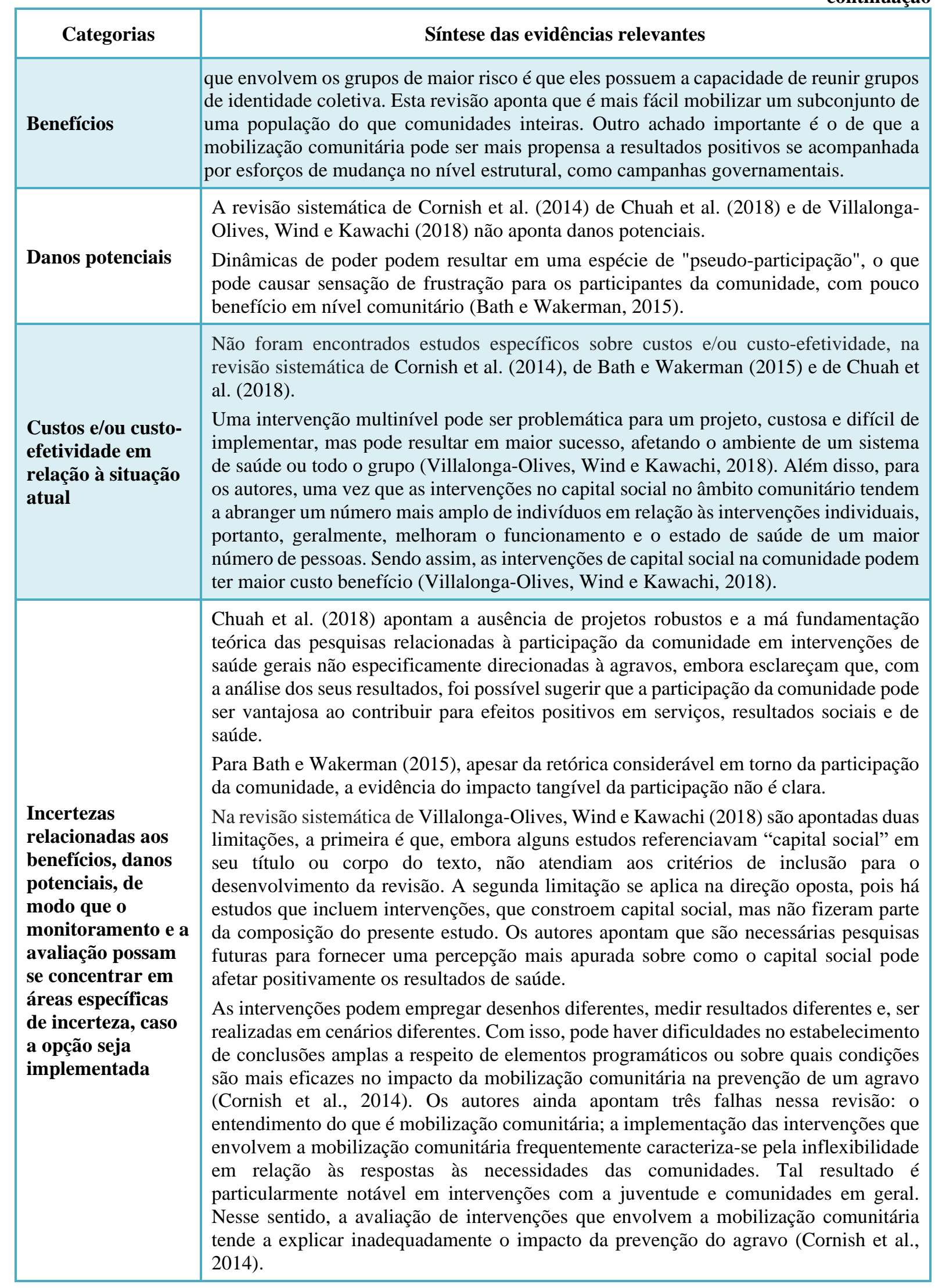


Quadro 5 - Descrição da síntese das evidências relevantes para a Opção 2

continuação

\begin{tabular}{|c|c|}
\hline Categorias & Síntese das evidências relevantes \\
\hline $\begin{array}{l}\text { Principais } \\
\text { elementos da } \\
\text { opção (se já foi } \\
\text { implementada/ } \\
\text { testada em outro } \\
\text { local) }\end{array}$ & 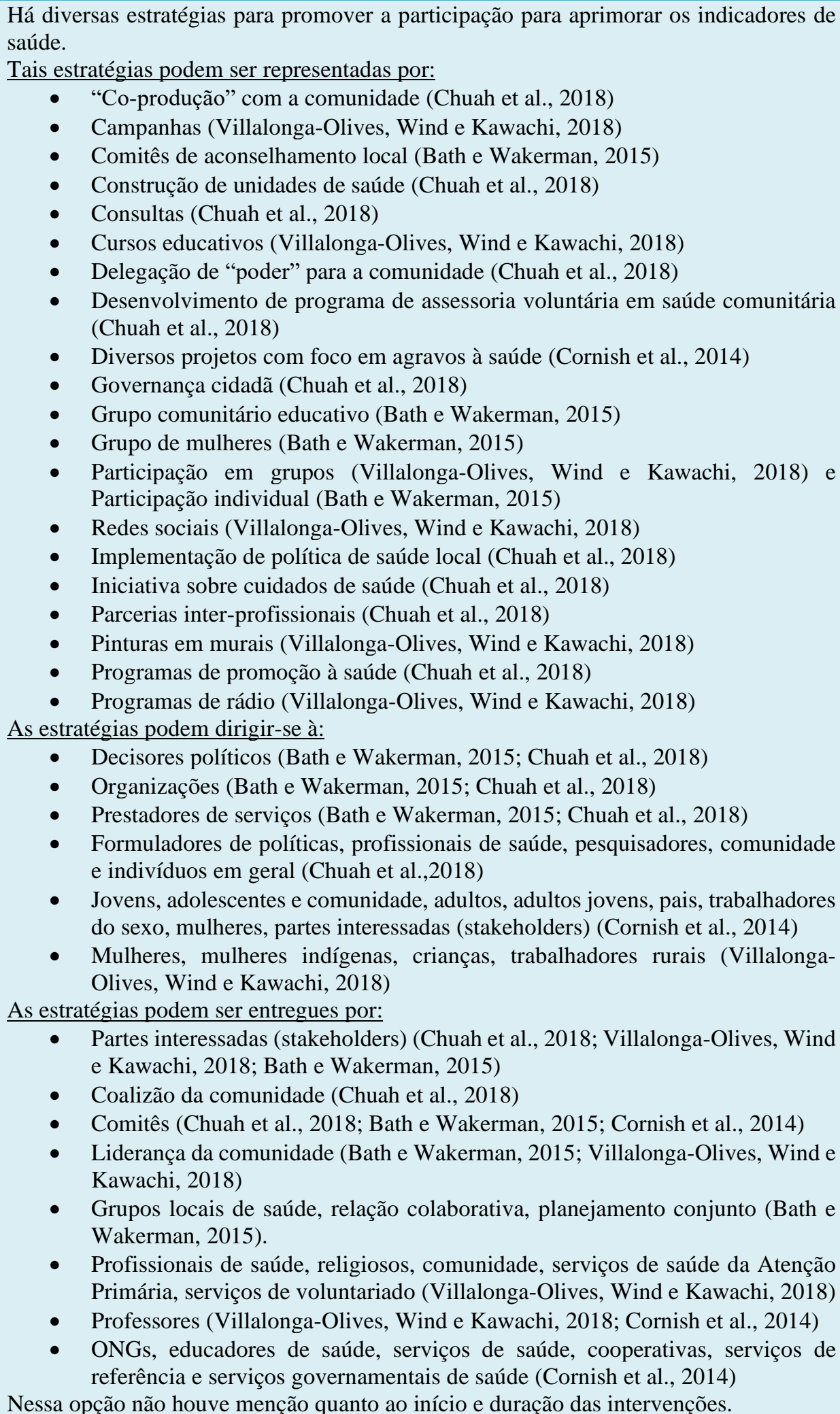 \\
\hline
\end{tabular}


Quadro 5 - Descrição da síntese das evidências relevantes para a Opção 2

continuação

\begin{tabular}{|l|l|}
\hline \multicolumn{1}{|c|}{ Categorias } & \multicolumn{1}{c|}{ Síntese das evidências relevantes } \\
\hline \multirow{5}{*}{$\begin{array}{l}\text { Percepções e } \\
\text { experiências das } \\
\text { partes } \\
\text { interessadas } \\
\text { (grupos de } \\
\text { interesse) }\end{array}$} & $\begin{array}{l}\text { Um estudo qualitativo no Canadá explorou as opiniões das partes interessadas sobre } \\
\text { governança cidadã, verificando-se, que não sugeriam capacitação a respeito de seu papel } \\
\text { específico. Os sujeitos designados expressaram que não estavam esclarecidos sobre seus } \\
\text { papéis, a autoridade era limitada na tomada de decisões e sentiam-se restringidos pelo } \\
\text { sistema. Em outro estudo, no Reino Unido, sobre os processos de envolvimento público } \\
\text { na atenção primária à saúde e tomada de decisão no Reino Unido, os participantes } \\
\text { expressaram que os esforços de agências estatutárias para engajar a população } \\
\text { dependiam da compatibilidade de agendas (Chuah et al., 2018). } \\
\text { Mulheres de meia-idade no Japão expressaram satisfação em relação ao acesso à } \\
\text { informação sobre saúde, em um estudo realizado nesse país e que avaliou um programa } \\
\text { de promoção da saúde para mulheres de meia-idade. Outro estudo, transversal, que } \\
\text { examinou quatro parcerias inter-profissionais de comunidade na África do Sul } \\
\text { evidenciou satisfação com o desenvolvimento de parcerias colaborativas com agências, } \\
\text { enquanto os agentes de saúde comunitários experimentaram vários benefícios pessoais, } \\
\text { incluindo a sensação de ser reconhecido por outras pessoas da comunidade. Também } \\
\text { revelou que as parcerias interprofissionais melhoraram o acesso aos serviços de saúde } \\
\text { (Chuah et al., 2018). } \\
\text { Nenhum estudo utilizado na revisão sistemática de Cornish et al. (2014), de Bath e } \\
\text { Wakerman (2015) e de Villalonga-Olives, Wind e Kawachi (2018) mencionou as } \\
\text { percepções e experiências das partes interessadas (grupos de interesse). }\end{array}$ \\
\hline
\end{tabular}

conclusão

\subsection{CONSIDERAÇÕES SOBRE EQUIDADE NAS OPÇÕES}

A equidade é um dos princípios doutrinários do SUS. Deve ser considerada, na implementação de políticas públicas, para reduzir as desigualdades. Embora, em tese, todas as pessoas tenham direito à saúde, segundo a Constituição Federal, as pessoas não são iguais, pertencem a distintos grupos sociais e, diferentes necessidades.

Reduzir iniquidades requer redistribuição de recursos financeiros e materiais, intervenções precoces, integradas e intersetoriais que abranjam a participação e contem com mobilização social, sendo a participação um importante elemento de gestão e componente fundamental para elaboração das políticas públicas. Por isso, a implementação das opções de políticas deve levar em consideração que a participação social pode ser afetada de forma desproporcional em determinados grupos da sociedade. Assim, os benefícios, danos e custos das opções podem variar entre os diferentes grupos. Uma forma de identificar que os grupos necessitam de especial atenção, a fim de que as opções não aumentem as desigualdades populacionais, é o uso do acrônimo PROGRESS-Plus (https://methods.cochrane.org/equity/ 
projects/evidence-equity/progress-plus),formado pelas primeiras letras (em inglês), que podem ser utilizadas para descrever grupos: $\mathrm{P}$ (placeofresidence); R (racelethnicity/culture/language); $\mathrm{O}$ (occupation); G (gender/sex); R (religion); E (education); S (socioeconomic status) e S (social capital). A partir dessa classificação é possível priorizar diferentes opções de políticas em função da população-alvo. As opções podem adotar uma abordagem universal ou focal, voltadas, por exemplo, às comunidades que vivem em contextos de maior vulnerabilidade.

A abordagem da Equidade com referência às opções que emergiram neste presente estudo apresenta-se a seguir, e decorre da utilização do PROGRESS-Plus.

\subsubsection{Opção 1 - Participação social para melhorar a atenção à saúde (comitês e abordagens participativas)}

Os comitês e as abordagens participativas podem constituir espaços de participação como maneira de fortalecimento da democracia, buscando reconhecer as necessidades de saúde.

De acordo com Avritzer (2009, p. 82), “os espaços de participação constituem uma grande rede entre indivíduos, suas organizações, movimentos sociais e o Estado.” É por meio da participação que a sociedade civil forma opiniões, as expressam. Através da participação é possível o fortalecimento do poder coletivo e, assim interferir no cotidiano político, e de reprodução social.

Essa opção visa estabelecer estratégias de participação para melhorar a gestão de saúde através da estruturação de comitês e de abordagens participativas, sendo importante considerar a desigualdade social que impõe hierarquias sociais, políticas e/ou econômicas, que interferem no grau de participação daqueles que ocupam posições mais baixas na sociedade. Também é importante considerar que a representação deve não se restringir à esfera masculina, incluindo variadas identidades de gênero. Comitês devem representar os interesses de toda a comunidade, de todos os estratos sociais, garantindo diversidade econômica e cultural. Deve ser viabilizada a participação plena da comunidade na decisão sobre os cuidados de saúde (Avritzer, 2009).

O orçamento participativo pode permitir o envolvimento da comunidade no planejamento do desenvolvimento local com benefícios positivos para a saúde. O apoio de políticos locais também pode influenciar positivamente e fortalecer os comitês (McCoy, Hall e Ridge, 2011). 
Evans, Pilkington e McEachran (2010) reiteram que as desigualdades de poder entre as comunidades e os profissionais de saúde, restrições de tempo e recursos, e o ceticismo da comunidade podem influenciar as decisões organizacionais no campo da saúde.

É importante considerar a posição de desvantagem dos membros da sociedade civil nos comitês, materializada na disponibilidade de tempo, transporte, assessoria institucional, enfim toda infraestrutura que geralmente está presente em processos de participação social (Coelho, 2012). Fundamentalmente a ser considerada é a desigual correlação de forças em relação ao poder que coloca os grupos sociais mais fragilizados no processo de produção e de reprodução social em desvantagem em relação aos seus direitos sociais, inclusive em relação à saúde.

Em relação a isso há que se considerar que o Estado [capitalista - destaque da autora do presente estudo] responde de modo mais favorável aos grupos mais organizados e familiarizados à burocracia pública, favorecendo-os, sendo assim os grupos menos organizados e mais vulneráveis podem ser menos favorecidos e, como consequência, ampliar as desigualdades sociais (Coelho, 2012).

Também há que ponderar que o engajamento na comunidade parece estabelecer-se na população adulta, não em adolescentes e adultos jovens, portanto, ao pensar em intervenções que envolvam a participação social, a maneira de como desenvolver o protagonismo juvenil merece destaque (Talò, Mannarini e Rochira, 2014).

Nesse sentido, o alcance da equidade não é estabelecido de forma instantânea, apenas com a formação de comitês. A abordagem em que se pretende a participação não se limita a um desejo, mas efetiva-se na prática do cotidiano, na transparência, na exposição de motivos, na defesa de respostas às necessidades, construindo-se coletivamente.

\subsubsection{Opção 2 - Participação social para o aprimoramento de indicadores de saúde}

Os indicadores de saúde podem representar o grau de crescimento e desenvolvimento de um país/nação. Para as estratégias exitosas nos resultados ou nos indicadores de saúde cabe ressaltar os dois princípios do SUS, interligados à equidade. Um deles é a Universalização, que coloca a saúde como direito de cidadania, de todas as pessoas e cabe ao Estado assegurá-lo. O acesso às ações e serviços deve ser garantido a todos, independentemente de sexo, raça, ocupação, ou quaisquer outras características sociais ou pessoais. Já o princípio da Integralidade 
prevê a articulação e interlocução da saúde com outras políticas públicas, assegurando uma atuação intersetorial, com repercussão na saúde e qualidade de vida de todos.

A participação da comunidade em intervenções de saúde pode ocorrer de múltiplas formas, em diferentes níveis do sistema de saúde, e em uma ou mais fases de um ciclo de intervenção. À luz dessa diversidade é importante considerar a participação da comunidade como um processo complexo que reflita o contexto em que ocorre, e de quais forças sociais, tais como as relações de poder, devem ser consideradas (Chuah et al., 2018).

Para Chuah et al. (2018), a participação da comunidade pode ser moldada por influências políticas, padrões das relações inter e intra organizacionais, envolvimento das pessoas no planejamento da atenção primária à saúde, conflitos e divisões políticas, fatores sociais, culturais e de gênero, educação precária, desemprego, pobreza e comunidades desfavorecidas. Tais questões tem impacto na implementação de intervenções, no estabelecimento de prioridades, na (in)satisfação em relação à participação, na (des)valorização, na exclusão social e nas desigualdades. Para isso é essencial que as intervenções sejam sensíveis às necessidades das pessoas e dos grupos sociais, abertas à compreensão e ao entendimento autêntico a respeito das necessidades da comunidade, além de conhecer as suas características, o que podem garantir o sucesso nas iniciativas de participação da comunidade.

Bath e Wakerman (2015) estabelecem que, para evitar as desigualdades é importante considerar os fatores sociais, econômicos e políticos, que incidem nas populações, especialmente nas vulneráveis, por exemplo, a população indígena.

Estratégias focadas em populações com maior vulnerabilidade, que contemplem o envolvimento das partes interessadas, as relações comunitárias, o engajamento ativo da comunidade, a exemplo de eventos, do diálogo deliberativo no interior da comunidade, de negociações entre as partes interessadas e a esfera pública, a avaliação do contexto sóciopolítico, e a advocacia entre funcionários do governo e líderes comunitários podem proporcionar ações coletivas com potencial de trazer benefícios e intervenções mais inclusivas e efetivas para a comunidade (Cornish et al., 2014).

O gênero pode ser uma questão a ser debatida quando se pretende a participação da comunidade, uma vez que, tradicional e historicamente, as mulheres podem ter suas habilidades subestimadas, desvalorizadas e percebidas como amplamente invencíveis no cenário masculino dominante. Deve-se dar atenção especial às mulheres, ao envolvê-las em atividades de 
participação, uma vez que, em geral, são responsabilizadas pelas demandas das atividades da vida diária como, por exemplo, o cuidado dos filhos (Chuah et al., 2018), as atividades domésticas e sua participação no mercado de trabalho, dentre outras questões, podem limitar e comprometer a sua participação e, como consequência, não ter suas necessidades reconhecidas e atendidas.

O status socioeconômico de uma comunidade também pode ser um fator que influencia o nível de participação. As comunidades desfavorecidas, menos equipadas e organizadas podem ser menos propensas a participar, o que contribui para ter mais necessidade de intervenções de saúde (Chuah et al., 2018).

\subsection{CONSIDERAÇÕES SOBRE A IMPLEMENTAÇÃO DAS OPÇÕES}

Considerando as opções em relação à participação social, para informar políticas de saúde, como estratégias para a redução de inequidades e para melhorar a atenção à saúde, as opções apresentadas não requerem, necessariamente ser implementadas de forma conjunta e/ou completa, ou seja, em sua integralidade. O sucesso da implementação das opções deve ser condicionado às particularidades e viabilidade local, inserindo-se na governabilidade da tomada de decisão, independentemente da dimensão do sistema de saúde (nacional, regional ou local), bem como do tipo de financiamento, das parcerias, da política de saúde, das características da população, dos trabalhadores de saúde, de seus representantes políticos, dentre outros. Também é importante considerar as barreiras, fragilidades e potencialidades da APS na implementação das opções, especialmente as localizadas no campo da organização do sistema e dos serviços, bem como as localizadas no campo da cultura e das representações sociais dos usuários e dos trabalhadores de saúde.

A participação da comunidade é necessária para melhorar a coordenação, o monitoramento, a implementação, a segurança e a qualidade das intervenções de saúde e dos sistemas como um todo. Desta maneira, a comunidade pode estar envolvida na formulação de estruturas e modelos que podem ser usados para guiar a implementação de intervenções de saúde, que são relevantes para o contexto sócio-cultural da comunidade, desempenhando um papel fundamental na garantia da sustentabilidade de um programa de saúde (Chuah et al., 2018). A seguir nos quadros 6 e 7 estão descritas barreiras potenciais para a implementação de 
cada uma das duas opções, separadas em quatro níveis: usuários do sistema de saúde (pacientes/tomadores de decisão/população em geral), trabalhadores de saúde, organização dos serviços e sistemas de saúde.

Quadro 6 - Implementação da opção 1 e implicações em relação aos usuários, trabalhadores de saúde e para a organização dos serviços e sistemas de saúde.

continua

\begin{tabular}{|c|c|}
\hline Níveis & $\begin{array}{c}\text { Opção } 1 \text { - Participação social para melhorar a atenção à saúde, por meio de } \\
\text { comitês e de abordagens participativas }\end{array}$ \\
\hline $\begin{array}{l}\text { Usuários do } \\
\text { sistema de saúde }\end{array}$ & $\begin{array}{l}\text { Os usuários do sistema de saúde precisam compreender a importância da participação e } \\
\text { da mobilização social na formulação das políticas públicas de saúde. A clareza e o } \\
\text { consenso sobre os papéis e funções são relevantes e influenciam a eficácia dos comitês } \\
\text { e das abordagens participativas (desenvolvimento dos comitês; engajamento, } \\
\text { envolvimento e participação da comunidade). A presença de mulheres é de extrema } \\
\text { importância, a fim de superar as fortes tradições do patriarcado, assim como a presença } \\
\text { de pessoas em vulnerabilidade e de segmentos sociais menos favorecidos. Essas são } \\
\text { algumas das premissas para o reconhecimento das necessidades de saúde (McCoy, Hall } \\
\text { e Ridge, 2011). } \\
\text { Considerar o ceticismo da comunidade, a respeito de sua influência nas decisões } \\
\text { profissionais/organizacionais (Evans, Pilkington e McEachran, 2010). }\end{array}$ \\
\hline $\begin{array}{l}\text { Trabalhadores de } \\
\text { saúde }\end{array}$ & $\begin{array}{l}\text { As desigualdades de poder entre os indivíduos e os profissionais, a linguagem técnica } \\
\text { profissional, as restrições de tempo e de recursos podem influenciar as decisões } \\
\text { profissionais/organizacionais (humanos, materiais, financeiros) (Evans, Pilkington e } \\
\text { McEachran, 2010). } \\
\text { As atitudes, habilidades e percepções dos trabalhadores sobre a participação e a } \\
\text { mobilização social podem influenciar o funcionamento dos comitês. Dessa maneira, } \\
\text { atitudes negativas de profissionais de saúde e funcionários do governo em relação à } \\
\text { competência e a capacidade dos membros da comunidade podelimitar o trabalho efetivo } \\
\text { dos comitês. Os trabalhadores de saúde devem reconhecer, identificar e mediar as } \\
\text { dificuldades da população. A equipe de saúde deve entender a saúde para além da } \\
\text { perpectivado agravo, adotando postura, responsiva, cooperativa, disposta a solucionar } \\
\text { conflitos e a mediar interesses políticos locais (Gohn, 2013). }\end{array}$ \\
\hline $\begin{array}{l}\text { Organização de } \\
\text { serviços de saúde }\end{array}$ & $\begin{array}{l}\text { É preciso haver participação e mobilização comunitária mais ampla e a sociedade civil } \\
\text { precisa ser fortalecida para contrabalançar a influência negativa das políticas locais, } \\
\text { proporcionando espaços para movimentos e diálogos deliberativos, a fim de que se possa } \\
\text { reconhecer e responder às necessidades de saúde da população. O inadequado } \\
\text { funcionamento de unidades de saúde e recursos insuficientes pode estar associado ao } \\
\text { inadequado funcionamento dos comitês. Os comitês e as unidades de saúde devem } \\
\text { trabalhar sinergicamente entre si. Barreiras sociais e econômicas à participação podem } \\
\text { ser agravadas por barreiras físicas, associadas às características topográficas, distância } \\
\text { percorrida e disponibilidade de locomação (McCoy, Hall e Ridge, 2011). }\end{array}$ \\
\hline
\end{tabular}


Quadro 6 - Implementação da opção 1 e implicações em relação aos usuários, trabalhadores de saúde e para a organização dos serviços e sistemas de saúde.

continuação

\begin{tabular}{|c|c|}
\hline Níveis & $\begin{array}{c}\text { Opção } 1 \text { - Participação social para melhorar a atenção à saúde, por meio de } \\
\text { comitês e de abordagens participativas }\end{array}$ \\
\hline Sistemas de saúde & $\begin{array}{l}\text { As hierarquias econômicas, sociais e culturais podem evitar que os comitês de saúde } \\
\text { representem adequadamente os interesses de toda a comunidade e impeçam sua } \\
\text { participação plena da comunidade na prestação de cuidados primários de saúde. A } \\
\text { dinâmica política local pode afetar o funcionamento dos comitês. Para McCoy, Hall e } \\
\text { Ridge (2011), o orçamento participativo, facilitado pelo governo local, permite o } \\
\text { envolvimento da comunidade no planejamento local com benefícios positivos para a } \\
\text { saúde. O apoio político local pode influenciar positivamente e ajudar a fortalecer os } \\
\text { comitês. Os formuladores de políticas de saúde também podem ser importantes para } \\
\text { influenciar as abordagens do governo para a participação social. Os sistemas de saúde } \\
\text { com cultura de gestão encorajam a transparência e a abertura necessária para apoiar a } \\
\text { eficácia dos comitês. Para que os comitês sejam eficazes, precisam ser apoiados e } \\
\text { nutridos pelo sistema de saúde. O funcionamento dos comitês está claramente ligado ao } \\
\text { funcionamento do sistema de atenção primária à saúde como um todo. }\end{array}$ \\
\hline
\end{tabular}

conclusão

Quadro 7 - Implementação da opção 2 e implicações em relação aos usuários, trabalhadores de saúde e para a organização dos serviços e sistemas de saúde.

continua

\begin{tabular}{|c|l|}
\hline Níveis & Opção 2 - Participação social para o aprimoramento de indicadores de saúde \\
\hline $\begin{array}{l}\text { Comunidades desfavorecidas muitas vezes enfrentam marginalização e desigualdades, } \\
\text { portanto, é essencial que as intervenções sejam mais sensíveis às suas necessidades. } \\
\text { As crenças, situações complexas de vida, a dinâmica familiar, a necessidade de renda, } \\
\text { podem limitar a participação social em intervenções de políticas públicas (Atienzo, } \\
\text { Kaltenthaler e Baxter, 2016). Um facilitador apontado por esses autores diz respeito à } \\
\text { motivação dos usuários, descrita como uma importante possibilidade para melhorar o } \\
\text { acesso a e a dar continuidade à participação social em intervenções de políticas públicas. }\end{array}$ \\
$\begin{array}{l}\text { Usuários do } \\
\text { sistema de saúde }\end{array}$ & $\begin{array}{l}\text { Atienzo, Kaltenthaler e Baxter (2016) identificaram algumas barreiras relativas às } \\
\text { pessoas que implementam intervenções, bem como em relação a outras partes } \\
\text { interessadas, formuladores de políticas e tomadores de decisão, tais como gerentes de } \\
\text { programas, líderes comunitários, ou autoridades de saúde e decisores políticos. Tais } \\
\text { barreiras referem-se à evidência de que a implementação de uma intervenção pode ser } \\
\text { adversamente afetada pelos tomadores de decisão ou pelas partes interessadas que } \\
\text { podem ter baixo compromisso com uma determinada intervenção. Por outro lado, três } \\
\text { facilitadores para o processo de implementação, foram identificados: } \\
\text { habilidades/conhecimentos dos tomadores de decisão; tomadores de decisão ou partes } \\
\text { interessadas que entendem a relevância de uma intervenção, isto é, sensibilizados em } \\
\text { relação à intervenção, envolvem-se mais intensamente nas atividades e na operação das } \\
\text { intervençães. Além disso, o desejo de contribuir para a comunidade facilita o } \\
\text { envolvimento de atores-chave. }\end{array}$ \\
\hline
\end{tabular}


Quadro 7 - Implementação da opção 2 e implicações em relação aos usuários, trabalhadores de saúde e para a organização dos serviços e sistemas de saúde.

continuação

\begin{tabular}{|c|c|}
\hline Níveis & Opção 2 - Participação social para o aprimoramento de indicadores de saúde \\
\hline $\begin{array}{l}\text { Trabalhadores de } \\
\text { saúde }\end{array}$ & $\begin{array}{l}\text { O desequilíbrio de poder entre os profissionais de saúde ou funcionários do governo e } \\
\text { participantes da comunidade pode desestabilizar o processo participativo. Em } \\
\text { consequência, grupos marginalizados podem estar mal representados (Bath e Wakerman, } \\
\text { 2015). } \\
\text { Habilidades de liderança que promovem visibilidade, abertura, legitimidade, clareza e } \\
\text { comunicação são cruciais para a participação da comunidade e produzem resultados } \\
\text { positivos. Proporcionar treinamento a líderes comunitários para compreensão de } \\
\text { modelos, processos lógicos de programas e seu papel, são fundamentais para facilitar o } \\
\text { envolvimento da comunidade (Chuah et al., 2018). } \\
\text { A evidência apontada pelos autores Atienzo, Kaltenthaler e Baxter (2016) é a limitada } \\
\text { habilidade de alguns profissionais em gerenciar situações de conflitos emocionais, } \\
\text { decorrentes de atividades com a população. Outra barreira identificada foi a dificuldade } \\
\text { dos profissionais em mediar interesses e conflitos de organizações e questões políticas } \\
\text { locais. Por fim, a última barreira referente aos trabalhadores de saúde, relaciona-se à } \\
\text { comunicação ineficiente entre diferentes atores-chave envolvidos e as crenças negativas } \\
\text { dos profissionais ou outras partes interessadas sobre uma abordagem ou eficácia } \\
\text { poderiam limitar o seu envolvimento nas atividades de uma intervenção. }\end{array}$ \\
\hline $\begin{array}{l}\text { Organização de } \\
\text { serviços de saúde }\end{array}$ & $\begin{array}{l}\text { A falta de materiais ou instalações, a falta de clareza ou inconsistência nas intervenções, } \\
\text { a falta de recursos e restrições de tempo, o número limitado de participantes da } \\
\text { comunidade, supervisão inadequada das intervenções que podem ser percebidas como } \\
\text { uma sobrecarga de trabalho e a necessidade de submeter relatórios quanto à } \\
\text { implementação das intervenções podem limitar a implantação das intervenções (Atienzo, } \\
\text { Kaltenthaler e Baxter, 2016). } \\
\text { O envolvimento de diferentes setores, instituições, organizações ou partes interessadas } \\
\text { (ou seja, colaboração multidisciplinar e/ou multissetorial) é importante. A participação } \\
\text { de líderes comunitários e autoridades de saúde tem papel relevante na implantação de } \\
\text { intervenções e no desempenho bem-sucedido de atividades devido à experiência } \\
\text { diversificada dos envolvidos. A supervisão é essencial para permitir a implementação } \\
\text { das intervenções, assim como a boa comunicação, e a obtenção de financiamento de } \\
\text { instituições privadas e públicas, incluindo governos, uma vez que garantem a } \\
\text { disponibilidade de materiais e instalações. Todos esses, além de rigorosos padrões } \\
\text { metodológicos facilitam a implementação de intervenções (Atienzo, Kaltenthaler e } \\
\text { Baxter, 2016). }\end{array}$ \\
\hline Sistemas de saúde & $\begin{array}{l}\text { É necessário que os formuladores de políticas fortaleçam o apoio às políticas e } \\
\text { financiamento para mecanismos participativos na APS. } \\
\text { Muitos tomadores de decisão e formuladores de políticas enfrentam a necessidade de } \\
\text { tomar decisões sobre a manutenção da qualidade metodológica da intervenção, o que } \\
\text { significa abordagem mais dispensiosa e limitada; assim, por vezes, opta-se por uma } \\
\text { abordagem mais flexível, mas que restringe recursos. A pressão para a quantidade e não } \\
\text { a qualidade das intervenções pode ocorrer por parte de autoridades locais (município, } \\
\text { governo ou sistema de saúde). A promoção de padrões rigorosos para a implementação } \\
\text { pode contribuir para minimizar a pressão, mas, para isso, é necessário aumentar o } \\
\text { conhecimento e a conscientização entre as partes interessadas e autoridades, quanto à } \\
\text { importância e objetivos das intervenções e condições necessárias para implementá-las. }\end{array}$ \\
\hline
\end{tabular}


Quadro 7 - Implementação da opção 2 e implicações em relação aos usuários, trabalhadores de saúde e para a organização dos serviços e sistemas de saúde.

continuação

\begin{tabular}{|c|l|}
\hline \multicolumn{1}{|c|}{ Níveis } & Opção 2 - Participação social para o aprimoramento de indicadores de saúde \\
\hline Sistemas de saúde & $\begin{array}{l}\text { Outro aspecto relevante a ser considerado é o contexto social a que se destina uma } \\
\text { intervenção a ser implementada. Por fim, a América Latina, especialmente o Brasil, é } \\
\text { uma região heterogênea, sendo necessário que os sistemas de saúde compreendam a } \\
\text { necessidade e a possibilidade de adaptar as intervenções a diferentes tipos de populações, } \\
\text { levando em consideração diversos perfis socioeconômicos e demográficos. Pobreza, } \\
\text { desestrutura familiar, relações de gênero, vulnerabilidades afetam o cotidiano de muitas } \\
\text { pessoas e devem ser cuidadosamente contemplados nas intervenções a serem } \\
\text { implementadas (Atienzo, Kaltenthaler e Baxter, 2016). } \\
\text { Os sistemas de saúde devem estabelecer confiança no âmbito comunitário, e esta é um } \\
\text { importante facilitador para a participação efetiva (Chuah et al., 2018). }\end{array}$ \\
\hline
\end{tabular}

conclusão 
6 LACUNAS DE EVIDÊNCIA 


\section{LACUNAS DE EVIDÊNCIA}

Algumas lacunas de evidência devem ser apontadas no presente estudo. A lacuna mais importante diz respeito ao número de estudos incluídos e sua qualidade. No processo de busca nas bases de dados, foram encontrados apenas seis estudos que corporificam a presente síntese. Ademais, muitas revisões sistemáticas, embora tendo como foco o objeto de estudo, não traziam resultados de intervenções o que impossibilitou sua utilização.

De acordo com Evans, Pilkington e McEachran (2010), a conclusão de uma falta de evidência é comum em revisões sistemáticas.

Revisões sistemáticas sobre intervenções que considerem a participação social na APS, para responder às necessidades de saúde resultaram escassas e consomem muito tempo. Ademais, as estratégias de busca podem frequentemente, sofrer pela falta de especificidade. Outro impacto importante é a não inclusão da literatura cinzenta. Por outro lado, conforme mencionado por Evans, Pilkington e McEachran (2010), a inclusão da literatura cinzenta pode apresentar limitações em termos de qualidade aos trabalhos publicados.

Embora possa haver preocupações com relação as evidências apresentadas no presente estudo, encontrou-se alguns resultados consistentes entre os estudos, alguns dos quais refletem elementos identificados em pesquisas anteriores e que refletem importantes achados para formuladores de políticas e tomadores de decisão.

Mesmo com essas limitações, os resultados desta síntese acrescentam informações valiosas, ao proporcionar a identificação de fatores/elementos/condições que podem afetar a implementação e os resultados de intervenções promissoras em relação à participação social como resposta às necessidades de saúde. Outro achado de extrema relevância refere-se ao fato de que os estudos analisados na presente síntese procedem de diversos países ( Brasil, Bolívia, Peru, África do Sul, México, entre outros), mas que podem representar proximidade em relação à realidade brasileira, o que contribui e torna possível o diálogo deliberativo, a implementação e a avaliação dos resultados em pesquisas futuras.

Outra lacuna a ser reconhecida é a necessidade de estudos mais robustos quanto a compreensão teórica sobre o conceito da participação social. Essa afirmativa corrobora com os 
achados de Chuah et al. (2018), que afirmam que a participação social é comumente considerada fundamental para viabilizar o sucesso de muitas iniciativas de saúde. No entanto, os construtos teóricos e as evidências sobre os conceitos e questões relacionais que moldam a participação estão faltando. 
7 CONSIDERACÕES FINAIS 


\section{CONSIDERAÇÕES FINAIS}

No presente estudo foram elaboradas duas opções para informar políticas de saúde a respeito da participação social como resposta a necessidades de saúde no âmbito da Atenção Primária à Saúde (APS), a partir da identificação de seis revisões sistemáticas.

As formas de participação social encontradas nos estudos: comitês, assim como abordagens participativas contribuem para melhorar a atenção à saúde e para o aprimoramento de indicadores de saúde, no âmbito da Atenção Primária à Saúde. De fato, o que se verificou nessas revisões, são abordagens que possibilitam a participação, mas que operam, sobretudo, no âmbito institucional.

Não se verificou a participação como uma ferramenta para o aprimoramento e para a garantia da saúde como um direito social, em cujo âmago estaria à emancipação dos cidadãos ou na perspectiva do reconhecimento das necessidades de saúde, o que evidencia limitação nas abordagens apresentadas. A participação social é, sobretudo, uma condição fundamental para o pleno exercício da saúde, sendo crucial para entender os processos econômicos e políticos e ajudar a reduzir as iniquidades e transformar a atenção à saúde.

O processo de construção do Sistema Único de Saúde (SUS) foi impulsionado pela participação de diversos membros da sociedade civil, entre outros atores sociais envolvidos, unidos no Movimento da Reforma Sanitária, que defendia um projeto de um sistema de saúde capaz de abranger políticas públicas, incidindo sobre as condições de vida e de trabalho da população, promovendo também proteção coletiva contra agravos de saúde, e assegurando saúde em todas as suas vertentes. Desse projeto, em meio a muitas lutas e debates, nasceu na Constituição de 1988, o SUS, instituindo princípios e diretrizes que norteiam as ações de saúde, dentre estes, a garantia da participação da comunidade, sendo então uma garantia constitucional, tornando-a pauta fundamental nas reivindicações da saúde.

É a esse respeito que os achados deste estudo representam instâncias concretas de gestão participativa que possibilitam melhorias na atenção à saúde. Entretanto, a participação social vai além dos espaços restritos de comitês e de abordagens participativas, remetendo ao conceito de cidadania e aos direitos sociais. 
Atualmente, no Brasil, presencia-se uma marcante desigualdade social, péssimas condições de vida e trabalho alienado, o que leva à descrença no Estado, uma vez que está conciliado a valores neoliberais, que acabam sendo incorporados pela sociedade, e que também reproduza injustiça social.

A participação da sociedade civil em reivindicações e mobilizações em prol de políticas públicas de saúde é voluntária. A carência de apoio institucional a eventuais movimentos de greve, somada à ausência de tempo dos cidadãos para dedicar-se a tais movimentos em que estão em pauta as necessidades sociais, e todo esse contexto movido por um sistema capitalista que promove valores individuais e restringe a sociedade ao consumo e à acumulação, configuram expressivos obstáculos para a participação/mobilização social.

A participação social é um determinante fundamental da democracia, mas ainda vivemos em uma sociedade imatura quanto a adotar uma postura política; vivemos o desmonte do SUS, e precisamos alcançar o amadurecimento político e a ampliação da cidadania, fundamentais para o desenvolvimento de uma sociedade justa e distante das práticas opressivas de poder que estamos atravessando neste momento histórico de regressão do Brasil.

A reflexão crítica sobre a práxis da participação social, por parte da sociedade civil organizada, com identidade própria, jamais pode ser esquecida ou abandonada. A participação/mobilização social podem responder de maneira mais ampliada às necessidades de saúde, melhorando a atenção à saúde, implementando as políticas públicas de saúde, reduzindo a desigualdade social, proporcionando e garantindo o bem estar social da população e o acesso aos serviços públicos de saúde de qualidade.

Espera-se que as evidências apresentadas no presente estudo possam apoiar gestores, formuladores de políticas, tomadores de decisão e profissionais da APS no avanço da construção das políticas de saúde sobre a participação social como resposta a necessidades de saúde, repensando os modelos de sistemas clínicos, hospitalocêntricos, focados em indivíduos, e em enfermidades. Mas, que possam apoiar a adoção de abordagens para mobilizar e fortalecer a capacidade da comunidade, a sua organização e participação em comitês embasados e atrelados às reais necessidades de saúde da população. Espera-se também que um diálogo deliberativo futuro possa subsidiar a implantação de algumas opções abordadas nesta síntese. 
REFERENCIAS 


\section{REFERÊNCIAS}

Aguiar ZN, organizador. SUS: Sistema Único de Saúde -antecedentes, percurso, perspectivas e desafios. $1^{\mathrm{a}}$ ed. São Paulo: Martinari; 2011.

Atienzo EE, Kaltenthaler E, Baxter SK. Barriers and Facilitators to the Implementation of Interventions to Prevent Youth Violence in Latin America: A Systematic Review and Qualitative Evidence Synthesis. Trauma, Violence \& Abuse. 2016:1-11.

Avritzer L, organizador. Experiências nacionais de participação social. Coleção: Democracia participativa. São Paulo: Cortez; 2009.

Barreto JOM, Toma TS. Métodos EVIPNet Brasil: Ferramentas SUPPORT para políticas de saúde informadas por evidências. Boletim do Instituto de Saúde Bis. Políticas de Saúde Informadas por Evidências. Volume 17, nº 1. São Paulo - Brasil, julho 2016, p. 43-49.

Bath J, Wakerman J. Impact of community participation in primary health care: what is the evidence? Australian Journal of Primary Health. 2015;21:2-8.

Bertolozzi MR, Grecco RM. As políticas de saúde no Brasil: reconstrução histórica e perspectivas atuais. Rev Esc Enferm USP. 1996 [citado 2018 abr. 27]. Disponível em: http://www.scielo.br/scielo.php?pid=S0080-2341996000300004\&script=sci_abstract\&tlng=pt

Beverley SJ, Jeremy GM, George WA, Boerset M, Anderson N, Hamel C, et al. Development of AMSTAR: a measurement tool to assess the methodological quality of systematic reviews. BMC Medical Research Methodology.2007, 7:10. [cited 2018 May. 06]. Available from: https://bmcmedresmethodol.biomedcentral.com/articles/10.1186/1471-2288-7-10

Bortoli MC, Freire LM, Tesser TR. Políticas de Saúde Informadas por Evidências: propósitos e desenvolvimento no mundo e no país. In: Toma TS et al, organizadores. Avaliação de tecnologias de saúde \& políticas informadas por evidências. São Paulo: Instituto de Saúde; 2017, p. 29-52.

Brasil. Conselho Nacional de Secretários de Saúde. As Conferências Nacionais de Saúde: Evolução e perspectivas. Brasília: CONASS; 2009a. 100 p. (CONASS Documenta; 18) [citado 2018 mai 20] Disponível em: http://www.conass.org.br/conassdocumenta/cd_18.pdf

Brasil. Conselho Nacional de Secretários de Saúde. Legislação Estruturante do SUS. Brasília: CONASS; 2011 [citado 2018 abr. 28]. Disponível em:

http://bvsms.saude.gov.br/bvs/publicacoes/para_entender_gestao_sus_v13.pdf 
Brasil. Lei 8.142/90. Dispõe sobre a participação da comunidade da gestão do Sistema Único de Saúde (SUS) e sobre as transferências intergovernamentais de recursos financeiros na área da saúde e dá outras providências. Diário Oficial da União. Brasília, 28 de dezembro de 1990a. [citado 2018 abr. 27]. Disponível em:

http://conselho.saude.gov.br/legislacao/lei8142_281290.htm

Brasil. Ministério da Saúde. Conselho Nacional de Saúde. Diretrizes nacionais para o processo de educação permanente no controle social do SUS. Brasília: Editora do Ministério da Saúde; 2006.

Brasil. Ministério da Saúde. Relatório final da VIII Conferência Nacional de Saúde. Brasília; 17 a 21 mar.1986 [citado 2018 Abr. 27]. Disponível em:

http://bvsms.saude.gov.br/bvs/publicacoes/8_conferencia_nacional_saude_relatorio_final.pdf

Bravo MIS, Menezes JSB. Participação Popular em Saúde. In: Soares CB, Campos CMS, organizadoras. Fundamentos de saúde coletiva e o cuidado de enfermagem. Barueri: Manole; 2013. p. 49-74.

Caldart RS. O MST e a formação dos sem-terra: o movimento social como princípio educativo. Estudos avançados. 2001;15(43):207-24.

Campos CMS, Bataiero MO. Necessidades de saúde: uma análise da produção científica brasileira de 1990 a 2004. Interface (Botucatu). 2007;11(23):605-18. [citado 2018 mai. 22]. Disponível em: http://www.scielo.br/scielo.php?script=sci_arttext\&pid=S141432832007000300014

Campos CMS, Soares CB. Necessidades de saúde e o cuidado de enfermagem em saúde coletiva. In: Soares CB, Campos CMS. Fundamentos de saúde coletiva e o cuidado de enfermagem. Barueri: Manole; 2013. p. 265-292.

Campos CMS. Necessidades de saúde como objeto das políticas públicas: as práticas do Enfermeiro na Atenção Básica [tese livre-docência]. São Paulo: Escola de Enfermagem, Universidade de São Paulo; 2013.

Campos CMS. Reconhecimento das necessidades de saúde dos adolescentes. In: Borges ALV, Fujimori E. Enfermagem e a saúde do adolescente na atenção básica. Barueri: Manole; 2009. p. $142-167$.

Carvalho AI. Conselhos de saúde no Brasil: participação cidadã e controle social. Rio de Janeiro: FASE/IBAM; 1995. p. 24.

Chapman E. Mecanismo de tradução do conhecimento para a formulação de Políticas Informadas por Evidências. In Boletim do Instituto de Saúde Bis. Políticas de Saúde Informadas por Evidências. Volume 17, nº 1. São Paulo - Brasil, julho 2016, p. 7-17. 
Chuah FLH, Srivastava A, Singh SR, Haldane V, Koh GCH, Seng CK, et al. Community participation in general health initiatives in high and uppermiddle income countries: A systematic review exploring the nature of participation, use of theories, contextual drivers and power relations in community participation. Social Science \& Medicine. 2018;213:106-22.

Ciconello A. A Participação Social como processo de consolidação da democracia no Brasil. Oxfam International. From poverty to power. Junho de 2008. p. 1-12.

Coelho JS. Construindo a Participação Social no SUS: um constante repensar em busca da equidade e transformação. Saúde e Sociedade. São Paulo; 2012;21(supl. 1):138-51.

Comparato BK. A ação política do MST. São Paulo em Perspectiva. 2001;15(4):105-18.

Cornish F, Priego-Hernandez J, Campbell C, Mburu G, McLean S. The impact of Community Mobilisation on HIV Prevention in Middle and Low Income Countries: A Systematic Review and Critique. AIDS Behav. 2014;18:2110-34.

Costa AM, Bahia L, Scheffer M. Onde foi parar o sonho do SUS? Le Monde Diplomatique Brasil. 2013. [citado 2018 mai. 22] disponível em: https://diplomatique.org.br/onde-foi-pararo-sonho-do-sus/

Development Assistance Committee Working Party on Aid Evaluation: Glossaryof Key Terms in Evaluation and Results Based Management. Paris: OECD Publications; 2002 [cited 2018 Apr. 30]. Available from: https://www.oecd.org/dac/evaluation/2754804.pdf

Evans D, Pilkington P, McEachranM. Rhetoric or reality? A systematic review of the impact of participatory approaches by UK public health units on health and social outcomes. Journal of Public Health. 2010;32(3):418-26.

Fretheim A, Oxman AD, Lavis JN, Lewin S. Ferramentas SUPPORT para a elaboração de políticas de saúde baseadas em evidências (STP): uma coletânea de artigos publicados na revista "Health Research Policy and System". 18. Como monitorar o planejamento e avaliação de políticas; 2009 [citado 2018 abr.30]. Disponível em:

http://www1.paho.org/hq/dmdocuments/2010/PORT\%20STP\%2018\%20KO\%20050510.pdf

Gaiotto EMG, Isoyama SV. Relato de experiência da implantação de um Grupo de Evidências em um município de médio porte do estado de São Paulo. In Boletim do Instituto de Saúde Bis. Políticas de Saúde Informadas por Evidências. Volume 17, nº 1. São Paulo - Brasil, julho 2016, p.132-140.

Gaiotto EMG. Elaboração de uma Síntese de Evidências para Políticas de Saúde: reduzindo a mortalidade perinatal no Município de Porto Feliz-SP. São Paulo: Coordenadoria de Recursos Humanos da Secretaria de Estado da Saúde de São Paulo; 2016. 
Galvão TF, Pereira MG. Revisões sistemáticas da literatura: passos para sua elaboração. Epidemiol. Serv. Saúde, Brasília. 2014;23(1):183-4, [citado 2018 mai. 05]. Disponível em: http://www.scielo.br/pdf/ress/v23n1/2237-9622-ress-23-01-00183.pdf

Gohn MG. Sociologia dos movimentos sociais. Questões da nossa época; v. 47. São Paulo: Cortez; 2013.

Gouveia R, Palma JJ. SUS: na contramão do neoliberalismo e da exclusão social. Estudos avançados. 1999:13;(35):139-46.

Guizardi FL, Pinheiro R. Dilemas culturais, sociais e políticos da participação dos movimentos sociais nos Conselhos de Saúde. Ciênc. Saúde Coletiva. 2006;11(3):797-805.

Lavis JN, Oxman AD, Lewin S, Fretheim A. Ferramentas SUPPORT para a elaboração de políticas de saúde baseadas em evidências (STP): uma coletânea de artigos publicados na revista "Health Research Policy and System". 3. Estabelecimento de prioridades para apoiar a formulação de políticas baseadas em evidências; 2009a [citado 2018 abr.30]. Disponível em: http://www1.paho.org/hq/dmdocuments/2010/PORT\%20STP\%203\%20KO\%20040510.pdf

Lavis JN, Wilson M, Oxman AD, Lewin S, Fretheim A. Ferramentas SUPPORT para a elaboração de políticas de saúde baseadas em evidências (STP): uma coletânea de artigos publicados na revista "Health Research Policy and System". 4. Como usar evidências de pesquisa para esclarecer um problema?; 2009b [citado 2018 abr.30]. Disponível em: http://www1.paho.org/hq/dmdocuments/2010/PORT\%20STP\%204\%20KO\%20040510.pdf

Lewin S, Oxman AD, Lavis JN, Fretheim A. Ferramentas SUPPORT para a elaboração de políticas de saúde baseadas em evidências (STP): uma coletânea de artigos publicados na revista "Health Research Policy and System". 8. Decidindo até que ponto uma revisão sistemática pode ser considerada confiável; 2009 [citado 2018 abr.30]. Disponível em: http://www1.paho.org/hq/dmdocuments/2010/PORT\%20STP\%208\%20KO\%20050510.pdf

Martins PC, Cotta RMM, Mendes FF, Priore SE, Franceschinni SCC, Cazal MM, et al. De quem é o SUS/ Sobre as representações sociais do Programa Saúde da Família. Ciência \& Saúde Coletiva. 2011;16(3):1933-42.

McCoy DC, Hall JA, Ridge M. A systematic review of the literature for evidence on health facility committees in low- and middle-income countries. Health Policy and Planning. 2011;27:449-66.

Milani CRS. O princípio da participação social na gestão de políticas públicas locais: uma análise de experiências latino-americanas e europeias. Revista de Administração Pública. Rio de Janeiro. 2008;42(3):551-79.

Ministério da Saúde. Portaria no 2.001/GM/MS, de 12 de setembro de 2013. Altera o art. $2^{\circ}$ da Portaria $\mathrm{n}^{\circ}$ 2.363/GM/MS, de 7 de outubro de 2009, que institui e define atribuições do 
Conselho Consultivo da EVIPNet Brasil. Diário Oficial da União. 13 set 2013; Seção 1:63. [citado 2018 abr. 29]. Disponível em:

http://bvsms.saude.gov.br/bvs/saudelegis/gm/2013/prt2001_12_09_2013.html

Ministério da Saúde. Portaria n ${ }^{\circ}$ 2.636/GM/MS, de 7 de outubro de 2009. Institui e define atribuições do Conselho Consultivo da EVIPNet Brasil. Diário Oficial da União. 8 out 2009; Seção 1:90; 2009b [citado 2018 abr. 29]. Disponível:

http://bvsms.saude.gov.br/bvs/saudelegis/gm/2009/prt2363_07_10_2009.html

Ministério da Saúde. Secretaria Nacional de Assistência à Saúde. ABC do SUS: doutrinas e princípios. Brasília: Secretaria Nacional de Assistência Social; 1990b. v.1, 20p.

Moher D, Liberati A, Tetzlaff J, Altman DG. Preferred Reporting Items for Systematic Reviews and Meta-Analyses: The PRISMA Statement PLoSMed [Internet]. 21Jul 2009;6(7):e1000097. Available from: https://dx.plos.org/10.1371/journal.pmed100097

Moreira MR, Escorel S. Dilemas da participação social em saúde: reflexões sobre o caráter deliberativo dos conselhos de saúde. Saúde em Debate, Rio de Janeiro. 2010;34(84):47-55.

Navarro V. A Critique of Social Capital. International Journal of Health Services; 2002;32(3):423-32.

Navarro V. What is a National Health Policy? International Journal of Health Services. 2007;37(1):1-14.

Nespoli G. Biopolíticas da participação na saúde: o SUS e o governo das populações. In: Guizard FL, Nespoli G, Cunha MLS, Machado F, Lopes M. Políticas de Participação e Saúde. Rio de Janeiro: EPSJV; Recife: Editora Universitária- UFPE; 2014. p. 59-90.

Oliver K, Innvar S, Lorenc T, Woodman J, Thomas J. A systematic review of barriers to and facilitators of the use of evidence by policymakers. BMC Health Services Research. 2014;14:2 [cited 2018 May. 05]. Available from: https://bmchealthservres.biomedcentral.com/articles/10.1186/1472-6963-14-2

Oxman AD, Lewin S, Lavis JN, Fretheim A. Ferramentas SUPPORT para a elaboração de políticas de saúde baseadas em evidências (STP): uma coletânea de artigos publicados na revista "Health Research Policy and System". 15. Envolvendo o público na elaboração de políticas baseadas em evidências; 2009 [citado 2018 abr.30]. Disponível em: http://www1.paho.org/hq/dmdocuments/2010/PORT\%20STP\%2015\%20KO\%20050510.pdf

Paim J, Travassos C, Almeida C, Bahia L, Macinko J. O sistema de saúde brasileiro: história, avanços e desafios. The Lancet, Saúde no Brasil, maio de 2011. Séries 11. 
Paiva CHA, Teixeira LA. Reforma Sanitária e a criação do Sistema Único de Saúde: notas sobre contextos e autores. História, Ciências, Saúde - Manguinhos, Rio de Janeiro; 2014;21(1).

Paula AG. Os Movimentos de Mulheres na Ditadura: uma análise sobre as Mães da Praça de Maio (Argentina) e o Movimento Feminino pela Anistia (Brasil). In: Anais do II Simpósio Internacional Pensar e Repensar a América Latina. Ano: 2016, p. 1-11.

Rolim LM, Cruz RSBLC, Sampaio KJAJ. Participação popular e o controle social como diretriz do SUS: uma revisão narrativa Saúde em Debate. Rio de Janeiro; 2013;37(96):139-47. [citado 2018 mai. 05]. Disponível em: http://www.scielo.br/pdf/sdeb/v37n96/16.pdf

Roncalli AG. O desenvolvimento das políticas públicas de saúde no Brasil e a construção do Sistema Único de Saúde. In: Pereira AC, organizador. Odontologia em Saúde Coletiva: planejando ações e promovendo saúde. Porto Alegre: Artmed; 2003. Cap. 2. p. 28-49 [citado 2018 mai. 05]. Disponível em:

http://leg.ufpi.br/subsiteFiles/nesp/arquivos/files/downloads/especializacao12007/modulo_I/desenv_pol_pub_saude_brasil.pdf

Shea BJ, Grimshaw JM, Wells GA, Boers M, Anderson N, Hamel C, et al. Development of AMSTAR: A measurement tool to assess the methodological quality of systematic reviews. BMC Med Res Methodol. 2007;7:1-7.

Shea BJ, Hamel C, Wells GA, Bouter LM, Kristjansson E, Grimshaw J, et al. AMSTAR is a reliable and valid measurement tool to assess the methodological quality of systematic reviews. J Clin Epidemiol [Internet]. 2009;62(10):1013-20. Available from: https://linkinghub.elsevier.com/retrieve/pii/S0895435608003259

Shea BJ, Hamel C, Wells GA, Bouter LM, Kristjansson E, Grimshaw J, et al. AMSTAR is a reliable and valid measurement tool to assess the methodological quality of systematic reviews. J Clin Epidemiol [Internet]. outubro de 2009;62(10):1013-20. Available from: https://linkinghub.elsevier.com/retrieve/pii/S0895435608003259

Souza AV, Krüger TR. Participação Social no SUS: proposições das conferências sobre o conselho local de saúde. Rev Saúde Pública. Florianópolis. 2010;3(1).

Talò C, Mannarini T, Rochira A. Sense of Community and Community Participation: A MetaAnalytic Review. Social Indicators Research: An International and Interdisciplinary Journal for Quality-of-Life Measurement. 2014;117(1):1-28.

Tostes APB, Silva LVB. Das praças para as urnas: movimentos dos Indignados e Occupy Wall Street From squares to ballot: "Indignados" Movement and Occupy Wall Street. Mural Internacional. 2015;6(2):245-60. 
Villalonga-Olives E, Wind TR, Kawachi I. Social capital interventions in public health: A systematic review. Soc Sci Med. 2018 Sep;212:203-218.

Wichimann RM, Carlan E, Barreto JOM. Consolidação da Rede para Políticas Informadas por Evidências - EVIPNet Brasil: relato de experiência nacional na construção de uma plataforma de tradução do conhecimento para o SUS. In Boletim do Instituto de Saúde Bis. Políticas de Saúde Informadas por Evidências. Volume 17, n. ${ }^{\circ}$ 1. São Paulo - Brasil, julho 2016, p.18-31.

World Health Organization (WHO): Declaration of Alma Ata: Report of the International Conference on Primary Health Care. Geneva: World Health Organization; 1978 [cited 2018 Apr. 29]. Available from: http://www.who.int/publications/almaata_declaration_en.pdf 
ANEXO 


\section{ANEXO}

Quadro 8 - AMSTAR (A measurement tool to assess the methodological quality of systematic reviews) ferramenta para a avaliação e classificação da qualidade da revisão sistemática

\begin{tabular}{|c|c|}
\hline \multicolumn{2}{|c|}{ Itens avaliados e instruções categorias } \\
\hline $\begin{array}{l}\text { 1. Um projeto/protocolo do estudo foi fornecido a priori? } \\
\text { Os critérios de inclusão e a pergunta da pesquisa devem ser } \\
\text { estabelecidos antes da realização da revisão. }\end{array}$ & $\begin{array}{l}\text { ( ) Sim } \\
\text { ( ) Não } \\
\text { ( ) Não é possível } \\
\text { responder } \\
\text { ( ) Não se aplica }\end{array}$ \\
\hline $\begin{array}{l}\text { 2. A seleção dos estudos e extração dos dados foram feitas } \\
\text { em duplicata? } \\
\text { Deve haver pelo menos dois revisores independentes para } \\
\text { extrair os dados, e um consenso sobre procedimento para } \\
\text { discordâncias deve ser estabelecido. }\end{array}$ & $\begin{array}{l}\text { ( ) Sim } \\
\text { ( ) Não } \\
\text { ( ) Não é possível } \\
\text { responder } \\
\text { ( ) Não se aplica }\end{array}$ \\
\hline $\begin{array}{l}\text { 3. Uma busca abrangente da literatura foi realizada? } \\
\text { Ao menos duas fontes eletrônicas devem ser buscadas. Os } \\
\text { estudos têm que incluir os anos e a base de dados que foram } \\
\text { utilizadas (ex. Central, Embase e MedLine. Palavras-chave } \\
\text { e/ou termos MeSH devem ser informados e, sempre que } \\
\text { possível, a estratégia de busca deve ser fornecida. Todas as } \\
\text { buscas devem ser contempladas consultando conteúdos } \\
\text { atuais, revisões, livros, registros especializados ou } \\
\text { especialistas de uma área particular de estudo, além de haver } \\
\text { revisão da lista de referências dos estudos relevantes } \\
\text { incluídos. }\end{array}$ & $\begin{array}{l}\text { ( ) Sim } \\
\text { ( ) Não } \\
\text { ( ) Não é possível } \\
\text { responder } \\
\text { ( ) Não se aplica }\end{array}$ \\
\hline $\begin{array}{l}\text { 4. O status da publicação (ou seja, literatura cinzenta) foi } \\
\text { utilizado como um critério de inclusão? } \\
\text { Os autores devem declarar que as buscas por estudos foram } \\
\text { feitas independentemente, por seu tipo de publicação. Os } \\
\text { autores devem declarar se excluíram ou não quaisquer } \\
\text { estudos (da revisão sistemática), com base no seu status de } \\
\text { publicação, idioma etc. }\end{array}$ & $\begin{array}{l}\text { ( ) Sim } \\
\text { ( ) Não } \\
\text { ( ) Não é possível } \\
\text { responder } \\
\text { ( ) Não se aplica }\end{array}$ \\
\hline
\end{tabular}




\begin{tabular}{|c|c|}
\hline $\begin{array}{l}\text { 5. Uma lista dos estudos (incluídos e excluídos) foi } \\
\text { fornecida? } \\
\text { Uma lista dos estudos incluídos e excluídos deve ser } \\
\text { fornecida. }\end{array}$ & $\begin{array}{l}\text { ( ) Sim } \\
\text { ( ) Não } \\
\text { ( ) Não é possível } \\
\text { responder } \\
\text { ( ) Não se aplica }\end{array}$ \\
\hline $\begin{array}{l}\text { 6. A característica dos estudos incluídos foi fornecida? } \\
\text { De maneira agregada em uma tabela, os dados dos estudos } \\
\text { originais devem ser fornecidos, descrevendo os participantes, } \\
\text { intervenções e desfechos. Devem ser relatadas as diversas } \\
\text { características em todos os estudos analisados, como idade, } \\
\text { raça, sexo, dados socioeconômicos relevantes, o estado da } \\
\text { doença, duração, gravidade ou outras doenças. }\end{array}$ & $\begin{array}{l}\text { ( ) Sim } \\
\text { ( ) Não } \\
\text { ( ) Não é possível } \\
\text { responder } \\
\text { ( ) Não se aplica }\end{array}$ \\
\hline $\begin{array}{l}\text { 7. A qualidade científica dos estudos incluídos foi avaliada } \\
\text { e documentada? } \\
\text { Os métodos de avaliação devem ser descritos a priori (ex. os } \\
\text { estudos de efetividade, caso os autores optem por incluir } \\
\text { estudos randomizados, duplo-cego, placebo-controlado ou } \\
\text { com uma ocultação de alocação como critérios); para os } \\
\text { outros tipos de estudos é importante que existam itens } \\
\text { alternativos. }\end{array}$ & $\begin{array}{l}\text { ( ) Sim } \\
\text { ( ) Não } \\
\text { ( ) Não é possível } \\
\text { responder } \\
\text { ( ) Não se aplica }\end{array}$ \\
\hline $\begin{array}{l}\text { 8. A qualidade científica dos estudos incluídos foi usada } \\
\text { adequadamente na formulação das conclusões? } \\
\text { Os resultados do rigor metodológico e qualidade científica } \\
\text { devem ser considerados nas análises e conclusões da revisão } \\
\text { e explicitamente declarados na formulação das } \\
\text { recomendações. }\end{array}$ & $\begin{array}{l}\text { ( ) Sim } \\
\text { ( ) Não } \\
\text { ( ) Não é possível } \\
\text { responder } \\
\text { ( ) Não se aplica }\end{array}$ \\
\hline $\begin{array}{l}\text { 9. Os métodos usados para combinar os estudos foram } \\
\text { apropriados? } \\
\text { Para combinação dos resultados, deve ser feito um teste para } \\
\text { assegurar que os estudos são combináveis, avaliando a sua } \\
\text { homogeneidade. (ex. teste de qui-quadrado para } \\
\text { homogeneidade ou } \mathrm{I}^{2} \text { ). Se houver heterogeneidade, um } \\
\text { modelo de efeito randômico deve ser usado e/ou a adequação } \\
\text { clínica da combinação deve ser considerada (ex. a } \\
\text { combinação é sensata?). }\end{array}$ & $\begin{array}{l}\text { ( ) Sim } \\
\text { ( ) Não } \\
\text { ( ) Não é possível } \\
\text { responder } \\
\text { ( ) Não se aplica }\end{array}$ \\
\hline
\end{tabular}




\section{O risco de viés da publicação foi avaliado? \\ Uma avaliação do viés de publicação deve incluir uma combinação de auxílio gráfico (ex. gráfico de funil, outros testes disponíveis) e/ou testes estatísticos (ex. teste de regressão de Egger).}

\section{O conflito de interesses foi informado?}

Potenciais fontes de apoio devem claramente reconhecidas, tanto na revisão sistemática quanto nos estudos incluídos.
( ) $\mathrm{Sim}$

( ) Não

( ) Não é possível

responder

( ) Não se aplica
( ) Não

( ) Não é possível responder

( ) Não se aplica

Classificação da qualidade da revisão sistemática pontos.

Alta -8 a 11

Média -4 a 7

Baixa $-\leq 3$

Para todos os itens, com exceção do item 4, a classificação "Sim" é considerada adequada. Para o item 4, a classificação "Não" (a revisão não excluiu literatura não publicada ou cinzenta) é considerada adequada. Uma revisão que satisfaz adequadamente a todos os 11 itens é considerada da mais alta qualidade.

Fonte: Adaptado de Shea et al., 2015. 
APÊNDICES 


\section{APENDICES}

\section{APÊNDICE A}

Quadro 9 - Revisões sistemáticas sobre a opção 1. Participação social para melhorar a atenção à saúde (comitês e abordagens participativas).

\begin{tabular}{|c|c|c|c|c|c|c|c|c|}
\hline \multicolumn{9}{|c|}{ continua } \\
\hline Estudo & Elementos da opção & $\begin{array}{l}\text { Objetivo do } \\
\text { estudo }\end{array}$ & Principais achados & AMSTAR & $\begin{array}{c}\text { Proporção } \\
\text { de estudos } \\
\text { que } \\
\text { incluíram a } \\
\text { população- } \\
\text { alvo }\end{array}$ & $\begin{array}{l}\text { Proporção de } \\
\text { estudos } \\
\text { realizados em } \\
\text { Low Middle } \\
\text { Income } \\
\text { Countries } \\
\text { (LMI) e } \\
\text { demais países }\end{array}$ & $\begin{array}{c}\text { Proporção } \\
\text { de estudo } \\
\text { com foco } \\
\text { no } \\
\text { problema }\end{array}$ & $\begin{array}{l}\text { Ano do } \\
\text { estudo }\end{array}$ \\
\hline $\begin{array}{c}\text { McCoy, } \\
\text { Hall e } \\
\text { Ridge, } 2011\end{array}$ & $\begin{array}{l}\text { A revisão sistemática relata } \\
\text { a eficácia dos comitês de } \\
\text { unidades de saúde e os } \\
\text { fatores que influenciam o } \\
\text { funcionamento, } \\
\text { desempenho e a eficácia } \\
\text { dos comitês. } \\
\text { Desenvolvidas para } \\
\text { unidades de saúde } \\
\text { (profissionais de saúde) e } \\
\text { comunidade. Entregue por } \\
\text { comitês e desenvolvidas } \\
\text { por representantes da } \\
\text { comunidade/representantes } \\
\text { de profissionais de saúde e } \\
\text { do Ministro da Saúde. }\end{array}$ & $\begin{array}{l}\text { Revisar a literatura } \\
\text { e a base de } \\
\text { evidências sobre a } \\
\text { eficácia Comitês } \\
\text { de Unidades de } \\
\text { Saúde (Health } \\
\text { Facility } \\
\text { Committees - } \\
\text { HFCs) em países } \\
\text { de baixa ou média } \\
\text { renda. }\end{array}$ & $\begin{array}{l}\text { Nesta revisão sistemática quatro } \\
\text { estudos preencheram os critérios de } \\
\text { inclusão. Dois estudos tiveram um } \\
\text { grupo controle: um foi um estudo de } \\
\text { caso-controle e o outro foi um estudo } \\
\text { controlado randomizado. Um terceiro } \\
\text { trabalho foi uma análise retrospectiva } \\
\text { com um pequeno elemento de } \\
\text { comparação com um controle, } \\
\text { enquanto o quarto artigo foi um estudo } \\
\text { antes e depois, sem grupo controle. } \\
\text { Todos os quatro estudos apresentaram } \\
\text { evidências sobre o efeito benéfico dos } \\
\text { HFCs em vários indicadores de } \\
\text { desempenho, bem como dados e } \\
\text { discussão sobre os fatores que } \\
\text { influenciam o funcionamento dos } \\
\text { HFCs. }\end{array}$ & $3 / 9$ & $\begin{array}{l}\text { Não se } \\
\text { aplica }\end{array}$ & 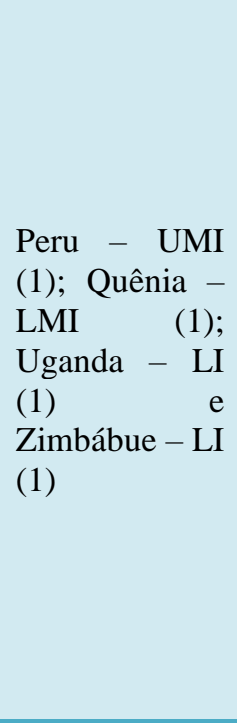 & $4 / 4$ & 2000 \\
\hline
\end{tabular}


Quadro 9 - Revisões sistemáticas sobre a opção 1. Participação social para melhorar a atenção à saúde (comitês e abordagens participativas).

\begin{tabular}{|c|c|c|c|c|c|c|c|c|}
\hline \multicolumn{4}{|c|}{ continução } & & & & & \\
\hline Estudo & Elementos da opção & $\begin{array}{l}\text { Objetivo do } \\
\text { estudo }\end{array}$ & Principais achados & AMSTAR & $\begin{array}{c}\text { Proporção } \\
\text { de estudos } \\
\text { que } \\
\text { incluíram a } \\
\text { população- } \\
\text { alvo }\end{array}$ & $\begin{array}{c}\text { Proporção de } \\
\text { estudos } \\
\text { realizados em } \\
\text { Low Middle } \\
\text { Income } \\
\text { Countries } \\
\text { (LMI) e } \\
\text { demais países }\end{array}$ & $\begin{array}{c}\text { Proporção } \\
\text { de estudo } \\
\text { com foco } \\
\text { no } \\
\text { problema }\end{array}$ & $\begin{array}{c}\text { Ano do } \\
\text { estudo }\end{array}$ \\
\hline $\begin{array}{c}\text { Evans, } \\
\text { Pilkington e } \\
\text { McEachran, } \\
2010\end{array}$ & $\begin{array}{l}\text { A revisão sistemática relata que } \\
\text { houve um bom grau de } \\
\text { heterogeneidade metodológica entre } \\
\text { os sete estudos. Quatro dos estudos } \\
\text { foram qualitativos, enquanto três } \\
\text { foram estudos mistos entre } \\
\text { qualitativos e quantitativos. Dois } \\
\text { estudos utilizaram entrevistas semi- } \\
\text { estruturadas, enquanto uma utilizou } \\
\text { entrevistas semi-estruturadas e } \\
\text { grupos focais. Um estudo usou uma } \\
\text { mistura de quatro métodos } \\
\text { qualitativos: um exercício de "teia de } \\
\text { aranha", discussões e questionários } \\
\text { com três grupos de oficinas de } \\
\text { residentes e um diário de avaliação. } \\
\text { Três dos estudos não descreveram } \\
\text { seus métodos qualitativos em } \\
\text { detalhes para categorizá-los ou } \\
\text { avaliá-los. Em termos do elemento } \\
\text { quantitativo três estudos utilizaram } \\
\text { método misto, dois utilizaram } \\
\text { pesquisas por questionário e uma } \\
\text { análise envolvida de dados de rotina. }\end{array}$ & $\begin{array}{l}\text { Avaliar } 0 \\
\text { impacto das } \\
\text { abordagens } \\
\text { participativas } \\
\text { pelo NHS } \\
\text { (National Health } \\
\text { Service) do } \\
\text { Reino Unido em } \\
\text { unidades de } \\
\text { saúde pública. }\end{array}$ & $\begin{array}{l}\text { Nesta revisão sistemática sete } \\
\text { estudos preencheram os } \\
\text { critérios de inclusão. Em cinco } \\
\text { dos sete estudos a intervenção } \\
\text { avaliada foi uma iniciativa de } \\
\text { desenvolvimento de saúde } \\
\text { comunitária; dois casos foram } \\
\text { tópicos específicos (saúde do } \\
\text { coração em um caso, combater } \\
\text { o tabagismo no outro) } \\
\text { enquanto três eram mais } \\
\text { genéricos. As duas últimas } \\
\text { intervenções foram o } \\
\text { desenvolvimento de estratégias } \\
\text { de saúde pública em toda a } \\
\text { cidade. }\end{array}$ & $6 / 9$ & $\begin{array}{l}\text { Não se } \\
\text { aplica }\end{array}$ & $\begin{array}{l}\text { Reino Unido - } \\
\text { HI (1) }\end{array}$ & $1 / 0$ & 2007 \\
\hline
\end{tabular}


Quadro 10 - Revisões sistemáticas sobre a opção 2. Participação social para o aprimoramento de indicadores de saúde.

\begin{tabular}{|c|c|c|c|c|c|c|c|c|}
\hline Estudo & Elementos da opção & Objetivo do estudo & Principais achados & AMSTAR & $\begin{array}{l}\text { Proporção } \\
\text { de estudos } \\
\text { que } \\
\text { incluíram a } \\
\text { população- } \\
\text { alvo }\end{array}$ & $\begin{array}{c}\text { Proporção de } \\
\text { estudos } \\
\text { realizados em } \\
\text { Low Middle } \\
\text { Income } \\
\text { Countries (LMI) } \\
\text { e demais países }\end{array}$ & $\begin{array}{c}\text { Proporção } \\
\text { de estudo } \\
\text { com foco } \\
\text { no } \\
\text { problema }\end{array}$ & $\begin{array}{l}\text { Ano do } \\
\text { estudo }\end{array}$ \\
\hline $\begin{array}{l}\text { Chuah et } \\
\text { al., } 2018\end{array}$ & $\begin{array}{l}\text { Nesta revisão a literatura específica } \\
\text { para doença foi excluída, } 27.232 \\
\text { registros foram identificados, com } \\
23.468 \text { após a remoção duplicada. } 79 \\
\text { artigos atenderam aos critérios do } \\
\text { estudo. No geral, os resultados } \\
\text { mostram que as estratégias para } \\
\text { incentivar a participação da } \\
\text { comunidade em iniciativas de saúde } \\
\text { podem ser categorizadas ao longo de } \\
\text { um contínuo que varia de menos a } \\
\text { mais participação e controle entre a } \\
\text { comunidade. A análise dos resultados } \\
\text { relatados demonstra que a participação } \\
\text { da comunidade em iniciativas gerais } \\
\text { de saúde pode contribuir para } \\
\text { processos positivos, sociais e de saúde. } \\
\text { Os resultados sociais são mais } \\
\text { frequentemente associados a aumentar } \\
\text { a participação da comunidade. As } \\
\text { descobertas reafirmam o } \\
\text { entendimento de que a participação da } \\
\text { comunidade é um processo complexo } \\
\text { que é fortemente influenciado pelo } \\
\text { contexto em que ocorrem, fatores } \\
\text { sociais, como as relações de poder, } \\
\text { devem ser cuidadosamente } \\
\text { consideradas. }\end{array}$ & $\begin{array}{lr}\text { Examinar } & \text { as } \\
\text { evidências } & \text { de } \\
\text { publicações } & \\
\text { acadêmicas } & \text { de } \\
\text { literatura sobre } & \text { a } \\
\text { participação } & \text { da } \\
\text { comunidade } & \text { em } \\
\text { relação a iniciativas } \\
\text { gerais de saúde } \\
\text { específicas, que não } \\
\text { usam de teorias para } \\
\text { informar } & \text { a } \\
\text { participação } & \text { da } \\
\text { comunidade, e } & \text { o } \\
\text { estudo de fatores } \\
\text { contextuais e questões } \\
\text { relacionais } \\
\text { influenciam que } \\
\text { participação } \\
\text { comunidade, com foco } \\
\text { nos países de renda } \\
\text { alta e média alta. }\end{array}$ & $\begin{array}{l}\text { Nesta revisão dos } 79 \text { artigos, } 36 \\
\text { eram descrições de programas } \\
(46 \%), 22 \text { eram estudos qualitativos } \\
(29 \%) \text {, } 13 \text { foram estudos } \\
\text { quantitativos (15\%) e } 8 \text { foram } \\
\text { estudos de métodos mistos }(10 \%) \text {. } \\
\text { Dos } 13 \text { estudos quantitativos, } 2 \\
\text { foram estudos de intervenção, } 2 \\
\text { foram estudos de coorte pré-pós e } 9 \\
\text { envolveram inquéritos transversais. } \\
\text { Dos } 8 \text { estudos de métodos mistos, } 1 \\
\text { foi um pré-estudo de avaliação de } \\
\text { coorte, e os } 7 \text { restantes foram } \\
\text { estudos transversais. Em termos de } \\
\text { locais de estudo, } 44 \text { artigos eram do } \\
\text { Norte da América Latina (57\%), } 16 \\
\text { da Europa (20\%), } 9 \text { da Oceania } \\
\text { (11\%), } 4 \text { da África (5\%), } 3 \text { da Ásia } \\
\text { (4\%) e } 3 \text { da América do Sul (4\%). } \\
\text { Com base nas classificações do } \\
\text { Banco Mundial, } 68 \text { artigos tiveram } \\
\text { estudos que foram conduzidos em } \\
\text { países de alta renda (86\%), metade } \\
\text { dos quais provenientes dos Estados } \\
\text { Unidos, enquanto } 11 \text { artigos foram } \\
\text { estudos que foram feitos em países } \\
\text { de renda média-alta (14\%). }\end{array}$ & $5 / 11$ & $\begin{array}{c}\text { Não se } \\
\text { aplica }\end{array}$ & $\begin{array}{l}\text { África o Sul - } \\
\text { UMI (4); } \\
\text { Bélgica - HI (1); } \\
\text { Austrália - HI (7); } \\
\text { Nova Zelândia - } \\
\text { HI (2); } \\
\text { Brasil - UMI (2); } \\
\text { Canadá - HI (7); } \\
\text { Coréia - HI (1); } \\
\text { Japão - HI (1); } \\
\text { Países Baixos - HI } \\
\text { (2); } \\
\text { EUA - HI (34); Irã } \\
\text { - UMI (1) Itália - } \\
\text { HI (2); Alemanha } \\
\text { - HI (2); } \\
\text { México - UMI } \\
\text { (3); } \\
\text { Peru - UMI (1); } \\
\text { Reino Unido - HI } \\
\text { (8); } \\
\text { Reino Unido e } \\
\text { Polônia e e } \\
\text { Eslovênia - HI (1) }\end{array}$ & $79 / 11$ & 2016 \\
\hline
\end{tabular}


Quadro 10 - Revisões sistemáticas sobre a opção 2. Participação social para o aprimoramento de indicadores de saúde.

\begin{tabular}{|c|c|c|c|c|c|c|c|c|}
\hline & & & & & & & \multicolumn{2}{|c|}{ continuação } \\
\hline Estudo & Elementos da opção & Objetivo do estudo & Principais achados & AMSTAR & $\begin{array}{l}\text { Proporção } \\
\text { de estudos } \\
\text { que } \\
\text { incluíram a } \\
\text { população- } \\
\text { alvo }\end{array}$ & $\begin{array}{l}\text { Proporção de } \\
\text { estudos } \\
\text { realizados em } \\
\text { Low Middle } \\
\text { Income } \\
\text { Countries (LMI) } \\
\text { e demais países }\end{array}$ & $\begin{array}{c}\text { Proporção } \\
\text { de estudo } \\
\text { com foco } \\
\text { no } \\
\text { problema }\end{array}$ & $\begin{array}{l}\text { Ano do } \\
\text { estudo }\end{array}$ \\
\hline $\begin{array}{c}\text { Bath e } \\
\text { Wakerma } \\
\text { n, } 2015\end{array}$ & $\begin{array}{l}\text { Nesta revisão as intervenções são } \\
\text { entregues para resultados na APS: } \\
\text { prevenção diabetes, diminuição da } \\
\text { mortalidade materna e neonatal, } \\
\text { crescimento da criança e utilização dos } \\
\text { serviços de saúde. Desenvolvidas para } \\
\text { decisores políticos, organizações e } \\
\text { prestadores de serviços. Entregues por } \\
\text { comitês, grupos locais de saúde, } \\
\text { liderança da comunidade, } \\
\text { stakeholders, relação colaborativa, } \\
\text { planejamento } \\
\text { Desenvolvidas por participação } \\
\text { individual, comitês de } \\
\text { aconselhamento local, grupo } \\
\text { comunitário educativo, stakeholders, } \\
\text { grupo de mulheres. }\end{array}$ & $\begin{array}{lr}\text { Localizar e } & \text { avaliar } \\
\text { evidências } & \text { do } \\
\text { impacto } & \text { da } \\
\text { participação } & \text { da } \\
\text { comunidade na APS } \\
\text { nos resultados de } \\
\text { saúde. }\end{array}$ & $\begin{array}{l}\text { Nesta revisão sistemática os resultados } \\
\text { revelaram um pequeno, mas substancial } \\
\text { corpo de evidências de que a } \\
\text { participação da comunidade está } \\
\text { associada a melhores resultados na } \\
\text { saúde. Há um corpo limitado de } \\
\text { evidências de que a participação da } \\
\text { comunidade está associada a resultados } \\
\text { intermediários, como acesso a serviços, } \\
\text { utilização, qualidade e capacidade de } \\
\text { em última análise, contribuir para os } \\
\text { resultados de saúde. Os formuladores } \\
\text { de políticas devem fortalecer a política } \\
\text { e o apoio financeiro para mecanismos } \\
\text { na atenção primária à saúde, um } \\
\text { componente importante é o apoio } \\
\text { contínuo à comunidade indígena } \\
\text { controlados pelos Serviços de Saúde, } \\
\text { como exemplos de participação } \\
\text { comunitária na Austrália. Organizações } \\
\text { primárias de saúde e os prestadores de } \\
\text { serviços são encorajados a considerar } \\
\text { mecanismos participativos onde a } \\
\text { participação é um processo e as pessoas } \\
\text { estão ativamente envolvidas na } \\
\text { determinação de prioridades e } \\
\text { implementação de soluções. }\end{array}$ & $6 / 9$ & $\begin{array}{l}\text { Não se } \\
\text { aplica }\end{array}$ & $\begin{array}{l}\text { Estudos } \\
\text { australianos e no } \\
\text { Reino Unido - HI } \\
\text { (revisão } \\
\text { sistemática cita os } \\
\text { países, no entanto, } \\
\text { não relata quantos } \\
\text { estudos ocorreram } \\
\text { em cada país) }\end{array}$ & $02 / 0$ & 2011 \\
\hline
\end{tabular}


Quadro 10 - Revisões sistemáticas sobre a opção 2. Participação social para o aprimoramento de indicadores de saúde.

\begin{tabular}{|c|c|c|c|c|c|c|c|c|}
\hline & & & & & & & \multicolumn{2}{|c|}{ continuação } \\
\hline Estudo & Elementos da opção & Objetivo do estudo & Principais achados & AMSTAR & $\begin{array}{l}\text { Proporção } \\
\text { de estudos } \\
\text { que } \\
\text { incluíram a } \\
\text { população- } \\
\text { alvo }\end{array}$ & $\begin{array}{c}\text { Proporção de } \\
\text { estudos } \\
\text { realizados em } \\
\text { Low Middle } \\
\text { Income } \\
\text { Countries (LMI) } \\
\text { e demais países }\end{array}$ & $\begin{array}{c}\text { Proporção } \\
\text { de estudo } \\
\text { com foco } \\
\text { no } \\
\text { problema }\end{array}$ & $\begin{array}{l}\text { Ano do } \\
\text { estudo }\end{array}$ \\
\hline $\begin{array}{l}\text { Villalonga } \\
\text {-Olives, } \\
\text { Wind e } \\
\text { Kawachi, } \\
2018\end{array}$ & $\begin{array}{l}\text { A revisão sistemática concluiu que a } \\
\text { maioria das intervenções procurou } \\
\text { fortalecer diretamente o capital social } \\
\text { e influenciar os resultados de saúde. } \\
\text { Primeiro, uma importante intervenção } \\
\text { do capital social no domínio da saúde } \\
\text { pública deve melhorar os resultados da } \\
\text { saúde. Segundo argumentos que uma } \\
\text { intervenção do capital social deve } \\
\text { envolver uma alteração estrutural ou } \\
\text { uma indução comportamental. } \\
\text { Desenvolvidas para comunidade, } \\
\text { mulheres em geral incluindo as } \\
\text { indígenas, crianças, trabalhadores } \\
\text { rurais. Entregues por profissionais de } \\
\text { saúde, comunidade, serviços de saúde } \\
\text { da AP, enfermeiras, serviços de } \\
\text { voluntariado. Desenvolvidas por } \\
\text { comitês, profissionais de saúde, } \\
\text { líderes da comunidade, religiosos, } \\
\text { professores, programas de rádio, } \\
\text { campanhas, cursos educativos, } \\
\text { pinturas murais, participação em } \\
\text { grupos, redes sociais. }\end{array}$ & 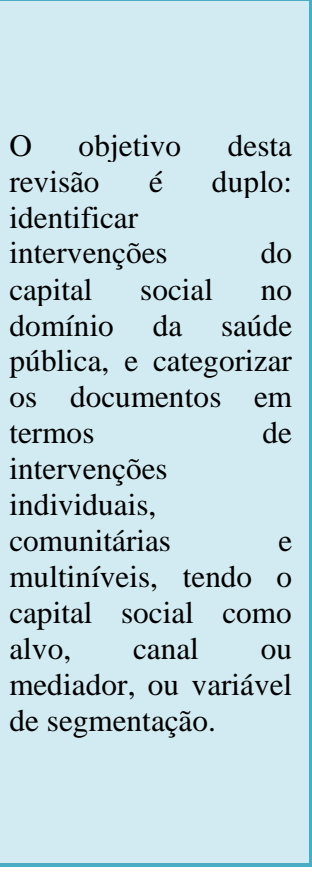 & $\begin{array}{l}\text { Nesta revisão sistemática dos } 4.922 \\
\text { artigos identificados, foram } \\
\text { selecionamos } 107 \text { após a primeira } \\
\text { revisão. Considerando os critérios } \\
\text { de inclusão } 17 \text { estudos preencheram } \\
\text { os critérios estabelecidos pelos } \\
\text { autores. O cenário do estudo variou } \\
\text { entre países de baixa e média renda } \\
\text { e países desenvolvidos. }\end{array}$ & $4 / 9$ & $\begin{array}{l}\text { Não se } \\
\text { aplica }\end{array}$ & $\begin{array}{l}\text { África do Sul - } \\
\text { UMI (01); } \\
\text { Austrália - HI } \\
\text { (01); Bolívia - } \\
\text { LMI (01); } \\
\text { Canadá - HI (01); } \\
\text { Congo - LI (01); } \\
\text { Dinamarca - HI } \\
\text { (02); } \\
\text { Espanha-HI (01); } \\
\text { EUA - HI (02); } \\
\text { Japão - HI (03); } \\
\text { Nicarágua - LMI } \\
\text { (01); } \\
\text { Países Baixos - HI } \\
\text { (01); } \\
\text { Quênia - LMI (01) } \\
\text { e } \\
\text { Ruanda - LI (01) }\end{array}$ & & 2014 \\
\hline
\end{tabular}


Quadro 10 - Revisões sistemáticas sobre a opção 2. Participação social para o aprimoramento de indicadores de saúde.

\begin{tabular}{|c|c|c|c|c|c|c|c|c|}
\hline & & & & & & & \multicolumn{2}{|c|}{ continuação } \\
\hline Estudo & Elementos da opção & $\begin{array}{l}\text { Objetivo do } \\
\text { estudo }\end{array}$ & Principais achados & AMSTAR & $\begin{array}{l}\text { Proporção } \\
\text { de estudos } \\
\text { que } \\
\text { incluíram a } \\
\text { população- } \\
\text { alvo }\end{array}$ & $\begin{array}{l}\text { Proporção de } \\
\text { estudos } \\
\text { realizados em } \\
\text { Low Middle } \\
\text { Income } \\
\text { Countries (LMI) } \\
\text { e demais países }\end{array}$ & $\begin{array}{c}\text { Proporção } \\
\text { de estudo } \\
\text { com foco } \\
\text { no } \\
\text { problema }\end{array}$ & $\begin{array}{l}\text { Ano do } \\
\text { estudo }\end{array}$ \\
\hline $\begin{array}{l}\text { Cornish et } \\
\text { al., } 2014\end{array}$ & $\begin{array}{l}\text { A revisão sistemática avaliou o impacto da } \\
\text { mobilização comunitária na prevenção do } \\
\text { HIV e intervenções }(\mathrm{N}=20 \text { ), biomédica, } \\
\text { comportamental e resultados sociais. Entre } \\
\text { a maioria dos grupos de risco } \\
\text { (particularmente sexo entre trabalhadores), } \\
\text { a evidência é consistente, indicando a } \\
\text { tendência de impacto positivo, com } \\
\text { resultados mais comportamentais e sociais } \\
\text { do que para os biomédicos. Entre os jovens } \\
\text { e comunidades em geral, a evidência } \\
\text { permanece inconclusiva. O sucesso parece } \\
\text { ser aprimorado pelo engajamento de } \\
\text { grupos com forte identidade coletiva e } \\
\text { simultaneamente abordando o contexto } \\
\text { sociopolítico. Desenvolvidas para } \\
\text { prevenção e redução de risco. Entregues } \\
\text { para jovens, adolescentes e comunidade, } \\
\text { adultos, adultos jovens, pais, trabalhadores } \\
\text { do sexo, mulheres, stakeholders. Entregues } \\
\text { por ONGs, comitês, educadores de saúde, } \\
\text { professores (educadores) e serviços de } \\
\text { saúde e desenvolvidas por profissionais de } \\
\text { saúde, comunidade, enfermeiras, } \\
\text { stakeholders, cooperativas, serviços de } \\
\text { saúde, serviços de referência e serviços de } \\
\text { saúde governamentais. }\end{array}$ & 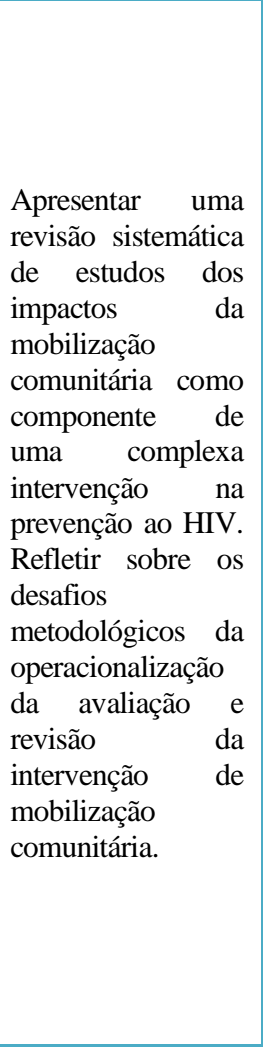 & $\begin{array}{l}\text { Nesta revisão sistemática dos vinte } \\
\text { estudos, sete foram estudos clínicos } \\
\text { randomizados controlados: Projeto } \\
\text { Accept, a intervenção Regai Dzive Shiri, } \\
\text { o julgamento do kwa Vijana da MEMA, } \\
\text { os Stepping Stones intervenção, o Projeto } \\
\text { Manicaland, o Projeto IMAGEM, e um } \\
\text { julgamento no Distrito de Masaka, } \\
\text { Uganda. O Projeto Accept foi realizado } \\
\text { simultaneamente na África Subsaariana e } \\
\text { no Sul e Sudeste da Ásia, enquanto outros } \\
\text { seis ensaios foram implementados na } \\
\text { África Subsaariana. Os restantes doze } \\
\text { estudos utilizaram várias observações. Na } \\
\text { Índia, no sul e sudeste da Ásia, o Projeto } \\
\text { RISHTA, o Projeto Parivartan, o Projeto } \\
\text { Avahan, o Projeto de Prevenção de } \\
\text { Fronteiras (Índia), um programa da Índia } \\
\text { HIV / AIDS Alliance, bem como uma } \\
\text { replicação de Sonagachi foram } \\
\text { implementadas; na América Latina e no } \\
\text { Caribe, o Projeto Encontros, o Projeto } \\
\text { Princesinha, o Projeto Fronteiras de } \\
\text { Prevenção (Equador), inspirado em } \\
\text { Sonagachi intervenção. O Projeto de } \\
\text { Carletonville foi realizado na África } \\
\text { Subsaariana África e uma intervenção } \\
\text { participativa foi implementada em } \\
\text { Chengdu, China. }\end{array}$ & $4 / 9$ & $\begin{array}{c}\text { Não se } \\
\text { aplica }\end{array}$ & $\begin{array}{l}\text { África do Sul - } \\
\text { UMI (03); } \\
\text { Brasil - UMI (03); } \\
\text { China-UMI (01); } \\
\text { Equador - UMI } \\
\text { (01); } \\
\text { Índia-LMI (12); } \\
\text { República } \\
\text { Dominicana - } \\
\text { UMI (01); } \\
\text { Tailândia - UMI } \\
\text { (01); } \\
\text { Tanzânia - LI } \\
\text { (02); } \\
\text { Uganda-LI (01); } \\
\text { Zimbábue - LI } \\
\text { (01) e } \\
\text { Zimbábue - LI } \\
\text { (02) }\end{array}$ & $28 / 28$ & 2013 \\
\hline
\end{tabular}




\section{APÊNDICE B}

Quadro 11 - Estudos excluídos após leitura completa.

\begin{tabular}{|c|c|c|c|c|}
\hline Base de dados & Autor & Estudo & Ano do estudo & Motivo da Exclusão \\
\hline $\begin{array}{l}\text { ProQuest (Applied Social } \\
\text { Sciences Index \& Abstracts - } \\
\text { ASSIA, Educational Resources } \\
\text { Information Center - ERIC, e } \\
\text { Sociological Abstracts) }\end{array}$ & $\begin{array}{l}\text { Cosimo Talò, Terri Mannarini } \\
\text { and AlessiaRochira }\end{array}$ & $\begin{array}{l}\text { Sense of Community and } \\
\text { Community Participation:A } \\
\text { Meta-Analytic Review }\end{array}$ & 2013 & $\begin{array}{l}\text { Recorta o objeto de estudo, no } \\
\text { entanto não traz resultados de } \\
\text { intervenções }\end{array}$ \\
\hline $\begin{array}{l}\text { ProQuest (Applied Social } \\
\text { Sciences Index \& Abstracts - } \\
\text { ASSIA, Educational Resources } \\
\text { Information Center - ERIC, e } \\
\text { Sociological Abstracts) }\end{array}$ & $\begin{array}{l}\text { Nathan Manning and Kathy } \\
\text { Edwards }\end{array}$ & $\begin{array}{l}\text { Does civic education for young } \\
\text { people increase political } \\
\text { participation? A systematic } \\
\text { review }\end{array}$ & 2014 & $\begin{array}{l}\text { Recorta o objeto de estudo, no } \\
\text { entanto não traz resultados de } \\
\text { intervenções }\end{array}$ \\
\hline $\begin{array}{l}\text { ProQuest (Applied Social } \\
\text { Sciences Index \& Abstracts - } \\
\text { ASSIA, Educational Resources } \\
\text { Information Center - ERIC, e } \\
\text { Sociological Abstracts) }\end{array}$ & $\begin{array}{l}\text { Erika E. Atienzo, Eva } \\
\text { Kaltenthaler, and Susan K. } \\
\text { Baxter }\end{array}$ & $\begin{array}{l}\text { Barriers and Facilitators to the } \\
\text { Implementation of Interventions } \\
\text { to Prevent Youth Violence in } \\
\text { Latin America: A Systematic } \\
\text { Review and Qualitative } \\
\text { Evidence Synthesis }\end{array}$ & 2016 & \begin{tabular}{lrr} 
Recorta o objeto de estudo, no \\
entanto, não traz resultados de \\
intervenções. & \multicolumn{2}{c}{ Revisão } \\
sistemática & utilizada & para \\
considerações & sobre & a \\
implementação & &
\end{tabular} \\
\hline $\begin{array}{l}\text { ProQuest (Applied Social } \\
\text { Sciences Index \& Abstracts - } \\
\text { ASSIA, Educational Resources } \\
\text { Information Center - ERIC, e } \\
\text { Sociological Abstracts) }\end{array}$ & $\begin{array}{l}\text { Sara Vestergrena, John Druryb } \\
\text { and Eva Hammar Chiriaca }\end{array}$ & $\begin{array}{l}\text { The biographical consequences } \\
\text { of protest and activism: a } \\
\text { systematic review and a new } \\
\text { typology }\end{array}$ & 2016 & $\begin{array}{l}\text { Recorta o objetode estudo, no } \\
\text { entanto não traz resultados de } \\
\text { intervenções }\end{array}$ \\
\hline
\end{tabular}

